\title{
Walking the path
}

Citation for published version (APA):

Megregian, M. P. (2021). Walking the path: Creating a framework for midwifery ethics education in the United States. [Doctoral Thesis, Maastricht University]. Maastricht University.

https://doi.org/10.26481/dis.20210615mm

Document status and date:

Published: 01/01/2021

DOI:

10.26481/dis.20210615mm

Document Version:

Publisher's PDF, also known as Version of record

\section{Please check the document version of this publication:}

- A submitted manuscript is the version of the article upon submission and before peer-review. There can be important differences between the submitted version and the official published version of record.

People interested in the research are advised to contact the author for the final version of the publication, or visit the DOI to the publisher's website.

- The final author version and the galley proof are versions of the publication after peer review.

- The final published version features the final layout of the paper including the volume, issue and page numbers.

Link to publication

\footnotetext{
General rights rights.

- You may freely distribute the URL identifying the publication in the public portal. please follow below link for the End User Agreement:

www.umlib.nl/taverne-license

Take down policy

If you believe that this document breaches copyright please contact us at:

repository@maastrichtuniversity.nl

providing details and we will investigate your claim.
}

Copyright and moral rights for the publications made accessible in the public portal are retained by the authors and/or other copyright owners and it is a condition of accessing publications that users recognise and abide by the legal requirements associated with these

- Users may download and print one copy of any publication from the public portal for the purpose of private study or research.

- You may not further distribute the material or use it for any profit-making activity or commercial gain

If the publication is distributed under the terms of Article $25 \mathrm{fa}$ of the Dutch Copyright Act, indicated by the "Taverne" license above, 


\section{WALKING THE PATH}

CREATING A FRAMEWORK FOR MIDWIFERY ETHICS EDUCATION IN THE UNITED STATES

Michele Megregian, CNM 
(C) copyright M.P. Megregian, United States, 2021

Printing: ProefschriftMaken || www.proefschriftmaken.nl ISBN 9789464232554

All rights reserved. No part of this publication may be reproduced, stored in a retrieval system or transmitted, in any form or by any means, electronic, mechanical, photocopying, recording or otherwise, without prior permission of the author or the copyright-owning journals for previous published chapters. 


\section{Walking the Path: \\ Creating a Framework for Midwifery Ethics Education in the United States}

\section{DISSERTATION}

To obtain the degree of Doctor at Maastricht University on the authority of the Rector Magnificus, Prof. dr. Rianne M. Letschert In accordance with the decision of the Board of Deans

To be defended in public on Tuesday, 15 June 2021 at 16.00 hours

By

Michele Patricia Megregian

Date of birth: $10^{\text {th }}$ May 1970, Madison, Wisconsin, United States 
Supervisors:

Co-supervisor:

Assessment Committee:
Prof. Dr. M.J. Nieuwenhuijze

Prof. Dr. R.G. de Vries

Prof. Dr. L. Kane Low, University of Michigan

Prof. Dr. P.M Teunissen (Chair)

Prof. Dr. G.D.E.M van der Weijden

Prof. Dr. G.M.W.R. de Wert

Prof. Dr. H.P. Kennedy, Yale University, USA

Prof. Dr. J.A.C.A. Kuipers, University of

Antwerp, Belgium 
Part One: Introduction

Chapter 1: Introduction

Part Two: Ethics Education

Chapter 2: Ethics Education in Midwifery Education Programs in the United States

Chapter 3: Students' experiences of ethics education in midwifery programs in the United States

Chapter 4: "I'm sure we talked about it": Midwives experiences of ethics education and ethical dilemmas, a qualitative study

Chapter 5: Essential components of midwifery ethics education: results of a Delphi study

Part Three: Shared Decision-Making

Chapter 6: The impact of shared decision making in perinatal care, a scoping review

Chapter 7: Choosing to Decline: Finding Common Ground through the Perspective of Shared Decision Making

Part Four: General Discussion

Chapter 8: Discussion

Summary

Impact Statement

Curriculum Vitae (CV)

Acknowledgements

The research presented in this thesis was conducted at CAPHRI Care and Public Health Research Institute, Department Midwifery Science, of Maastricht University. CAPHRI participates in the Netherlands School of Public Health and Care Research CaRe 



\section{CHAPTER 1}

Introduction

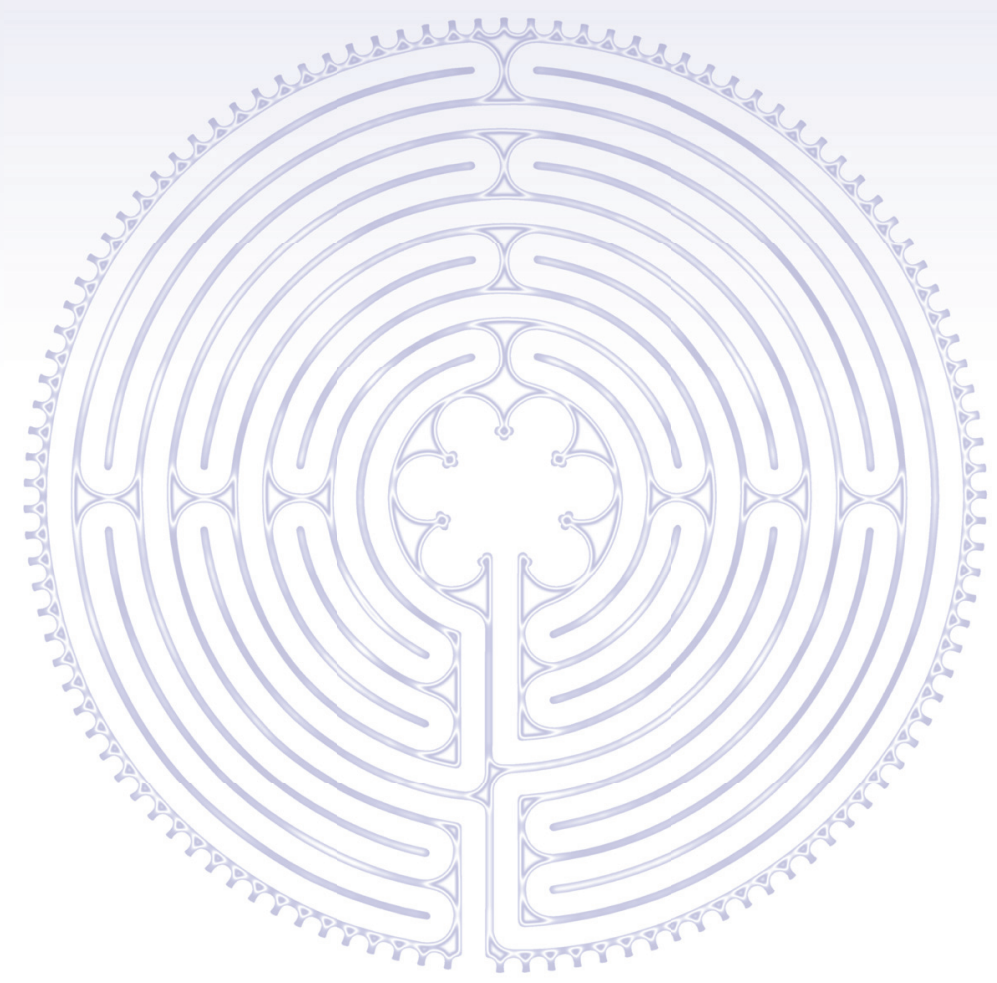


8|Chapter One 
"The practice of obstetrics is the most modern and medieval, the kindest to mothers and the cruelest. I know of many instances of cruelty, stupidity and harm done to mothers by obstetricians who are callous or completely indifferent to the welfare of their patients. Women are herded like sheep through an obstetrical assembly line, are drugged and strapped on tables while their babies are forceps-delivered ... Modern painkillers and methods are used for the convenience of the doctor, not to spare the mother. There is so much that can be done to make childbirth the easy natural thing it should be, but most of the time the mother is terrified, unhappy, and foiled in every attempt to follow her own wishes ... "Woman quoted in "Cruelty in Maternity Wards" by Gladys Denny Shultz, Ladies Home Journal, 1958.

In 1958, the Ladies Home Journal, an American magazine for women, published an exposé on the treatment of women during childbirth and called upon maternity care providers, policymakers, and women themselves to address this crisis. ${ }^{1}$ The stories of the women's experiences helped to usher in a reinvigorated interest in empowered childbirth education, "natural" childbirth, and midwifery care. ${ }^{2}$ Like other reproductive health transitions, pregnancy and birth are transformative experiences, where the acceptance of vulnerability and unpredictability are in a constant tension with feelings of fear and uncertainty. Through their stories, women have given us the keys to meeting their needs in their transitions - they desire the support of skilled, empathetic providers who partner with women in their care, focusing on the needs of the woman and family and on pregnancy and birth as physiologic processes. ${ }^{3,4}$ This is, essentially, person-centered care, a dynamic and relational process that emphasizes respect, trust, transparency and decision-making based on the person's preferences, values, and goals. ${ }^{5}$

Despite the philosophical shift to person-centered care, women continue to fight for their dignity, for the right to be seen and heard as whole, autonomous beings, and for the right to participate in decisions regarding their health and the health of their families. Almost 60 years after the Ladies Home Journal article, the World Health Organization published a statement on the disrespectful treatment of women receiving maternity care, "Prevention and Elimination of Disrespect and Abuse during Facility-based Childbirth". ${ }^{6}$ Studies and reports from countries such as Canada, the Netherlands, and the United States highlight the pervasiveness of this global issue..$^{2,7-9}$

The promotion of dignity lies at the heart of person-centered healthcare. Healthcare providers have a professional obligation to protect and promote the dignity of persons in their care. Education in ethics and in the application of ethics to clinical care is one critical pathway to fulfilling this obligation. In order to achieve truly respectful, person-centered care, providers should possess the awareness, intention, commitment and accountability that may be gained through ethics education.

\section{Doing Good / Being Good: The Nature of Ethics}

In its broadest sense, ethics is a branch of philosophy that examines proper human behavior and well-being. ${ }^{10}$ The study of ethics involves the systematic analysis of right or wrong human behaviors, asking three questions: 1) How do we promote well-being?; 2) How do we avoid harm?; and 3) How do we make proper decisions? 
In the context of healthcare, clinical interventions should promote well-being and avoid harm by supporting and guiding healthy physiologic processes (salutogenesis) or by treating pathologic processes or diseases (pathogenesis). In practice, a clinical intervention requires ethical considerations when the decisions being made involve balancing the risks and benefits of a particular intervention, balancing the interests of one or more individuals involved, or balancing personal and societal interests. In a given clinical situation, interests may align, diverge or compete with one another. Ethical decision-making involves the acknowledgment of the tensions that flow between these interests, recognizing when these interests converge or diverge, and subsequently determining the right action to be taken. ${ }^{11,12}$ Ethical challenges arise when the right action is unknown, uncertain, or unable to be fulfilled. ${ }^{13,14}$

Healthcare professional organizations have developed codes of ethics that reflect the principles underlying the expected standards of conduct for health care professionals and which address the question of why certain behaviors or actions may or may not be appropriate. ${ }^{15}$ The American College of Nurse-Midwives (ACNM) Code of Ethics codifies the expected standards for midwives and represents - to the public and to other professionals - what a professional midwife should be. ${ }^{16}$ The first Code of Ethics for Certified Nurse-Midwives (CNMs) was approved by the ACNM board in 1990, and it is reviewed every five years, most recently in 2015. ${ }^{17}$ The ACNM Code of Ethics describes the broad obligations of midwives in their professional relationships, in their clinical practice, and in maintaining the integrity of the midwifery profession. The International Code of Ethics for Midwives was adopted by the International Confederation of Midwives (ICM) in 2008 and, similar to the ACNM Code of Ethics, it is a codification of midwifery behavior that reflects the philosophy of midwifery and the mission of the ICM to advance the profession of midwifery. ${ }^{18}$

When professionals respond to the ethics questions listed above -- How do we promote well-being? How to we avoid harm? How do we make proper decisions? - they typically offer two different types of answers, in some cases the answers involve taking action, in other cases the answers are found in cultivating personal attributes.

Taking action means invoking specific principles to determine a proper decision. This is the essence of "doing good". Whether acting out of a sense of obligation or by adhering to a specific principled approach, such as the promotion of autonomy, the goal is to do the right thing. The ethical concern is with one's action and the results of that action. Alternately, solutions to ethical concerns may be addressed by cultivating specific personal attributes. These attributes, such as compassion or personal integrity, guide actions towards "being good". The right decision will be made, and the right action taken, based on one's character, who one is.

In discussions on medical ethics education, these two approaches are often characterized as the skills-virtue dichotomy. ${ }^{19,20}$ They represent two distinct aims of ethics education. In a skills-based framework, emphasis is placed on the learning and integrating of critical thinking skills, moral reasoning, and ethics decision-making. In a values-based 
framework, character-building is emphasized, by enhancing personal values and attributes such as compassion. I believe this is a false dichotomy. In fact, ethics learning is best achieved by integrating these two approaches. Compassionate, respectful midwives still need to learn the skills to recognize and negotiate ethical challenges, and the acquisition and demonstration of those skills require empathy and respect if they are to be fully realized.

\section{Ethics as Relationship}

The ACNM and ICM codes of ethics emphasize the midwife's ethical obligation to work in relationships, particularly with women and families in their care. One of the hallmarks of midwifery care is the development of a "partnership with the woman in which each shares relevant information that leads to informed decision-making, consent to an evolving plan of care, and acceptance of responsibility for the outcome of their choices". ${ }^{16}$ Being in a partnering relationship is a central aspect of person-centered care. Personcentered care and informed consent have emerged as essential and influential ethical concepts in medicine and midwifery in the past few decades. ${ }^{21}$ The role of the individual's voice in medical decision-making has swung from virtually absent (paternalism) to omnipresent (consumerism) and back again. ${ }^{22}$ More recently, the concept of shared decision-making has become the dominant paradigm of person-provider interaction in the maternity healthcare setting. Shared decision-making seeks to build upon the informed consent process through the clear and thorough transmission of accurate information, the exploration, clarification, and inclusion of a person's values, preferences and goals, and the use of risk communication strategies that are free from bias. It is a collaborative process; the provider shares knowledge and expertise while the person seeking care shares values, goals, preferences, and input from significant others. ${ }^{22}$ Studies suggest that shared decision-making impacts how individuals feel about the decisions they make (e.g. decisional regret), how they feel about the information they have received, and how they view the relationship with their provider. ${ }^{23-26}$

Women receiving maternity care describe the importance of access to information, of being involved in decision making and of being seen as an individual, leading to increased satisfaction with their care. ${ }^{3,27}$ Midwives play an essential role in involving women in decision-making and in supporting them in their choices. ${ }^{3}$ A midwife's decision and actions which support a woman's informed choice are grounded in her ethical commitment to being in relationship with the woman. For example, engaging in shared decision-making is considered to be a key component contributing to the promotion of normal physiologic birth. ${ }^{28}$ Promoting physiologic birth, trusting the intrinsic self-knowledge of pregnant individuals, and viewing the woman and fetus as interconnected, are among the ethical commitments of midwives. The emphasis on context and relationship that is present in the shared decision-making process holds midwives accountable to the commitment of viewing woman as whole, interconnected being. Traditional obstetric models that emphasize the separate, and potentially conflicting, interests of the woman and fetus and which deemphasize the maternal-fetal interaction as a relationship, fail to articulate the full experience of women in the context of their lives and relationships. ${ }^{29-31}$ The promotion of the relationship that is central to 


\section{2 |Chapter One}

ethical midwifery care involves ethical frameworks that emphasize context and interrelatedness, such as care ethics. ${ }^{32,33}$

\section{Ethics Praxis: Begin with the Beginners}

The processes of clinical reasoning and decision making in midwifery are outlined in the ACNM Core Competencies for Basic Midwifery. ${ }^{34}$ Following the "midwifery management process", a midwife will gather data, identify and analyze problems or dilemmas presented by the case within a theoretical framework, create a comprehensive plan in partnership with other stakeholders, and base clinical decisions and actions on this plan. The midwife will then evaluate her decisions and actions for their effectiveness, repeating the process to identify and correct any ineffective results or to resolve conflicts. ${ }^{34}$ The deliberative skills of analysis, integration, and evaluation of data and decisions are acquired and honed across a lifetime of providing clinical care and through the hundreds of decisions a midwife makes during clinical encounters, from the seemingly simple decisions such as recommendations regarding prenatal vitamins to potentially life-altering decisions such as a recommendation for cesarean birth.

Midwives learn ethical reasoning and decision making using the same deliberative skills. They apply their knowledge of ethics and ethical principles (such as beneficence or respect for autonomy) and choose the proper courses of action. Indeed, ethical components are often present in clinical decisions. For example, choices made in verbal communication, what words to say or not say, shape the preferences and actions of women. ${ }^{35-37}$ The overlap of clinical and ethical components in the clinical encounter suggests that ethical and clinical decision making should be learned simultaneously. ${ }^{38-40}$

Just as midwifery educational programs have an obligation to provide the information, resources, and opportunities to acquire the skills associated with the midwifery management process, so too do they have the same obligation in the area of ethics and ethics decision making. Educators in medicine, nursing, and midwifery agree that new providers should have a grasp of clinical ethics concepts and the communication skills necessary to navigate difficult ethical situations. ${ }^{10,19,40,41}$ Competency in ethics knowledge and ethics reasoning contributes to person-centered care, decreases moral distress experienced by providers, and contributes to high-functioning interdisciplinary teams. ${ }^{40,42,43}$ Providers are better prepared to negotiate the ethical challenges that may occur in the course of everyday clinical encounters, particularly if ethics training includes not only the controversial or extreme cases but also highlights everyday ethical challenges. ${ }^{40}$ Despite the interprofessional consensus on the need for ethics competencies, the actualization of an ethics curriculum has been challenged by the lack of articulated goals and objectives, clearly defined concepts, evidence-based competencies, learning activities that lead to successfully accomplishing those competencies, and related assessment and evaluation strategies. In order to achieve the educational goal of creating safe, beginning providers who have a foundational understanding of ethics and the skills to recognize and negotiate ethical situations and challenges, further studies which address these issues are needed. 


\section{This Thesis}

The setting for the studies in this thesis is midwifery education in the United States (U.S.). In the U.S., there are multiple pathways to becoming a midwife, resulting in different degrees, titles and eligibility for midwifery practice licenses or registration. ${ }^{44}$ These pathways include graduate educational programs accredited by Accreditation Commission for Midwifery Education (ACME) which confer eligibility for certification as a Certified Nurse-Midwife (CNM) or Certified Midwife (CM), and educational programs accredited by Midwifery Education and Accreditation Council (MEAC) which do not require a prior academic degree and which confer eligibility for certification as a Certified Professional Midwife (CPM). In addition, most ACME-accredited programs require students to be registered nurses (RN) as a prerequisite to admission to the graduate program in midwifery. Students may enter as experienced RNs, or become RNs via an accelerated pathway, earning a Bachelor of Science in Nursing (BSN) degree and proceeding directly into the graduate midwifery program. ${ }^{45}$ Given the complexity of midwifery education in the U.S, we focused on midwifery programs that confer graduate-level degrees with eligibility to become certified as a Certified Nurse-Midwife (CNM) or Certified Midwife (CM), with the exception of initial survey of program directors (Chapter 2) which include ACME and MEAC-accredited programs.

ACME-accredited midwifery educational programs in the United States committed to a competency-based educational framework in 1978 with the adoption of the ACNM Core Competencies for Basic Midwifery Practice. ${ }^{46}$ In competency-based educational frameworks, students demonstrate particular skills, attitudes, or behaviors that are linked to particular learning outcomes and must meet certain linked assessment criteria in order to proceed in the curriculum. ${ }^{47,48}$ The most effective competency-based programs are those in which the learning outcomes and assessment criteria are evidencebased and tied to stakeholders' needs. ${ }^{47,49,50}$

Per the ACNM Core Competencies for Basic Midwifery Practice, upon completion of the accredited midwifery program, students must possess a "broad understanding of bioethics" as a component of midwifery care, and practice according to the Hallmarks of Midwifery, which include "advocating for informed choice, shared decision-making, and the right to self-determination".$^{34}$ The content of the competencies outlined in the ACNM Core Competencies for Basic Midwifery Practice are informed by input from midwifery educators and recently certified midwives. In the most recent update (2020), the competencies related to bioethics knowledge and advocacy for informed choice, shared decision-making and self-determination were carried forward unaltered. Midwifery programs must focus their curricular activities in a way that allow students to achieve the goal of successfully acquiring the skills and behaviors that fulfill these competencies and of becoming competent new providers. The studies in this thesis were designed to form the framework for a potential ethics curriculum for midwifery programs via an initial needs exploration. In order to understand the needs and experiences of current and future midwives, we sought to hear directly from midwifery students, experienced midwives, and midwifery educators about the ethical dilemmas they face in providing reproductive health care, what they consider to be best practices in ethics education, and 


\section{4|Chapter One}

what they see as the role of midwifery educational programs in preparing them to face these challenges.

Despite the complexity of multi-option paths to becoming a midwife in the United States, the philosophy of care and the competency-based educational framework of midwifery in the U.S. align with the philosophy and competencies set forth by the International Confederation of Midwives (ICM) and World Health Organization (WHO). ${ }^{51}$ Midwives around the world are called to support individuals throughout their reproductive lives (and beyond) within relationships which embody person-centered care and which empower informed choice and shared decision-making. In addition, foundational to midwives worldwide is to trust, nurture, and promote normal physiologic labor and birth, as well as support individuals when physiologic labor or birth may no longer be possible. These commitments are made clear in the ICM code of ethics and competencies for midwifery practice and are reflected in the ACNM code of ethics and codes of ethics for midwives in many other countries around the world. This highlights the unity of the global midwifery community, despite residing in different countries and being beholden to different regulatory systems.

\section{General Aim and Research Questions}

The central aim of this thesis is to contribute to the optimization of ethics education in midwifery programs, developing a curricular framework that can complement current educational practice. We endeavored to explore the current state of ethics education and to identify potential gaps in that educating using surveys, focus groups, and interviews with midwifery educators, midwives and students. In addition, given the emphasis placed upon the process of shared decision-making and its role in the promotion of respectful and person-centered midwifery care, we sought to explore shared decision-making in further detail. It is important that the next generation of midwives are trained not only in the practical application of shared decision-making, but also in the foundational ethical concepts upon which it is constructed. The groundwork for training in ethics, including shared decision-making, would ideally occur in the degree-conferring educational programs. Accredited midwifery programs have the need to operationalize an ethics curriculum that prepares new providers to negotiate the ethical challenges that they will encounter in their clinical work. To better understand the current state of ethics education in midwifery programs and to lay the foundation for a midwifery ethics curriculum, we developed the following research questions:

- What is the current state of ethics education in accredited midwifery programs in the U.S., specifically regarding format, topics, and evaluation tools?

- What is the student experience of ethics education in their midwifery programs?

- What is the experience of midwives with regard to recognizing and negotiating ethical dilemmas, and what was the role of their midwifery program in their sense of preparedness to engage in ethical challenges? 
- What do midwifery educators (midwifery program directors, midwifery faculty, and clinical midwifery preceptors) consider to be the essential components of ethics education for midwifery students?

- Given the current emphasis on shared decision-making in clinical midwifery care and in midwifery ethics education, what is the potential impact of shared decision-making on perinatal outcomes?

- How can the shared decision-making process be practically applied to midwifery care as part of a midwifery ethics framework?

\section{Outline of this thesis}

The general aims and research questions are addressed in the following chapters:

Chapter 2 presents the findings of an online survey of program directors of ACME- and MEAC-accredited midwifery educational programs in the United States regarding the logistics of ethics education in their curricula, namely the topics covered, learning formats used, amount of time dedicated to ethics learning, and use of evaluation tools.

Chapter 3 describes the results of focus groups conducted with student midwives on their thoughts and opinions regarding manner and content of ethics education in midwifery educational programs.

Chapter 4 describes the results of individual interviews with midwives regarding their experiences of ethical dilemmas in practice, and their thoughts about their ethics education through their midwifery educational programs.

Chapter 5 reports the results of a Delphi study on the consensus of midwifery educators regarding the essential components of ethics education for midwifery students.

Chapter 6 presents the results of a scoping review on the impact of shared decisionmaking in perinatal care.

Chapter 7 presents a clinical case report which provides an example of the intersection of midwifery ethics and shared decision-making.

In Chapter 8 we discuss the main findings of the studies and the methodological strengths and limitations of those studies. We then reflect on the implications for midwifery education and identify opportunities for future research. 


\section{6|Chapter One}

\section{References}

1. Shultz GD. Cruelty in Maternity Wards. Ladies Home Journal. 1958;(May):44-45.

2. Goer H. Cruelty in Maternity Wards: Fifty Years Later. Journal of Perinatal Education. 2010;19(3):33-42. doi:10.1624/105812410X514413

3. Bringedal H, Aune I. Able to choose? Women's thoughts and experiences regarding informed choices during birth. Midwifery. 2019;77:123-129. doi:10.1016/j.midw.2019.07.007

4. Nieuwenhuijze M, Leahy-Warren P. Women's empowerment in pregnancy and childbirth: A concept analysis. Midwifery. 2019;78. doi:10.1016/j.midw.2019.07.015

5. Institute of Medicine (US) Committee on Quality of Health Care in America. Crossing the Quality Chasm: $A$ New Health System for the 21st Century. National Academies Press; 2001. doi:10.17226/10027

6. World Health Organization. The Prevention and Elimination of Disrespect and Abuse during Facility-Based Childbirth.; 2015. Accessed September 28, 2020.

https://apps.who.int/iris/bitstream/handle/10665/134588/WHO_RHR_14.23_eng.pdf?sequence=1

7. Morton $\mathrm{CH}$, Henley MM, Seacrist M, Roth LM. Bearing witness: United States and Canadian maternity support workers' observations of disrespectful care in childbirth. Birth. 2018;45(3):263-274. doi:10.1111/birt.12373

8. Petersen EE, Davis NL, Goodman D, et al. Racial/Ethnic Disparities in Pregnancy-Related Deaths - United States, 2007-2016. MMWR Morbidity and Mortality Weekly Report. 2019;68(35):762-765. doi:10.15585/mmwr.mm6835a3

9. Vedam S, Stoll K, Taiwo TK, et al. The Giving Voice to Mothers study: Inequity and mistreatment during pregnancy and childbirth in the United States. Reproductive Health. Published online 2019. doi:10.1186/s12978-019-0729-2

10. Carrese JA, Malek J, Watson K, et al. The essential role of medical ethics education in achieving professionalism: The romanell report. Academic Medicine. 2015;90(6):744-752. doi:10.1097/ACM.0000000000000715

11. Butts JB, Rich KL. Nursing Ethics: Across the Curriculum and into Practice. 4th Ed. Jones \& Bartlett Learning; 2016.

12. Wocial L. Ethical Decision Making. In: Tracy MF, O'Grady ET, eds. Hamric and Hanson's Advanced Practice Nursing: An Integrative Approach. 6th ed. Elsevier Health Sciences; 2019:310-342.

13. Beauchamp TL, Childress JF. Principles of Biomedical Ethics. 6th ed. Oxford University Press; 2009.

14. Jonsen AR, Siegler M, Winslade WJ. Clinical Ethics: A Practical Approach to Ethical Decisions in Clinical Medicine. 7th Ed. McGraw-Hill Medical; 2010.

15. Thompson J. Professional Ethics. In: Professional Issues in Midwifery. Jones and Bartlett Publishers; 2007:277-300.

16. American College of Nurse-Midwives. ACNM Code of Ethics with Explanatory Statements. Published online 2015:1-16.

http://www.midwife.org/ACNM/files/ACNMLibraryData/UPLOADFILENAME/000000000293/Code-ofEthics-w-Explanatory-Statements-June-2015.pdf

17. Varney H, Thompson JB. A History of Midwifery in the United States. Springer Publishing Company; 2015. doi:10.1891/9780826125385

18. International Confederation of Midwives. An International Code of Ethics for Midwives. Nursing Ethics. Published online 2007. doi:10.1177/096973309400100109

19. Eckles RE, Meslin EM, Gaffney M, Helft PR. Medical Ethics Education: Where Are We? Where Should We Be G... : Academic Medicine. 2005;80(12):1143-1152. doi:10.1097/00001888-200512000-00020

20. Salih ZNI, Boyle DW. Ethics Education in Neonatal-Perinatal Medicine in the United States. Seminars in Perinatology. 2009;33(6):397-404. doi:10.1053/j.semperi.2009.07.008

21. Hoving C, Visser A, Mullen PD, van den Borne B. A history of patient education by health professionals in Europe and North America: From authority to shared decision making education. Patient Education and Counseling. 2010;78(3). doi:10.1016/j.pec.2010.01.015

22. Barry MJ, Edgman-Levitan S. Shared decision making - The pinnacle of patient-centered care. New England Journal of Medicine. Published online 2012. doi:10.1056/NEJMp1109283

23. Kennedy K, Adelson P, Fleet J, et al. Shared decision aids in pregnancy care: A scoping review. Midwifery. 2020;81:102589. doi:10.1016/j.midw.2019.102589

24. Mattison CA, Dion ML, Lavis JN, Hutton EK, Wilson MG. Midwifery and obstetrics: Factors influencing mothers' satisfaction with the birth experience. Birth. 2018;45(3):322-327. doi:10.1111/birt.12352

25. Say R, Robson S, Thomson R. Helping pregnant women make better decisions: a systematic review of the benefits of patient decision aids in obstetrics. BMJ Open. 2011;1(2):e000261-e000261.

doi:10.1136/bmjopen-2011-000261 
26. Vlemmix F, Warendorf JK, Rosman AN, et al. Decision aids to improve informed decision-making in pregnancy care: A systematic review. BJOG: An International Journal of Obstetrics and Gynaecology. 2013;120(3):257-266. doi:10.1111/1471-0528.12060

27. Coates D, Thirukumar P, Spear V, Brown G, Henry A. What are women's mode of birth preferences and why? A systematic scoping review. Women and Birth. Published online 2019. doi:10.1016/j.wombi.2019.09.005

28. American College of Nurse-Midwives. Shared Decision Making in Midwifery Care.; 2016. http://midwife.org/ACNM/files/ACNMLibraryData/\%ODUPLOADFILENAME/000000000305/SharedDecision-Making-in-\%0DMidwifery-Care-10-13-17.pdf. December 2016.

29. de Vries R. Obstetric Ethics and the Invisible Mother. Narrative Inquiry in Bioethics. Published online 2017. doi:10.1353/nib.2017.0068

30. Harris L. Rethinking maternal-fetal conflict: Gender and equality in perinatal ethics. Obstetrics and Gynecology. 2000;96:786-791.

31. Premkumar A, Gates E. Rethinking the Bioethics of Pregnancy. Obstetrics \& Gynecology. 2016;128(2):396399. doi:10.1097/AOG.0000000000001509

32. MacLellan J. Claiming an Ethic of Care for midwifery. Nursing Ethics. 2014;21(7):803-811. doi:10.1177/0969733014534878

33. Thompson FE. Moving from Codes of Ethics to Ethical Relationships for Midwifery Practice. Nursing Ethics. 2002;9(5):522-536. doi:10.1191/0969733002ne542oa

34. American College of Nurse-Midwives. ACNM Core Competencies for Basic Midwifery Practice.; 2020.

35. Lehmann LS, Sulmasy LS, Desai S. Hidden curricula, ethics, and professionalism: Optimizing clinical learning environments in becoming and being a physician: A position paper of the American college of physicians. Annals of Internal Medicine. 2018;168(7):506-508. doi:10.7326/M17-2058

36. Licqurish S, Seibold C. Bachelor of Midwifery students' experiences of achieving competencies: The role of the midwife preceptor. Midwifery. 2008;24(4):480-489. doi:10.1016/j.midw.2007.05.001

37. Nieuwenhuijze M, Thompson S, Gudmundsdottir EY, Gottfređsdóttir H. Midwifery students' perspectives on how role models contribute to becoming a midwife: A qualitative study. Women and Birth. Published online 2019. doi:doi.org/10.1016/j.wombi.2019.08.009

38. Hickman SE, Wocial LD. Team-Based Learning and Ethics Education in Nursing. Journal of Nursing Education. 2013;52(12):696-700. doi:10.3928/01484834-20131121-01

39. Kamali F, Yousefy A, Yamani N. Design and psychometric properties of an instrument to assess metacognition in moral reasoning in medicine. Nursing Open. 2019;6(4):1331-1345. doi:10.1002/nop2.331

40. Oelhafen S, Hölzli U, Häsänen M, et al. Increasing midwives' ethical competence: a European educational and practice development project. International Journal of Ethics Education. 2017;2(2):147-160. doi:10.1007/s40889-017-0033-3

41. Vynckier T, Gastmans C, Cannaerts N, de Casterlé BD. Effectiveness of ethics education as perceived by nursing students. Nursing Ethics. 2015;22(3):287-306. doi:10.1177/0969733014538888

42. Kulju K, Stolt M, Suhonen R, Leino-Kilpi H. Ethical competence: A concept analysis. Nursing Ethics. 2016;23(4):401-412. doi:10.1177/0969733014567025

43. Lechasseur K, Caux C, Dollé S, Legault A. Ethical competence: An integrative review. Nursing Ethics. 2018;25(6):694-706. doi:10.1177/0969733016667773

44. Marzalik PR, Feltham KJ, Jefferson K, Pekin K. Midwifery education in the U.S. - Certified Nurse-Midwife, Certified Midwife and Certified Professional Midwife. Midwifery. 2018;60:9-12. doi:10.1016/j.midw.2018.01.020

45. Maurer H, Kohl A, Cockerham A,. Midwifery Education Trends Report2019.; 2019. Accessed July 10, 2020 https://www.midwife.org/acnm/files/acnmlibrarydata/uploadfilename/000000000321/Midwifery_Ed ucation_Trends_Report_2019_Final.pdf

46. Phillippi JC, Avery MD. The 2012 American college of nurse-midwives core competencies for basic midwifery practice: History and revision. Journal of Midwifery and Women's Health. 2014;59(1):82-90. doi:10.1111/jmwh.12148

47. Gravina EW. Competency-Based Education and Its Effect on Nursing Education: A Literature Review. Teaching and Learning in Nursing. 2017;12(2):117-121. doi:10.1016/j.teln.2016.11.004

48. Iwasiw C, Andrusyszyn M-A, Goldenberg D. Curriculum Development in Nursing Education. Fourth ed. Jones \& Bartlett Learning; 2020.

49. Embo M, Helsloot K, Michels N, Valcke M. A Delphi study to validate competency-based criteria to assess undergraduate midwifery students' competencies in the maternity ward. Midwifery. 2017;53:1-8. doi:10.1016/j.midw.2017.07.005 


\section{8|Chapter One}

50. Woeber K. Development and implementation of a competency-based clinical evaluation tool for midwifery education. Midwifery. 2018;62:92-95. doi:10.1016/j.midw.2018.03.004

51. International Confederation of Midwives. Essential Competencies for Midwifery Practice.; 2019. 
Introduction |19 
20|Chapter One 


\section{CHAPTER 2}

\section{Ethics Education in Midwifery Education Programs in the United States}

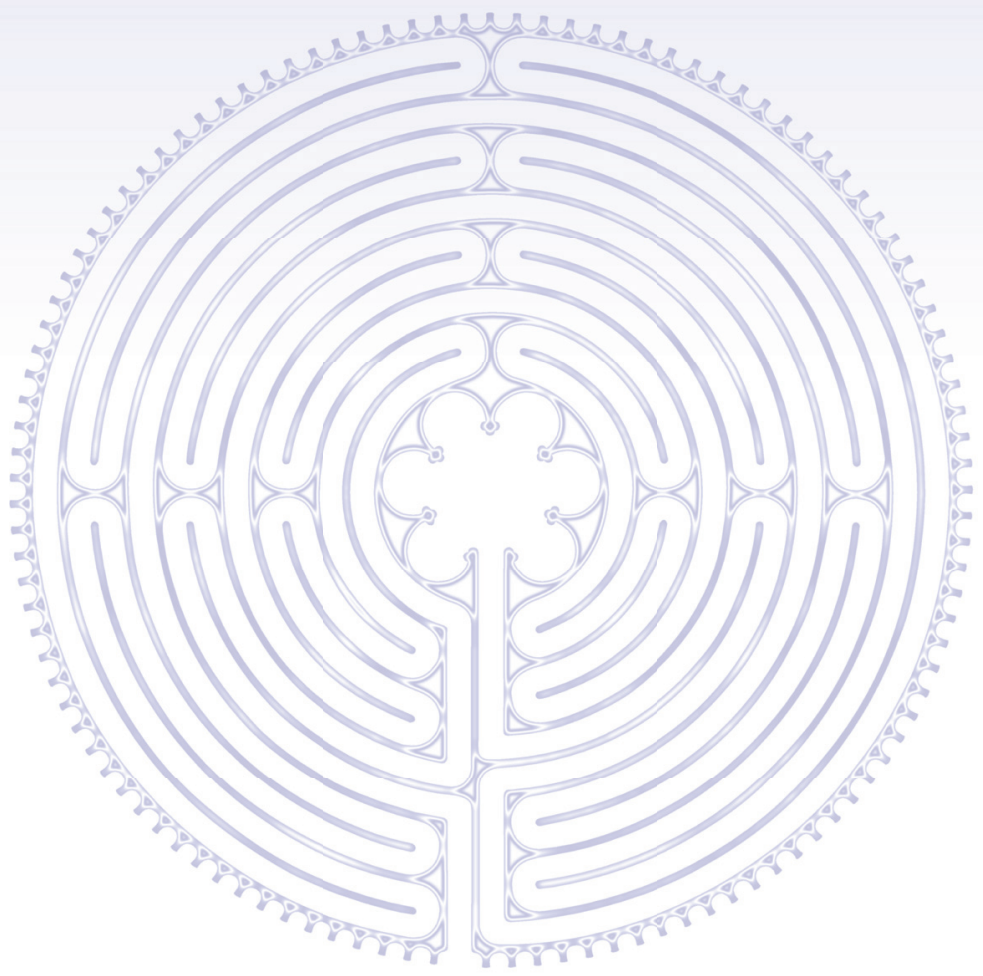

Michele Megregian

Journal of Midwifery \& Women's Health. 2016 Sep;61(5):586-592 


\title{
22 |Chapter Two
}

\begin{abstract}

\section{Introduction}

Familiarity with ethical concepts is a required competency for new graduates and a component of accreditation for midwifery programs in the United States. While midwifery educators have acknowledged the importance of ethics education in midwifery programs, little is known about current methods, format, or evaluation of ethics education.
\end{abstract}

\section{Methods}

A web-based survey was developed for program directors of accredited midwifery programs in the United States. Clock hours, formats, venues, content topics, barriers, and evaluation methods were evaluated by descriptive analysis.

\section{Results}

Fifty-one percent of programs completed the online survey (25/49). Of these, only 7 (28\%) offer ethics as a stand-alone class, although all responding programs integrate some ethics education into other core classes. Programs show variation in format, venue, resources, and clock hours dedicated to ethics education. The most frequent barrier to ethics education is an already crowded curriculum (60\%), although $32 \%$ of programs denied any barriers at all. The majority of programs include the ethical concepts of informed consent, shared decision-making, and effective communication in curriculum content.

\section{Discussion}

This survey found that there is considerable variation in ethics education in terms of content, format and evaluation among accredited midwifery programs in the United States. Midwifery educators have an opportunity to explore the ethical dilemmas unique to maternity care from a midwifery perspective. There is also the opportunity to create a comprehensive and dynamic midwifery ethics curriculum, which incorporates both standalone ethics courses and ethics concepts that are woven throughout the core midwifery curriculum.

\section{Keywords}

Ethics, midwifery ethics, ethics education, ethics curriculum 


\section{Quick Points}

- Familiarity with ethical concepts and bioethical principles such as shared decision-making is a key competency, and ethics education is a required component for accreditation by the Accreditation Commission for Midwifery Education and the Midwifery Education Accreditation Council. This is the first survey to examine details of ethics education in accredited US midwifery programs.

- A wide variety of formats, resources, hours, and evaluation tools are used by midwifery programs, indicating a lack of consistency and standardization in midwifery ethics education.

- The ethics content of the majority of programs includes informed consent, shared decision-making, and prenatal diagnosis/genetics, but the inclusion of other concepts such as maternal-fetal conflict, moral distress, and truth telling is inconsistent. 


\section{$24 \mid$ Chapter Two}

\section{Introduction}

Clinical ethical dilemmas are a ubiquitous aspect of modern health care. Conflicts between ethical principles may occur at the macro level, such as disparity in health care access, or at the micro level, such as the language used in providing informed consent. Over the past two decades medical and nursing educational programs have accepted the responsibility to provide students with foundational knowledge of ethical theory as well as the training and skills to navigate difficult ethical situations.

In 1990, Pellegrino introduced the 5 C's of medical ethics education: that it be clinically based, utilize cases as the teaching focus, be continuous throughout the medical curriculum, be coordinated with other objectives, and that clinicians actively participate as role models and instructors. ${ }^{1}$ Educators in medicine, nursing, and midwifery have consistently acknowledged the importance of ethics education for training new providers. Despite the addition of ethics education into program accreditation requirements, the practical demonstration of ethics training has lacked consistency and continuity. ${ }^{2,3}$ To that end, we have conducted a survey in order to explore current ethics education in accredited midwifery education programs in the United States.

Midwifery education programs in the United States that confer eligibility for graduates to take the national certification exam to become a certified nurse-midwife (CNM) or certified midwife (CM) are accredited by the Accreditation Commission for Midwifery Education (ACME). ACME accredited programs must adhere to the American College of Nurse Midwives (ACNM) Core Competencies, which delineate behaviors that must be demonstrated by students upon the completion of program coursework. ${ }^{4} \mathrm{An}$ understanding of biomedical ethics concepts is a fundamental component of midwifery care and a required Core Competency. In addition, promotion of family-centered care and the advocacy of informed choice and shared decision-making are considered Hallmarks of Midwifery. ${ }^{5}$

The Midwifery Education Accreditation Council (MEAC) provides accreditation for institutions and programs of midwifery education, reflecting the competencies and principles of the Midwifery Alliance of North America (MANA). Students who complete MEAC accredited programs are eligible to take the national certificate exam to become a certified professional midwife (CPM). ${ }^{6}$ Essential competencies include acting "consistently in accordance with professional ethics", and using "shared decision-making in partnership with women and their families; enable[ing] and support[ing] them in making informed choices about their health". ${ }^{7}$

Midwifery educators also view ethics as an important curriculum topic in midwifery education. In 1998, nurse practitioner and nurse-midwifery education programs were surveyed regarding a broad range of curriculum topics, with the purpose of identifying the current and ideal emphases placed on those topics, the most important curriculum topics, and barriers to curriculum change. "Patients as partners in health care" and "effective patient-provider relationships/communication" were among the five topics rated highest for both current and ideal emphasis. "Biomedical/health care ethics" was ranked 19th of 33 topics by ideal emphasis. ${ }^{3} \mathrm{~A}$ similar survey of ethics education in 
Masters of Science of Nursing (MSN) programs as accredited by the National League for Nursing Accrediting Commission or the Commission on Collegiate Nursing Education in 2007 found that $75 \%$ of respondent programs required a course that included formal ethics content. The survey revealed a wide variety in the methodology, programs hours dedicated to ethics, and the evaluation of ethics content. In addition, there was a surprising lack of emphasis on clinical ethics content, with only one third or fewer syllabi including the topics of consent, privacy and confidentiality, and truth telling. ${ }^{8}$ A 2015 Delphi study of ethics content for Doctor of Nursing Practice programs found that only the American Nursing Association's Code of Ethics and ethics terminology were identified as essential concepts of foundational knowledge. ${ }^{9}$

A recent survey of obstetric and gynecology residency programs showed that despite a 1990 recommendation for a national curriculum in obstetric ethics, and despite an ethics educational manual published by the Association of Professors in Obstetrics and Gynecology and the Council on Resident Education in Obstetrics and Gynecology (APGO/CREOG), ethics education in OB/GYN residency programs still lacks structure and consistency. Most programs offered 0-5 hours of ethics education, and only $50 \%$ offered a formal ethics course. ${ }^{1}$ Surveys of family medicine residency programs, Pediatric residency programs, Dental schools, and Medical school curricula have shown a similar lack of consistency in ethics education methodology, lack of continuity throughout the programs, similar barriers to ethics education, and lack of effective evaluation tools. ${ }^{10-13}$

Though the study of ethical principles and shared decision-making is a required component of midwifery education, and has been shown to be important to midwifery educators, to our knowledge, the specific components of ethics education in midwifery programs have not yet been examined. To this end, a survey was conducted to examine the current formats, venues, content, barriers, and hours dedicated to ethics education in accredited midwifery programs in the United States.

\section{Methods}

A thirteen question, primarily multiple-choice questionnaire was utilized for this survey, which was modeled after surveys of other disciplines, and which was adapted to include topics specific to midwifery education. ${ }^{12,13}$ The questionnaire was reviewed by 5 content experts and midwifery educators. The questionnaire consisted of one question regarding the type of degree(s) conferred by their program, and 12 questions regarding ethics education. Program directors were asked if they offered a stand-alone ethics class, into which classes (if any) ethical topics were integrated, and how many clock hours were dedicated to ethics education. The survey also included questions regarding venues of ethics education, formats and resources used, methods of evaluating ethics education, barriers to, and the most common topics included in their ethics curricula. Two openended questions were included, one which asked respondents to identify any unmet needs in ethics education, and a second which invited participants to discuss any concerns, thoughts, or ideas regarding ethics education in midwifery programs.

This survey was granted exempt status by the Institutional Review Board of Oregon Health \& Science University. The invitation email describing the survey included a 


\section{6|Chapter Two}

statement that participation was both voluntary and anonymous. ACME and MEAC accredited midwifery programs were identified from their respective databases as available on their websites. In July 2015, program directors of ACME accredited programs were invited by email to participate in the survey via the Directors of Medical Education (DOME) listserv. Program directors of MEAC accredited programs were invited via email through contact information provided on the MEAC website. The invitation email included a link to the survey via Survey Monkey. A second, reminder email was sent two weeks after the initial invitation email. The collected data were de-identified and descriptive analysis was performed using Microsoft Excel (2011).

\section{Results}

A total of 25 of 49 eligible programs participated in the survey, providing a response rate of $51 \%$. Six of $10(60 \%)$ eligible MEAC accredited programs responded, and 19 of $39(48 \%)$ of ACME accredited programs responded. Tables 1 and 2 present the responses to the survey questions. Of the MEAC accredited programs, 4 (66\%) offer a stand-alone ethics education course, compared to only $3(15 \%)$ of ACME accredited programs. All respondents indicated that ethics content is integrated into other core courses, most commonly a class on professionalism (88\%). The number of clock hours dedicated to ethics education varied widely, with $36 \%$ offering $1-10$ hours and $32 \%$ offering more than 40 hours. The most common venue was a didactic class with midwifery students. Only $36 \%$ of respondents included ethics content in an interprofessional didactic classroom setting. The most common format of presenting ethics content was case-based seminars with real-life cases (88\%), followed closely by lecture (84\%). Eight respondents (32\%) indicated the use of simulation as a format for ethics education, and 12 (48\%) utilize role playing/standardized patients. While the majority use codes of ethics or statements of value as a resource ( $92 \%$ or 23 respondents), the other most commonly used resources were midwifery/obstetric textbook (60\% or 15 respondents), midwifery professionalism book (48\% or 12 respondents), and midwifery/obstetric journals (44\% or 11 respondents). Only one respondent indicated that the hospital ethicist was utilized as a resource.

\begin{tabular}{|c|c|c|c|}
\hline \multicolumn{4}{|c|}{$\begin{array}{l}\text { Table } 1 \\
\text { Ethics education curricula characteristics and barriers }\end{array}$} \\
\hline & $\begin{array}{c}\text { CNM/CM } \\
(\mathrm{N}=19) \\
\mathrm{n}(\%)\end{array}$ & $\begin{array}{c}\text { CPM } \\
(\mathrm{N}=6) \\
n(\%)^{\mathrm{a}}\end{array}$ & $\begin{array}{c}\text { Total } \\
(\mathrm{N}=25) \\
\mathrm{n}(\%)\end{array}$ \\
\hline \multicolumn{4}{|c|}{ Curriculum includes stand-alone ethics class } \\
\hline Yes & $3(15.7)$ & $4(66.6)$ & $7(28)$ \\
\hline No & $16(84.2)$ & $2(33.3)$ & $18(72)$ \\
\hline \multicolumn{4}{|c|}{ Program integrates ethics content } \\
\hline Yes & $19(100)$ & $6(100)$ & $25(100)$ \\
\hline No & $0(0)$ & $0(0)$ & $0(0)$ \\
\hline \multicolumn{4}{|c|}{ Didactic courses which include ethics content } \\
\hline Professionalism & $16(84.2)$ & $6(100)$ & $22(88)$ \\
\hline IP/AP/PP/Gynecology & $17(89)$ & $3(50)$ & $20(80)$ \\
\hline Clinical seminars & $10(52.6)$ & $4(66.6)$ & $14(56)$ \\
\hline
\end{tabular}




\begin{tabular}{|l|c|c|c|}
\hline Clock hours of ethics education & & & \\
\hline$<1$ hour & $0(0)$ & $0(0)$ & $0(0)$ \\
\hline 1 -10 hours & $8(42.1)$ & $1(16.6)$ & $9(36)$ \\
\hline $11-20$ hours & $4(21)$ & $1(16.6)$ & $5(20)$ \\
\hline $21-30$ hours & $1(5.2)$ & $1(16.6)$ & $2(8)$ \\
\hline $31-40$ hours & $1(5.2)$ & $0(0)$ & $1(4)$ \\
\hline$>40$ hours & $5(26.3)$ & $3(50)$ & $8(32)$ \\
\hline Barriers to ethics education & & & $8(32)$ \\
\hline No barriers & $4(21)$ & $4(66.6)$ & $15(60)$ \\
\hline Already crowded curriculum & $14(73.6)$ & $1(16.6)$ & $4(16)$ \\
\hline Concern for duplication & $4(21)$ & $0(0)$ & $3(12)$ \\
\hline Inadequate funding & $3(15.7)$ & $0(0)$ & $2(8)$ \\
\hline Scheduling conflicts & $2(10.5)$ & $0(0)$ & $0(0)$ \\
\hline Faculty resistance/disinterest & $0(0)$ & $0(0)$ & $3(12)$ \\
\hline Lack of faculty expertise & $2(10.5)$ & $1(16.6)$ & $0(0)$ \\
\hline Student resistance/disinterest & $0(0)$ & $0(0)$ & $2(8)$ \\
\hline Administrative resistance & $2(10.5)$ & $0(0)$ & \\
\hline
\end{tabular}

\section{Table 2}

Ethics education venues, formats, resources, and evaluation methods

\begin{tabular}{|l|c|c|c|}
\hline & $\begin{array}{c}\text { CNM/CM } \\
(n=19) \\
n(\%)\end{array}$ & $\begin{array}{c}\text { CPM } \\
(n=6) \\
n(\%)\end{array}$ & $\begin{array}{c}\text { Total } \\
(\mathrm{N}=25) \\
n(\%)\end{array}$ \\
\hline Venue for ethics education & $0(0)$ & $0(0)$ & $0(0)$ \\
\hline None & $2(10.5)$ & $1(16.6)$ & $3(12)$ \\
\hline Grand Rounds & $2(10.5)$ & $0(0)$ & $2(8)$ \\
\hline Book/journal club & $1(5.2)$ & $0(0)$ & $1(4)$ \\
\hline Patient handoff & $9(47.3)$ & $3(50)$ & $12(48)$ \\
\hline Clinical hours & $16(84.2)$ & $6(100)$ & $22(88)$ \\
\hline Structured didactic class, midwifery classmates & $9(47.3)$ & $0(0)$ & $9(36)$ \\
\hline Structured didactic class, interdisciplinary classmates & & & \\
\hline Formats of ethics education & $0(0)$ & $0(0)$ & $0(0)$ \\
\hline None & $15(78.9)$ & $6(100)$ & $21(84)$ \\
\hline Lecture & $17(89.4)$ & $5(83.3)$ & $22(88)$ \\
\hline Case-based seminars, real-life cases & $10(52.6)$ & $4(66.6)$ & $14(56)$ \\
\hline Case-based seminars, paradigmatic cases & $8(42.1)$ & $2(33.3)$ & $10(40)$ \\
\hline Current events & $4(21)$ & $0(0)$ & $4(16)$ \\
\hline Novels or biographical accounts & $8(42.1)$ & $4(66.6)$ & $12(48)$ \\
\hline Reflective/journal writing & $8(42.1)$ & $4(66.6)$ & $12(48)$ \\
\hline Computer/web-based instruction & $11(57.8)$ & $1(16.6)$ & $12(48)$ \\
\hline Role-playing/standardized patients & $7(36.8)$ & $1(16.6)$ & $8(32)$ \\
\hline Simulation & & & \\
\hline Resources for ethics content & $0(0)$ & $0(0)$ & \\
\hline None & $5(26.3)$ & $0(0)$ & $5(20)$ \\
\hline Ethics book & $3(15.7)$ & $6(100)$ & $9(36)$ \\
\hline Midwifery ethics text & $11(57.8)$ & $1(16.6)$ & $12(48)$ \\
\hline Midwifery professionalism text & $18(94.7)$ & $5(83.3)$ & $23(92)$ \\
\hline Code of ethics/statement of values & $13(68.4)$ & $2(33.3)$ & $15(60)$ \\
\hline Midwifery/obstetric textbook & $2(10.5)$ & $1(16.6)$ & $3(12)$ \\
\hline Ethics journal(s) & & & \\
\hline
\end{tabular}




\begin{tabular}{|l|c|c|c|}
\hline Midwifery/obstetric journal(s) & $10(52.6)$ & $1(16.6)$ & $11(44)$ \\
\hline Online ethics education & $4(21)$ & $1(16.6)$ & $5(20)$ \\
\hline Evaluation of ethics content & & & \\
\hline No explicit evaluation tool & $6(31.5)$ & $0(0)$ & $6(24)$ \\
\hline Faculty observation & $8(42.1)$ & $4(66.6)$ & $12(48)$ \\
\hline Student essay & $7(36.8)$ & $3(50)$ & $10(40)$ \\
\hline Multiple choice questions & $5(26.3)$ & $1(16.6)$ & $6(24)$ \\
\hline Class participation & $11(57.8)$ & $6(100)$ & $17(68)$ \\
\hline Student case presentation & $9(47.3)$ & $4(66.6)$ & $13(52)$ \\
\hline
\end{tabular}

Thirty-two percent of respondents indicated that there were no barriers to ethics education. Of the respondents who did identify barriers, the most common barrier identified was curriculum crowding (60\%), followed by lack of faculty expertise (12\%). Most respondents evaluated ethics education through class participation (68\%), although $24 \%$ indicated that no particular tool for evaluation was employed.

The most common topics of ethics content are presented in Table 3 and included the areas of informed consent (100\%), informed refusal (92\%), shared decision-making (96\%), patient-provider communication (96\%), privacy and confidentiality (96\%), prenatal diagnosis and genetics (96\%) and professional codes of ethics (96\%). The least common topics discussed were ethical theories (44\%), moral distress (40\%), conscientious objection (36\%), and gestational carrier/surrogacy issues (32\%). Only $52 \%$ of respondents indicated that truth telling is included in ethics content, and $88 \%$ include patient safety as part of ethics education.

\section{Table 3}

Clinical ethics topics taught in accredited midwifery programs

\begin{tabular}{|c|c|c|c|}
\hline & $\begin{array}{c}\text { CNM/CM } \\
(n=19) \\
n(\%)\end{array}$ & $\begin{array}{l}\text { CPM } \\
(n=6) \\
n(\%)\end{array}$ & $\begin{array}{c}\text { Total } \\
(\mathrm{N}=25) \\
\mathrm{n}(\%)\end{array}$ \\
\hline Informed Consent & $19(100)$ & $6(100)$ & $25(100)$ \\
\hline Shared Decision-Making & $18(94.7)$ & $6(100)$ & $24(96)$ \\
\hline Prenatal diagnosis/genetic screening & $19(100)$ & $5(83.3)$ & $24(96)$ \\
\hline Professional codes of ethics or conduct & $18(94.7)$ & $6(100)$ & $24(96)$ \\
\hline Effective Patient-Provider Communication & $18(94.7)$ & $6(100)$ & $24(96)$ \\
\hline Privacy/confidentiality & $17(89.4)$ & $6(100)$ & $23(92)$ \\
\hline Informed Refusal & $17(89.4)$ & $6(100)$ & $23(92)$ \\
\hline Patient safety & $16(84.2)$ & $6(100)$ & $22(88)$ \\
\hline Ethics decision making processes & $16(84.2)$ & $6(100)$ & $22(88)$ \\
\hline Patient as partner in healthcare & $15(78.9)$ & $6(100)$ & $21(84)$ \\
\hline Healthcare disparities/allocation of resources & $16(84.2)$ & $5(83.3)$ & $21(84)$ \\
\hline Medical Errors & $17(89.4)$ & $3(50)$ & $20(80)$ \\
\hline Research ethics & $15(78.9)$ & $4(66.6)$ & $19(76)$ \\
\hline Maternal-fetal conflicts & $11(57.8)$ & $5(83.3)$ & $16(64)$ \\
\hline Principles of bioethics & $14(73.6)$ & $1(16.6)$ & $15(60)$ \\
\hline Right to life/right to die/wrongful birth & $12(63.1)$ & $1(16.6)$ & $13(52)$ \\
\hline Truth telling/veracity/disclosure & $9(47.3)$ & $4(33.3)$ & $13(52)$ \\
\hline Ethical theories & $7(36.8)$ & $4(66.6)$ & $11(44)$ \\
\hline Moral distress & $8(42.1)$ & $2(33.3)$ & $10(40)$ \\
\hline
\end{tabular}


Ethics Education in Midwifery Education Programs in the United States

\begin{tabular}{|l|c|c|c|}
\hline Conscientious objection & $7(36.8)$ & $2(33.3)$ & $9(36)$ \\
\hline Gestational carrier/surrogate pregnancy & $7(36.8)$ & $1(16.6)$ & $8(32)$ \\
\hline None & $0(0)$ & $0(0)$ & $0(0)$ \\
\hline
\end{tabular}

Nineteen respondents offered answers to the open-ended question of unmet needs in ethics education. Eight responses included the desire for a curriculum structure in which ethical content is woven through the entire program, with advancing complexity that corresponds to and mirrors the advancing midwifery content. Respondents also indicated a desire for more standardized curricula content, and identified the need for midwifery-specific ethical content. Assistance in practice implementation, administrative support, and faculty instruction were also mentioned.

Respondents were also offered the opportunity to comment freely on any other topic regarding ethics education. Fifteen respondents chose to answer, and many of the answers echoed the responses from the question regarding unmet needs, especially with regard to a standardized, midwifery-focused curriculum. Other respondents mentioned the importance of an education in ethical theory prior to applying these theories to clinical ethics. Two respondents addressed the importance of a safe learning environment for students, acknowledging that ethical dilemmas perforce engender complex and difficult conversations and that faculty may need additional resources and support in helping students grapple with challenging cases.

\section{Discussion}

This is the first survey of its kind to look specifically at ethics education in accredited midwifery programs in the United States. No standardized ethics curriculum in midwifery exists, and programs are only obligated to fulfill the accreditation requirement of teaching biomedical ethics in some capacity. This survey is the first step in assessing the need for a formal, standardized, midwifery-specific ethics curriculum.

It is interesting to note that, of the programs that responded to this survey, the majority of ACME accredited programs do not offer a stand-alone ethics course, while the majority of MEAC accredited programs do. This may be a function of curriculum crowding, which was cited as a barrier by $73 \%$ of ACME accredited programs, although by only $16 \%$ of MEAC accredited programs. Curricula may also be developed with the assumption that students have been exposed to the fundamental concepts of ethics in an undergraduate setting. A number of respondents also expressed an interest in a curriculum in which ethics education is intertwined with other clinical topics. What may be needed in the future are both stand-alone ethics classes to lay the foundation of ethical theory and ethics assessment, and a mechanism by which ethical theory is applied to clinical practice in such a manner that the complexity of ethical dilemmas mirror the complexity of the clinical course. This would require not only time in already crowded curricula, but also faculty and instructors who feel comfortable in analyzing and discussing difficult ethical dilemmas. 
This survey was not powered to elicit responses regarding the need for a standalone ethics class versus an ethics curriculum that is woven throughout the midwifery curriculum. However, many respondents commented on this issue, and there was an equally strong call for both. Griswold Pierce proposed an ethics curriculum for Doctor of Nursing Practice (DNP) students, stating that a Master's level degree did not provide sufficient preparation for new graduates. ${ }^{14}$ This curriculum was not limited to clinical ethics issues, but also included business ethics, research ethics, and legal issues. An understanding of all of these topics was required for the DNP graduate. However, the trend toward achieving a DNP as the primary midwifery degree has evolved slower than expected, and doesn't address alternative, accredited pathways to midwifery in the United States.

Twenty respondents use simulation or role playing/standardized patients as a format for ethics education, indicating a growing use of these formats. Simulation has the potential to allow students a direct experience in navigating ethical dilemmas and in developing communication skills. ${ }^{15}$ Simulation may also offer the students a more personal experience, and an opportunity for reflection and debriefing in a supported environment. ${ }^{16}$ About one half of respondents indicated that discussions of ethical issues occur with students during direct patient care, which may represent a missed opportunity to discuss ethical dilemmas in "real-time", and for modeling of an ethics assessment process by preceptors.

Only nine respondents offer the opportunity for interdisciplinary education. This may be due to lack of opportunity or lack of access to the students of other educational programs. Interdisciplinary ethics education has the potential to improve collaboration and mutual respect between professions and may offer the opportunity to explore ethical conflicts from different professional perspectives and philosophies, facilitating respectful communication. ${ }^{17}$

Although codes of ethics or statements of values are the most common resources, these midwifery educators indicated that a wide variety of resources are utilized for ethics education. Only one respondent indicated that a hospital ethicist was utilized as a resource, which points to a potentially underutilized resource for midwifery ethics education. Specific titles of midwifery texts or online sources were not requested, nor were they supplied by respondents. This is a weakness in the survey, as it may be helpful for future research to examine the exact sources of midwifery ethics education, in order to help identify those ethical dilemmas that may be particular to midwifery.

It is not surprising that the most common topics addressed in midwifery ethics education involve the patient-provider relationship in terms of informed consent, informed refusal, and shared decision-making. Shared decision-making is an important concept that has garnered a tremendous amount of attention in the literature. However, it has been difficult to implement in practice, and ethicists and educators are continuing to explore its true place in the context of a clinical encounter. ${ }^{18}$ It is interesting that some ethics topics were not covered more extensively, including topics related to value ethics (truth-telling, moral distress, conscientious objection). This may speak a potential tension 
when examining of the exact goal of ethics education. Is the focus of ethics education the creation of virtuous providers, who behave in an ethical manner by demonstrating respect and compassion? Or is the goal of ethics education to provide clinicians with the skills to recognize, navigate, and resolve ethical dilemmas? ${ }^{2}$

With the exception of prenatal diagnosis/genetics, topics that specifically address maternity care (maternal-fetal conflict, surrogacy/gestational carrier, and right to life/wrongful birth) were covered by fewer programs that might be expected. This may be a result of lack of exposure to a particular clinical conflict. For example, clinical presentations such as surrogate pregnancy, that can involve ethical dilemmas, may arise rarely in some midwifery practices. This may also be a result of the using the term "maternal-fetal conflicts" in the survey. It has been argued that the term "maternal-fetal conflict" is inaccurate and insufficient to fully represent the tensions within the relationships between woman, fetus, and provider in situations when the best interests of one may be in conflict with another, although the term is still commonly used in the literature. ${ }^{19}$

Similar to other ethics education surveys, there are a variety of mechanisms for evaluating ethics education. ${ }^{1,10,13}$ While most ethics education assessment methods rely upon subjective evaluation, such as class participation, currently there is no objective metric for evaluating student competence in evaluating, analyzing, and resolving ethical dilemmas. ${ }^{1}$ In addition, there is limited published data regarding the effectiveness of ethics education itself. Studies show improvement in ethical attitudes, increased sensitization to ethical issues, and improved skill in clarifying ethical issues. Other studies, however, failed to show a significant effect of ethics education intervention on provider communication or decision-making. ${ }^{20}$ If one of the goals of ethics education is to provide new clinicians with the skills for navigating difficult ethical dilemmas, then midwifery educators must also have a mechanism for evaluating those skills.

This survey has helped to illuminate the current status in ethics content in midwifery education curricula within the United States. It was structured to be similar to the surveys used for other disciplines, not to invite comparisons but rather to explore opportunities for continuity and collaboration. Another strength of the survey is that it included accredited-midwifery programs that represent different educational pathways to midwifery certification. One limiting factor is that only approximately half of accredited midwifery programs chose to participate in the survey. This is a similar response rate to recently published surveys in other disciplines. ${ }^{1,10}$ It may be that primarily those program directors with an interest in ethics education responded. The specific demographics of midwifery programs, such as geographical location, number of students, or number of faculty, were not obtained in order to protect program anonymity. In addition, clock hours may not be the optimal indicator for competency measurement. However, use of clock hours does allow for comparison across the different pathways of midwifery education. 


\section{2 |Chapter Two}

\section{Conclusion}

It is hoped that the results of this survey will begin the conversation regarding the content and format of ethics material in midwifery education programs. The survey also challenges the midwifery community to intentionally contemplate midwifery ethics -- is there a midwifery-specific ethic that can be identified and then woven into midwifery education? Unique ethical dilemmas can arise during maternity care, and the midwifery model brings a unique perspective to this arena. There is an opportunity for midwifery programs to be more deliberate in the methods and content of ethics education. This survey also points to areas for future research. First, there is an opportunity to solicit the perspectives of midwifery faculty, midwifery students, and new graduates regarding preparation for coping with clinical ethical dilemmas. Second, there is an opportunity to explore the idea of a standard ethics curriculum that directly addresses issues unique to reproductive care and women's health care, in relation to a midwifery perspective. Third, mechanisms for faculty support and continuing education in theoretical and clinical ethics are needed. Last, it is crucial that methods for ethics assessment and competency, including a metric for evaluation, be developed. 


\section{References}

1. Byrne J, Straub H, Digiovanni L, Chor J. Evaluation of ethics education in obstetrics and gynecology residency programs. American Journal of Obstetrics and Gynecology. 2015;212(3):397.e1-397.e8. doi:10.1016/j.ajog.2014.12.027

2. Eckles RE, Meslin EM, Gaffney M, Helft PR. Medical Ethics Education: Where Are We? Where Should We Be G... : Academic Medicine. 2005;80(12):1143-1152. doi:10.1097/00001888-200512000-00020

3. Bellack JP, Graber D, O’Neil EH, Musham C. Curriculum trends in nurse-midwifery education views of program directors. Journal of Nurse-Midwifery. 1998;43(5):341-350. doi:10.1016/S00912182(98)00031-7

4. Accreditation Commission for Midwifery Education (AMCB). Criteria for Programmatic Accreditation of Midwifery Education Programs with Instructions for Elaboration and Documentation. Published 2013. Accessed January 31, 2019.

http://www.midwife.org/ACNM/files/ccLibraryFiles/Filename/000000006672/CriteriaforProgrammati cAccreditationofMidwiferyEducationPrograms(June2013April2015)updatedpassrateinstructionsforclar ityJune2016_June2017.pdf

5. American College of Nurse-Midwives. Core competencies for basic midwifery practice. American College of Nurse Midwives Core Competencies. 2012;(July):1-8.

6. Midwifery Education Accreditation Council. Accreditation Handbook. Published October 2013. Accessed September 14, 2015. http://meacschools.org/wp-content/uploads/2013/10/2013-Section-AIntroduction_Accreditation-Handbook.pdf

7. Midwifery Education Accreditation Council. Curriculum Checklist of Essential Competencies 1 / COMPETENCY IN SOCIAL , EPIDEMIOLOGIC AND CULTURAL CONTEXT OF MATERNAL AND.; 2014. Accessed September 14, 2015. http://meacschools.org/wp-content/uploads/2014/12/CurriculumChecklist-of-Essential-Competencies-rev-2014.pdf

8. Burkemper JE, DuBois JM, Lavin MA, Meyer GA, McSweeney M. Ethics Education in MSN Programs: A Study of National Trends. Nursing Education Perspectives. 2007;28(1):10-17.

9. Laabs CA. Toward a Consensus in Ethics Education for the Doctor of Nursing Practice. Nursing Education Perspectives. 2015;36(4):249-251. doi:10.5480/13-1195

10. Manson HM, Satin D, Nelson V, Vadiveloo T. Ethics education in family medicine training in the United states: A national survey. Family Medicine. 2014;46(1):28-35.

11. DuBois JM, Burkemper J. Ethics Education in U.S. Medical Schools. Academic Medicine. 2002;77(5). doi:10.1097/00001888-200205000-00019

12. Lantz MS, Bebeau MJ, Zarkowski P. The status of ethics teaching and learning in U.S. dental schools. Journal of dental education. 2011;75(10):1295-1309.

13. Lang CW, Smith PJ, Ross LF. Ethics and Professionalism in the Pediatric Curriculum: A Survey of Pediatric Program Directors. Pediatrics. 2009;124(4):1143-1151. doi:10.1542/peds.2009-0658

14. Peirce AG, Smith JA. The Ethics Curriculum for Doctor of Nursing Practice Programs. Journal of Professional Nursing. 2008;24(5):270-274. doi:10.1016/j.profnurs.2007.06.008

15. Buxton M, Phillippi JC, Collins MR. Simulation: A New Approach to Teaching Ethics. Journal of Midwifery and Women's Health. 2015;60(1):70-74. doi:10.1111/jmwh.12185

16. Smith K v., Witt J, Klaassen JA, Zimmerman C, Cheng AL. High-fidelity simulation and legal/ethical concepts: A transformational learning experience. Nursing Ethics. 2012;19(3):390-398. doi:10.1177/0969733011423559

17. Hanson S. Teaching Health Care Ethics: why we should teach nursing and medical students together. Nursing Ethics. 2005;12(2). doi:10.1191/0969733005ne773oa

18. Gillick MR. Re-engineering shared decision-making. Journal of Medical Ethics. 2015;41(9). doi:10.1136/medethics-2014-102618

19. Harris L. Rethinking maternal-fetal conflict: Gender and equality in perinatal ethics. Obstetrics and Gynecology. 2000;96:786-791.

20. Salih ZNI, Boyle DW. Ethics Education in Neonatal-Perinatal Medicine in the United States. Seminars in Perinatology. 2009;33(6):397-404. doi:10.1053/j.semperi.2009.07.008 
34|Chapter Two 


\section{CHAPTER 3}

Students' experiences of ethics education in midwifery programs in the United States

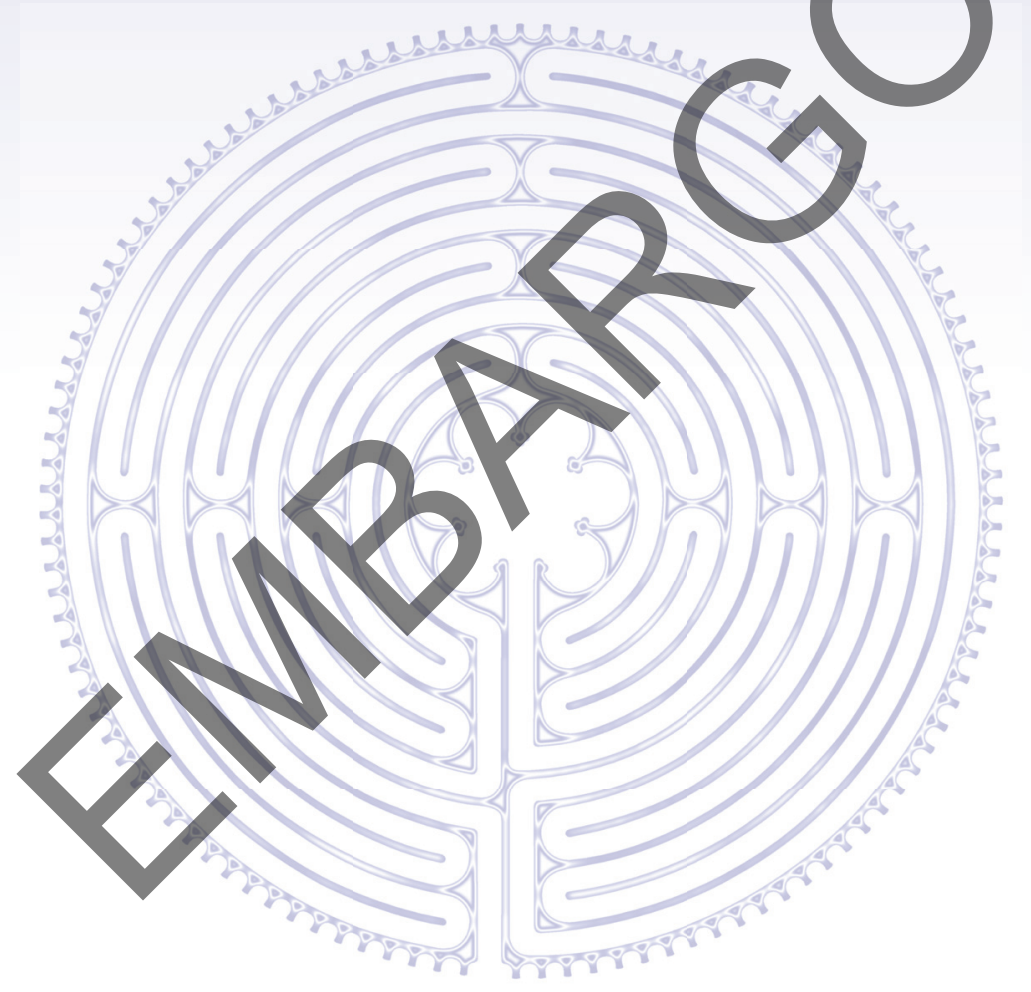

Michele Megregian, Lisa Kane Low, Cathy Emeis,

Raymond de Vries, Marianne Nieuwenhuijze

Nurse Education Today, submitted 


\section{CHAPTER 4}

\section{"I'm sure we talked about it":}

Midwives experiences of ethics education and ethical dilemmas, a qualitative study

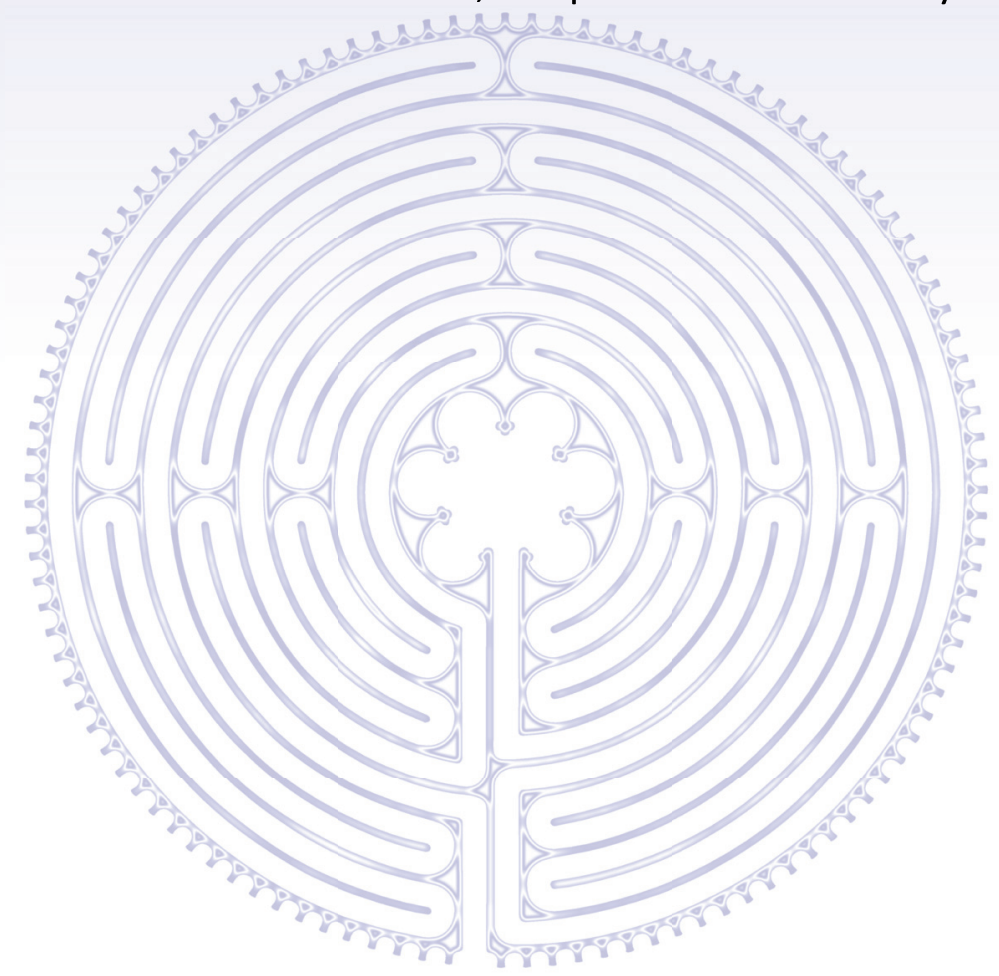

Michele Megregian, Lisa Kane Low, Cathy Emeis, Raymond de Vries, Marianne Nieuwenhuijze

Women and Birth 2020 Nov;33(6):e519-e526 


\section{2 |Chapter Four}

\section{Abstract}

\section{Aim}

Midwives are expected to identify and help resolve ethics problems that arise in practice, skills that are presumed to be taught in midwifery educational programs. In this study, we explore how midwives recognize ethical dilemmas in clinical practice and examine the sources of their ethics education.

\section{Methods}

We conducted semi-structured, individual interviews with midwives from throughout the United States (U.S.) ( $n=15)$. Transcripts of the interviews were analysed using an iterative process to identify themes and subthemes.

\section{Findings}

Midwives described a range of professional ethical dilemmas, including challenges related to negotiating strained interprofessional relationships and protecting or promoting autonomy for women. Ethical dilemmas were identified by the theme of unease, a sense of distress that was expressed in three subthemes: uncertainty of action, compromise in action, and reflecting on action. Learning about ethics and ethical dilemmas occurred, for the most part, outside of the classroom, with the majority of participants reporting that their midwifery program did not confer the skills to identify and resolve ethical challenges.

\section{Conclusion}

Midwives in this study reported a range of ethical challenges and minimal classroom education related to ethics. Midwifery educators should consider the purposeful and explicit inclusion of midwifery-specific ethics content in their curricula and in interprofessional ethics education. Reflection and self-awareness of bias were identified as key components of understanding ethical frameworks. As clinical preceptors were identified as a key source of ethics learning, midwifery educators should consider ways to support preceptors in building their skills as role models and ethics educators.

\section{Keywords}

midwifery; midwifery education; ethics; ethical dilemmas

\section{Statement of Significance}

\section{Problem}

Ethics curricula in midwifery programs may not adequately prepare midwives to recognize and negotiate common ethical dilemmas.

\section{What is already known}

Ethics education in midwifery programs in the United States is currently lacking in standardization regarding ethics content, methods of teaching and evaluation, and expected outcomes. 
"I'm sure we talked about it": Midwives experiences of ethics education and ethical dilemmas, a qualitative study $\mid \mathbf{5 3}$

\section{What this paper adds}

Midwives recognize ethical dilemmas through a sense of unease.

They report little ethics education from their midwifery programs, and rely upon clinical preceptors, not classroom content, for ethics learning.

\section{Implications for practice}

Midwifery education programs should consider purposeful inclusion of ethics content. Improved understanding of the function of clinical preceptors as role models of ethics is needed. 


\section{4|Chapter Four}

\section{Introduction}

Perinatal health care brings particularly complex ethical questions. Midwives and the women they care for are confronted with ethical dilemmas on a regular basis. Midwives are expected to possess a sensitivity to ethics and the skill to guide ethical, shared decision-making. ${ }^{1}$ However, there is no consensus regarding the specific skills that are needed to achieve competency in the recognition and negotiation of ethical situations and dilemmas, including the challenges associated with informed choice. ${ }^{1,2}$ There are few studies that explore the impact of providers' ethics education in undergraduate or graduate nursing, midwifery, or medical programs on their confidence to cope with ethical dilemmas or ethics decision-making. ${ }^{3-6}$ Oelhafen and colleagues looked at moral problems and moral distress experienced by midwives with the aim of developing a list of moral competencies that may be foundational to midwifery care and that should be included in midwifery education. ${ }^{7}$ Their results showed that interprofessional conflict resulting from constraints on a midwife's autonomy was identified as the most relevant ethical issue. A literature search revealed no published studies that specifically target the experiences of midwives from the U.S in recognizing, negotiating, or coping with ethical dilemmas.

\section{Aim}

This study had two aims: to explore the experiences of U.S. midwives with regard to ethical dilemmas in clinical practice and to identify key sources of their ethics learning. Our prior survey of program directors of U.S. midwifery programs showed a lack of standardization of ethics content in the curricula. ${ }^{8}$ We hypothesized that the effect of this lack of standardization would have an impact on practicing midwives through their experiences of recognizing, negotiating, and coping with ethical dilemmas in midwifery practice. Through interviews we sought to discover how midwives recognized situations of ethical conflict or concern, as well as how they reflected upon those situations in the context of their midwifery practice. In addition, we asked midwives to identify the key sources of ethics education and learning, and how those sources influenced their recognition and understanding of ethical dilemmas. We were particularly interested in their experience of ethics learning during their midwifery education, and all participants were asked to provide details as able.

\section{Methods}

\section{Design}

This is a qualitative descriptive thematic study, exploring midwives' experiences with ethical dilemmas in clinical practice, as well as key sources of learning about ethics. ${ }^{9}$ Indepth interviews with individual midwives in the U.S. were conducted between April and June 2018. We asked midwives to tell us about their experiences with identifying and negotiating ethical dilemmas and to describe how they learned about ethics, specifically regarding ethics content in their midwifery education and the degree to which they felt prepared to identify and respond to ethical problems.

\section{Participants}


Midwives were eligible if they were or had been in clinical practice and had graduated from an accredited midwifery program in the U.S. Email invitations were sent out to all active members of the American College of Nurse-Midwives (ACNM), asking them to reply with interest in participating in one-on-one interviews. Midwives were enrolled in the order of response to the initial email invitation. Participants were de-identified at the time of enrolment and assigned a number in the order they were interviewed (CNM1, CNM2, etc) in order to maintain confidentiality.

\section{Data Collection}

All midwives who responded to the initial invitation with an interest in participating were sent information sheets and invitation dates for interviews, which were subsequently scheduled for a time and method (for example, by telephone) most convenient for the participant. Interview questions were developed by the study team, based on current literature and the project aim. ${ }^{6,10-12}$ The semi-structured interview guide was comprised of six questions aimed at encouraging participants to use stories to illustrate their experiences with ethical dilemmas, ethical decision-making, and ethics education. (Table 1). Probes were used to encourage participants to reflect on their own stories, creating the opportunity to reveal the how they learned about ethics and how to negotiate ethical dilemmas.

\begin{tabular}{|ll|}
\hline & \\
\hline$\bullet$ & What do you consider to be ethical dilemmas that you face in clinical practice? \\
\hline$\bullet$ & Tell me about an ethical problem that was particularly impactful for you. \\
\hline$\bullet$ & To whom do/did you look for support when negotiating this challenge? \\
\hline$\bullet$ & Tell me how you came to the decision that you did, or to take action as you did. \\
\hline$\bullet$ & $\begin{array}{l}\text { How did you learn to negotiate or cope with the ethical challenges you have experienced (or are } \\
\text { experiencing)? }\end{array}$ \\
\hline$\bullet$ & $\begin{array}{l}\text { Tell me about, to the best of your ability, the ethics training that you received during your } \\
\text { midwifery program. }\end{array}$ \\
\hline
\end{tabular}

Participants were asked to describe the ethical dilemmas they experienced in everyday practice and the impact of those experiences on the way they practiced. We then asked them to reflect upon how they learned about ethics and clinical ethical dilemmas, the influence of that education on their practice in general and with regard to events they had previously revealed. To help us assess midwives' perception of ethics learning during their midwifery program, we specifically asked participants to describe any ethics education they had received during their graduate education.

All interviews were conducted by telephone by the first author (MM), a midwife from the U.S with experience in midwifery practice, midwifery education, and ethics. Participants were asked for limited demographic information, including the number of years in practice, current type of practice (for example, midwife-owned independent 
practice or hospital-owned practice with midwives, obstetrician-gynecologists, or other providers) and the name of the educational institution that conferred their midwifery degree. Interviews were audio recorded, transcribed verbatim, and reviewed for accuracy by the study team. Interview length ranged from 30 to 60 minutes.

\section{Data Analysis}

Transcribed interviews were uploaded into Dedoose, a qualitative data analysis software program. ${ }^{13}$ The transcripts were checked against the audio recordings to confirm accuracy, then read several times to facilitate familiarity with the data, and from this analysis memos were created outlining potential code and ideas. We used thematic analysis to examine midwives' experiences with identifying and negotiating ethical dilemmas. We developed an initial coding scheme informed by the interview process, which was then adjusted via iterative analysis of the transcripts and discussions among study team members (MM, MN). ${ }^{14}$ The final coding scheme yielded themes that were merged, split, reviewed, and then checked and rechecked by the study team members to confirm relation to the data and findings. We used thematic mapping to provide a visual representation of the coding scheme and to confirm the relationships between themes and subthemes. ${ }^{15}$ For data regarding sources of ethics learning, we reviewed the transcripts and performed content analysis of the data. Themes and subthemes regarding sources of ethics learning emerged from the data, which were then refined and reviewed for consistency and fidelity to the data by the study team. The themes and subthemes were discussed in order to obtain consensus and to reflect on the analytic process, drawing on the qualitative research expertise of the study team members. The standards for reporting qualitative research (SRQR) was used as a guide for the writing process. ${ }^{16}$

\section{Ethics}

This project was granted approval by the institutional review board of Oregon Health and Science University, Portland, OR. At the beginning of each interview, the participants were informed of the goals of the project. Information sheets explaining that participation was voluntary and that all data would be securely kept and confidential were emailed to each participant prior to the actual interview and reviewed at the start of each interview. Participants were compensated for their time with a ten dollar gift card.

\section{Findings}

After receiving responses from 50 midwives expressing a willingness to participate, recruitment was closed. Those 50 respondents were sent email invitations with interview dates and ultimately 20 interviews were scheduled. The remaining thirty midwives either failed to respond to further invitations $(\mathrm{N}=18)$ or declined to participate for other reasons (lack of time $\mathrm{N}=11$, declined to be interviewed $\mathrm{N}=1$ ). Of the 20 midwives who scheduled interviews, five cancelled due to unexpected scheduling conflicts and declined to reschedule, resulting in 15 completed interviews (Figure 1). Saturation was achieved after 13 interviews; analysis of the remaining interviews generated no new findings. ${ }^{17}$ The 15 participating midwives represented a diverse group of midwives, providing clinical care in home and hospital practices, private and academic practices, and independent and 
"I'm sure we talked about it": Midwives experiences of ethics education and ethical dilemmas, a qualitative study $\mid \mathbf{5 7}$

collaborative practices. Time in practice ranged from one to forty years, with seven midwives in practice for less than 10 years. Participants attended midwifery programs from across the United States, including in-person and online programs. (Table 2)

Figure 1: Participant Recruitment

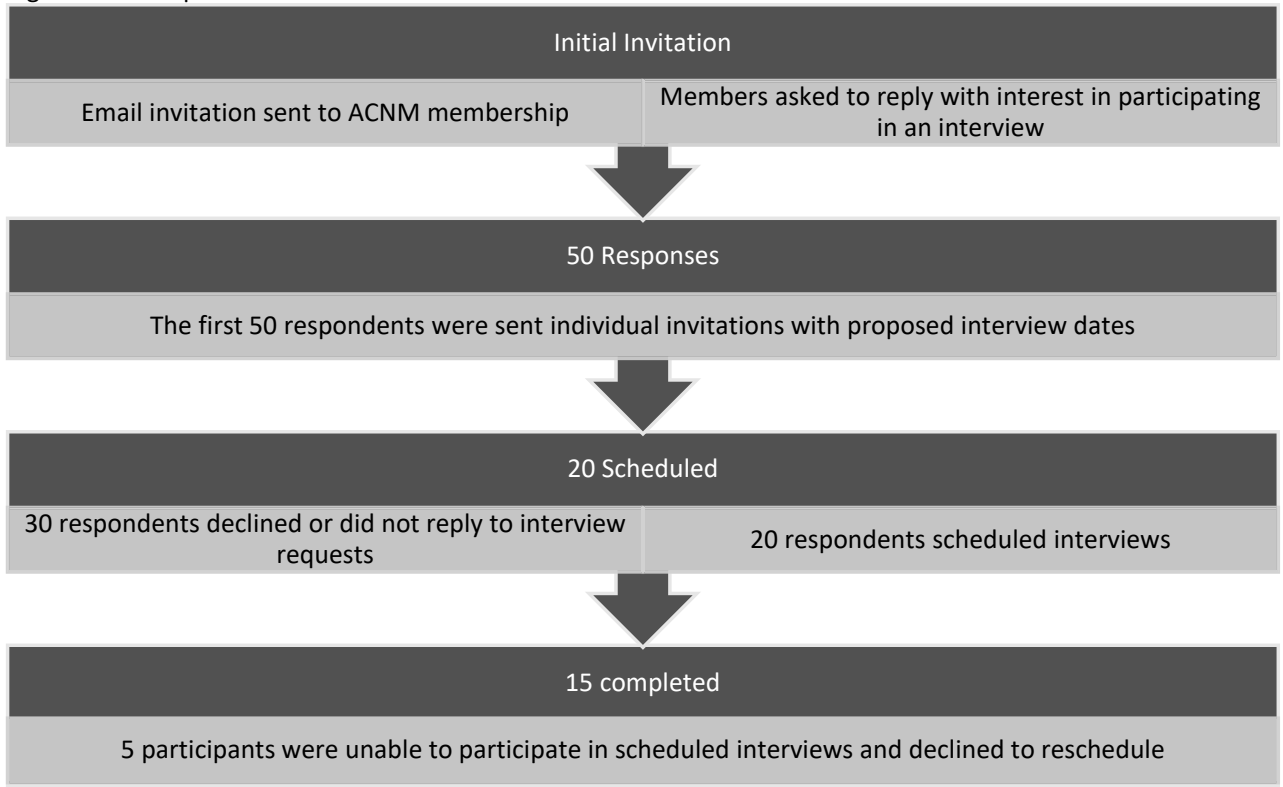




\begin{tabular}{|c|c|l|l|}
\hline \multicolumn{4}{|l|}{$\begin{array}{l}\text { Table 2 } \\
\text { Background Details of Participants }\end{array}$} \\
\hline CNM1 & 18 & Private CNM & Hospital \\
\hline CNM2 & 15 & Private CNM & Hospital \& Community \\
\hline CNM3 & 14 & Private, CNM \& OB & Hospital \\
\hline CNM4 & 6 & Private OB & Hospital \\
\hline CNM5 & 25 & Hospital, CNM \& OB & Hospital \\
\hline CNM6 & 40 & Retired & NA \\
\hline CNM7 & 30 & Private CNM & Community \\
\hline CNM8 & 18 & Private OB & Hospital \\
\hline CNM9 & 10 & Private CNM & Community \\
\hline CNM10 & 8 & Private OB & Hospital \\
\hline CNM11 & 4 & Private OB & Hospital \\
\hline CNM12 & 6 & Hospital, CNM & Hospital \\
\hline CNM13 & 2 & Hospital, CNM \& OB & Hospital \\
\hline CNM14 & 7 & Hospital CNM & Hospital \\
\hline CNM15 & 1 & Hospital, CNM \& OB & Hospital \\
\hline Private OB: Obstetrician-owned independent practice with employed midwives \\
\hline Legend:
\end{tabular}

\section{Ethical dilemmas: problems in practice}

The participating midwives recounted a wide range of experience with clinical and professional ethical dilemmas. Many of the midwives told stories about conflicts regarding abortion services, challenges in care for women with complex medical conditions and/or social circumstances, challenges to protecting or promoting autonomy and informed consent for women, and strained interprofessional relationships. One midwife described the difficult balancing act that she maintained in order to be recognized as a member of the obstetric team, particularly when policy decisions are made.

The midwives also discussed the difficulty women experienced in accessing appropriate care, particularly women in rural areas. These are women who may be seeking genetic screening or abortion care, who may require perinatal care outside of the midwife's scope of practice, or who may seek interventions that are contrary to the midwife's recommendation. They also recounted challenging situations involving potentially fraudulent business practices, situations involving state-level legislative or hospital-based restrictions that may curtail their scope of practice or ability to practice 


\section{"I'm sure we talked about it": Midwives experiences of ethics education and ethical dilemmas, a qualitative study $\mid \mathbf{5 9}$}

independently, and the difficulty of working in a healthcare system that does not reflect their midwifery philosophy.

Midwives also commented on the fatigue that they feel, not only from a physically demanding schedule and the difficulty in maintaining a work-life balance, but also the emotional toll experienced by coping with these daily ethical challenges. One midwife described it as an inability to be "fully present" (CNM10) with the women in her care.

\section{Ethical dilemmas: themes}

In our thematic analysis of how midwives identify and describe the nature of ethical dilemmas, we found one overarching theme - unease - and three associated subthemes. Ethical dilemmas were identified by a feeling of unease, a sense of distress felt either in the moment of an event or upon reflection of that event. This sense of unease was present in the three subthemes: uncertainty of action, compromise in action, and reflecting on action.

\section{Defining ethical dilemmas: Unease}

Some of the midwives found it difficult to provide a definition or an example of an actual ethical dilemma, reflecting on the challenge of understanding when a difficult situation or conflict becomes an ethical dilemma per se. Most of the midwives reported a sense of unease with the situation they were in, and it was this sense that prompted them to think about ethics, or that they were in an ethical situation. They described this unease in three ways: unease related to uncertainty of action, unease related to a compromise in action, and unease in reflecting on action.

\section{Unease in uncertainty of action}

Unease related to uncertainty of action was described by midwives in circumstances where there was no clear choice of the right action to be taken. This type of unease was expressed as uncertainty associated with situations with no right or wrong answer, or when there were multiple ways to approach and solve a particular problem. This ambiguity, or lack of a clear dichotomy of right or wrong was regarded as the essence of an ethical dilemma, and the uncertainty of action and the lack of a clear path forward was a potential cause of distress.

I don't know that there's a right and wrong answer for a lot of ethical questions too. It's really a matter of deepening our understanding and being able to know which are our highest priorities and how do we sort out who's rights are more important than others' rights.(CNM9)

I guess I feel like there's a lot of grey area, and so I'm not sure if I even know clearly myself like what would constitute an ethical issue in my clinical practice.(CNM15)

\section{$\underline{\text { Unease in compromise in action }}$}


Unease related to compromise in action occurred when there was incongruity between the midwife's ideas of the right action to be taken and her ability to implement that action. These situations were described as those where right and wrong were clearly defined and the decision-making path was obvious, but the midwife was prevented from implementing it. Midwives reported having a clear understanding of the action she should take, but, because of institutional pressures, they were unable to take that action. The midwife's ability to pursue right action was compromised by the context of her situation. This usually involved a conflict between the midwife's perception of what should be done in the best interests of the woman or in line with promoting physiologic birth and midwifery care, and what the midwife was allowed to do in that situation as dictated by a particular hospital system, community standard, or regulatory statute. One midwife (CNM4) emphasized the importance of having a clear understanding of right and wrong in this context and having the courage to challenge the authority responsible for constraining their action.

I would just say you have to know right from wrong ... You have to know right from wrong and know what your scope of practice is. And if someone higher up from you says it's okay you have to know if it's really okay or not okay. (CNM4)

I would describe an ethical dilemma as something that you feel as though is right in your heart, but you know that people around you or the institution may not want you to do that. (CNM2)

\section{Unease in reflecting on action}

Unease related to reflecting on action describes circumstances where the midwife understood herself to be in an ethical dilemma only upon reflection after the event. Midwives used reflection upon their actions and residual feelings of unease, not just to describe the impact of an ethical dilemma, but to categorize the event as an ethical dilemma in the first place. The idea of "can you sleep at night" was a touchstone, used to identify when an ethical dilemma was occurring and as a measure of moral distress associated with that conflict.

There's a way to find it within yourself so that you can sleep at night and feel like you were making the right decision even when things went wrong. Because you know things are always going to go wrong. So that was, you know, that's always the test. (CNM7)

I try to present it [genetic screening] in that manner, so that they can figure out exactly where they're at. But in this area I struggle. And you know, I don't wake up at night about it. But still ... I think it is an issue. And I always wonder if I'm adequately educating my client to make a really informed decision.(CNM8)

\section{Learning about ethics}

Participating midwives were asked about how they learned about ethics and how to be aware of ethical dilemmas, including any past experiences of learning, discussing, or thinking about ethics and ethical dilemmas. If they did not initially discuss their midwifery 
education, they were prompted to reflect upon any ethics education that they may have received during their midwifery program, and what impact it may have had upon their ability to recognize and negotiate ethical dilemmas. Descriptive analysis of their responses - how midwives learned to identify and negotiate ethical dilemmas - yielded three themes: learning from individuals outside of the classroom, such as mentors, colleagues, or clinical preceptors; using their own experiences to inform and guide their ethics decision making; and the contribution of their educational programs to their ability to recognize and negotiate ethical dilemmas.

\section{Learning ethics from others}

Many of the midwives reported that they learned about ethics outside of any classroom or dedicated didactic program time, instead learning about ethics from key people in their lives, such as mentors, role models, or clinical preceptors. Mentors included undergraduate professors and nursing and midwifery colleagues. They assisted the midwife in developing critical thinking skills to analyse an ethical dilemma and to reflect upon their own actions, values, and biases.

Midwives identified their mentors as role-models and key support people who helped them think through dilemmas and mitigate emotional distress. Clinical preceptors, in both nursing and midwifery, provided opportunities to observe positive ethical behaviors in action. While they looked to their clinical preceptors as role-models for demonstrating critical behaviors in difficult situations, discussions specific to ethics (for example, ethics principles or decision making) did not seem to be a part of their interaction. Observing the clinical preceptor in action allowed student midwives to reflect upon their own behavior and to imagine what they would do in a similar situation, actions that provided some motivation to learn that behavior.

For some, an understanding that the interactions that they observed were ethical interactions and examples of ethical behavior was gained in retrospect, rather than at the time of observation. The midwives were not necessarily aware that they were learning ethics in the moment.

You know I don't think that much of that really came from what happened in a classroom setting at school. But I do remember watching preceptors and seeing like, that's a conversation that went well. I want to be able to do that. (CNM11)

I went to her[undergraduate professor and ethicist] because I was so conflicted about what was the right answer in this situation, and what ... are the issues that I couldn't even sort any of that out myself at the time ... and she really framed it for me in an ethical perspective ... I remember that being a really formative experience for me of thinking through things in that way, that logical way. And I have sought advice from ethicists since then. (CNM9) 


\section{$62 \mid$ Chapter Four}

Learning ethics from the past: using one's own experience

Midwives also relied upon past experiences to provide them with the skills needed to recognize and cope with ethical dilemmas. Prior involvement in ethically fraught situations, as a student, nurse or midwife, no matter how central or peripheral their role, was key to providing opportunities for improved self-reflection and insight into their own values and biases. These prior experiences also provided a greater understanding of contextual factors and values involved in ethics decision making. One midwife (CNM 10) related that her ongoing experience participating in difficult conversations provided her with an enhanced sense of nuance and allowed her to promote autonomy in a deeper way. Since she had seen the outcomes of many divergent choices, she felt she could better interpret the evidence, balance risk perception, and improve shared decision making. Her experience increased her awareness of the ethical challenges involved in these discussions.

I think it's just been a culmination of all of my different experiences that have colored how I practice. (CNM10)

And I went into it kind of with my own experience. I mean I was 34 years old when I was going into midwifery. So I have some life experience around me, but I can't remember at [midwifery program] having those conversations about $O B$ [obstetric]related issues in particular. (CNM14)

Learning about ethics from educational programs

Midwives were divided about the influence that any formal education (non-nursing, nursing or midwifery) had on their sense of preparation when encountering ethical dilemmas in the "real world". Only a few of the midwives specifically remembered learning ethics content during their midwifery curricula.

I know we had an ethics course. I certainly had one in my registered nursing training some years back and ... then when I transferred over to [X], and that was for midwifery, they also had a portion of ethics. So I had ethics all along the way ... I think it really reinforced why we do what we do anyway. And to know that we are not only making a difference in each person's outcome that we come across when we are aware of not only just what is ethical in general but that that changes depending upon what that patient wants, needs, the whole package of evidence based practice and individualized care. And then the providers themselves, how we treat our colleagues. It's a systematic and systemic approach rather than how we feel about an issue or a topic or perspective. (CNM12)

They also credit the ethics content, in particular the emphasis placed on reflection and awareness of bias, with providing ethical frameworks that emphasized the woman's autonomy and self-awareness. Reflective discourse was viewed as a critical tool and skill for students to acquire in order to become competent in ethics decision-making.

If you don't feel that you can be nonjudgmental in your care and provide complete and accurate information to your patients, because you may be the only person who 
"I'm sure we talked about it": Midwives experiences of ethics education and ethical dilemmas, a qualitative study $\mid 63$

is honest with them, you've got to know where you're at yourself. And I'm not sure that you can do that solely on a self-study, I think it's involved in discussions, it's involved in reflection, in hearing other people's experiences. (CNM8)

I need to assess myself, where am I coming from. Do I have personal views that are feeding into this, and that each person involved in a patient's care, can do the same thing and take an objective approach at what should be done and how things should be handled. (CNM12)

Most of the other midwives remembered receiving ethics content during their graduate education, but they were critical of the classes as being unclear in their intention, poorly constructed, or not midwifery-specific in content. They remembered content that addressed issues of professionalism but did not distinguish between ethics and professionalism as distinct subjects. Some midwives had vague recollections of class discussions of paradigmatic cases or assigned readings, but again did not identify that as ethics content per se. As one participant stated, "I'm sure we talked about it" (CNM10)

[the program was] good at legal aspects of your license, women's healthcare and teen's rights. But as far as ethics though there wasn't anything. There wasn't really discussion or classwork about that. (CNM1)

We did have a class on it; I don't think it was particularly well taught. Um, we talked about some different ethical models and different lenses to look at things through. It wasn't specific to midwifery. It was for the whole nurse practitioner program. (CNM13)

The midwives also offered suggestions for midwifery programs regarding how best to provide ethics education for students. They emphasized the importance of including midwifery-specific content into any ethics discussion, particularly as a method of improving ethics awareness. Just as they identified interprofessional conflicts as an ethical dilemma, midwives identified improved interprofessional education as an important aspect of ethics education, including suggestions such as midwives teaching obstetric residents and medical students.

\section{Discussion}

These interviews with midwives offered insight into common ethical dilemmas and the challenges midwives experienced in defining them. An essential skill needed in clinical decision-making is ethical sensitivity or awareness. ${ }^{18,19}$ Some midwives had difficulty in articulating a precise definition of an ethical dilemma; for others ethical awareness was based on the perception of right and wrong framed as either polar opposites or as points along a continuum. Ethical awareness was also recognized in retrospect; a situation was considered an ethical dilemma only when later reflection triggered moral distress. For the midwives in this study, ethics learning occurred primarily through relationships with 
mentors or clinical preceptors. Few midwives could recall significant ethics learning from their midwifery program.

\section{Identifying ethical dilemmas and moral distress}

Ethical dilemmas have been defined as situations in which action must be taken when there are multiple and seemingly equal choices, and where each choice of action would promote or protect a particular value or ethical principle at the cost of another. ${ }^{6,11}$ Challenges may revolve around competing concerns, competing obligations, or competing interests held by different parties involved. The midwives in our study negotiated, for example, between the obligation to support a woman's choice to decline a particular medical intervention such as induction of labor, and the competing obligation to provide safe evidence-based care by recommending an induction of labor. Given that "advocacy for informed choice, shared decision-making, and the right to selfdetermination" is an ACNM Hallmark of Midwifery ${ }^{20, p .2}$ and a foundational concept of the Philosophy of Midwifery and Model of Care of the International Confederation of Midwives (ICM $)^{21}$, it is not surprising that midwives identified challenges to this core value as a common ethical dilemma. Midwives worked to find ways of supporting women when autonomy was constrained by institutional rules, by scope of practice, and by disagreements about medical interventions. Ethical dilemmas related to the limiting of both women's and providers' autonomy in decision-making is a common theme in midwifery and physician literature, and has been described as a significant source of moral distress. ${ }^{6,7,12}$ Incorporating elements of care ethics, such as attentiveness and responsiveness, may be one way in which the deleterious effects of constraining autonomy may be mitigated. ${ }^{22}$

Similar to our findings, conflicts in interprofessional relationships, issues surrounding abortion care, and the impact of restrictive and hierarchical institutional regulations are reported in international studies of ethical dilemmas as experienced by midwives, nurses, and physicians. , $7,11,23,24$ Key sources of interprofessional conflict include poor communication skills, poor negotiation and resolution of disagreements, and real or perceived power or hierarchical differentials regarding decision-making ${ }^{10,24}$ Interprofessional education activities have shown positive changes in attitudes and learning among students, but it is unclear if those positive changes continue into practice and contribute to improved interprofessional communication and collaboration. ${ }^{25}$ Further examination of the role of healthcare systems, including practice guidelines, legislation, and regulations addressing differing philosophies of perinatal care, midwifery licensure and scope of practice, and hospital medical staff by-laws, may contribute to better understanding of the underlying nature of interprofessional conflicts.

Experiencing an ethical dilemma or participating in complex ethical decisionmaking has the potential to produce moral distress in the individuals involved. The concept of moral distress has its origin in the nursing literature, and has been traditionally defined as emotional or psychological suffering experienced by individuals who are forced to participate in actions (or omissions of action) which they see as wrong or contrary to their individual values. ${ }^{26}$ Constraint of right action diminishes the provider's agency, locus of control, and role in decision-making, thereby compromising their ability to provide 
appropriate care to individuals in a caring and compassionate manner. ${ }^{24}$ However, sources of moral distress are not limited to experiences of power imbalance and inequity, but also include the need to make critical decisions when medical evidence is unclear or uncertain, the lack of objectivity in interpreting medical evidence, and the degree of medical acuity. ${ }^{27}$ Moral distress may also be an indicator of compassion and empathy that is, if a person did not possess and value compassion as a personal or professional attribute, then they would not feel moral distress when encountering its absence. ${ }^{27}$ The midwives in our study identified ethical dilemmas that reflect the aspects of moral distress described here. Ethical dilemmas involving interprofessional conflicts and institutional or regulatory constraints engendered moral distress in the traditional sense of feeling disempowered and lacking in agency. This finding is similar to other studies of midwives' experiences of ethical dilemmas. ${ }^{7}$ However, midwives in our study also identified ethical dilemmas as situations involving uncertainty of right action, characterized by the presence or absence of residual moral distress (the can I sleep at night touchstone). Ethical dilemmas involving a woman's autonomy often solidified the midwife's commitment to the ethical framework of supporting autonomy and promoting informed choice. Their additional awareness and acceptance of uncertainty, particularly as an aspect of risk perception and tolerance, allowed them to promote autonomy in a deeper and more nuanced manner.

\section{Ethics education and preparation}

An important aim of our study was to explore the sources of ethics knowledge and education for midwives, with specific reference to their experience in midwifery educational programs. An understanding of ethics content and the development of ethical awareness are considered to be critically important aspects of education for nurses and midwives. ${ }^{28,29}$ In addition, familiarity with bioethics is a core competency of midwifery practice. ${ }^{20,30}$ However, what constitutes familiarity is not clearly outlined, and ethics education in midwifery programs is currently lacking in standardization with regard to ethics content, methods of teaching, methods of evaluation, and expected outcomes. ${ }^{8,31}$ The integration of fundamental communication skills and understanding of ethical concepts into teaching ethics decision-making as a core competency in midwifery education has yet to be fully realized. That the midwives in this study relied upon sources outside of their didactic experiences for ethics learning, and the lack of awareness of ethics while involved in potential ethical dilemmas, indicates that midwifery programs should consider being purposeful in the inclusion of midwifery-specific ethics content in curricula.

The midwives in our study identified their experiences with clinical preceptors as critical to their ethics learning, for some more so than didactic learning. The role of the clinical preceptor must complement classroom learning and help to bridge the gap between theory and practice. Preceptors are called upon to create safe, effective learning environments for their students that allow students to hone their critical thinking skills in communication, risk awareness, informed choice, and clinical and ethical decisionmaking. ${ }^{32-34}$ Midwifery students may actively look to clinical preceptors to be role models 
of ideal midwifery behavior. ${ }^{35}$ The participants who identified their clinical preceptors as key to their ethics learning also acknowledged that their understanding and appreciation of learning ethics occurred in retrospect. They were not necessarily aware that they were observing an ethics dilemma at the time, or that their clinical preceptor was modeling ethical behavior or ethics decision making. Without explicit awareness of ethical dilemmas, the skills and behaviors demonstrated by preceptors in negotiating and resolving these dilemmas may be missed. Instead students may only receive only informal avenues of behavioral cues and cultural assimilation rather than through intentional instruction. The lack of purposeful ethics teaching may result in professional behaviors that conflict with the professional values discussed in academic programs. This informal education, or hidden curriculum, has been shown to promote systemic bias in the healthcare system and to have a negative influence on providers' empathy. ${ }^{36}$ Midwiferyethics specific post-graduate training for preceptors, as well as other avenues of support for clinical preceptors, should be considered.

\section{Limitations}

This study has several limitations. While there was initial interest in participation via email response rate, ultimately only fifteen midwives were able to participate in interviews. The sample did, however, represent a diverse group of midwives in terms of practice type, practice location, and midwifery program attended. While the results are limited in the demographic representation of midwives in the United States, they do offer insight into processes used to understand and think about the ethical dilemmas of midwifery. This study also relied upon midwives' memories of learning ethics content, which may not reflect the actual content covered during their programs, and which may not reflect any evolution in the form of ethics education since the time they were students.

\section{Conclusion}

Using interviews with midwives, this study provides insight into common ethical dilemmas experienced by midwives, how midwives define ethical dilemmas, and their sources of ethics learning. Although only US midwives were included, their experience of challenging interprofessional conflicts, difficulties in ethical sensitivity and moral distress, and reliance upon clinical preceptors as role models for ethical decision-making are reflected in the literature of published studies about ethics and midwifery or health care professionals from other countries. A deeper understanding of ethical dilemmas and ethics learning as perceived by midwives in clinical practice can contribute to the development of midwifery-specific ethics education and offers an alternative to existing approaches to obstetric ethics. ${ }^{37}$ In fact, the midwives in our study called for the purposeful inclusion of midwifery-specific ethics content in an integrated fashion throughout the curriculum and in a manner which complements other midwifery content. Reflection and self-awareness of bias were identified as key components of understanding ethical frameworks. Given that most of the midwives in this study relied upon clinical preceptors for ethics learning, midwifery educators should consider an exploration of preceptor skills, available post-graduate ethics training programs or workshops, and other ways to support preceptors. Current strategies for improving interprofessional relationships, particularly between midwives and obstetricians in the 
"I'm sure we talked about it": Midwives experiences of ethics education and ethical dilemmas, a qualitative study $\mid 67$

context of regulation-mandated oversight, may be inadequate, and new avenues, including interprofessional education, should be explored. In addition, more research is needed regarding the informal ways that midwives and midwifery students learn ethics, particularly in clinical situations and interprofessional interactions.

\section{Conflict of interest}

The authors have no conflicts of interest to declare.

\section{Funding}

No funding was received to support this study. 


\section{8}

\section{References}

1 Légaré F, Moumjid-Ferdjaoui N, Drolet R, et al. Core Competencies for Shared Decision Making Training Programs: Insights From an International, Interdisciplinary Working Group. Journal of Continuing Education in the Health Professions 2013. DOI:10.1002/chp.21197.

Carrese JA, Malek J, Watson K, et al. The essential role of medical ethics education in achieving professionalism: The romanell report. Academic Medicine 2015; 90: 744-52.

Monroe HA. Nurses' professional values: Influences of experience and ethics education. Journal of Clinical Nursing 2019; 28: 2009-19.

Kesselheim JC, Johnson J, Joffe S. Pediatricians' reports of their education in ethics. Archives of Pediatrics and Adolescent Medicine 2008; 162: 368-73.

Buxton M, Phillippi JC, Collins MR. Simulation: A New Approach to Teaching Ethics. Journal of Midwifery and Women's Health 2015; 60: 70-4.

DuVal G, Clarridge B, Gensler G, Danis M. A national survey of U.S. internists' experiences with ethical dilemmas and ethics consultation. Journal of General Internal Medicine 2004; 19: 251-8.

Oelhafen S, Monteverde S, Cignacco E. Exploring moral problems and moral competences in midwifery: A qualitative study. Nursing Ethics 2019; 26: 1373-86.

Megregian M. Ethics Education in Midwifery Education Programs in the United States. Journal of Midwifery and Women's Health 2016; 61: 586-92.

Creswell JW. Qualitative Inquiry \& Research Design. 2007 DOI:10.1111/1467-9299.00177.

Rainer J, Schneider JK, Lorenz RA. Ethical dilemmas in nursing: An integrative review. Journal of Clinical Nursing. 2018. DOI:10.1111/jocn.14542.

Bringedal B, Isaksson Rø K, Magelssen M, Førde R, Aasland OG. Between professional values, social regulations and patient preferences: Medical doctors' perceptions of ethical dilemmas. Journal of Medical Ethics 2018; 44: 239-43.

Hurst SA, Hull SC, DuVal G, Danis M. How physicians face ethical difficulties: A qualitative analysis. Journal of Medical Ethics 2005; 31: 7-14.

Dedoose Version 8.2.14. Web application for managing, analyzing, and presenting qualitative and mixed method research data. 2019.

Spencer L, Ritchie J, O'Connor W, Morrell G, Ormston R. Analysis in Practice. In: Ritchie J, Lewis J, McNaughton Nicholls C, Ormston R, eds. Qualitative Research Practice, 2nd Editio. London: Sage Publications, 2014: 295-346.

Braun V, Clarke V. Using thematic analysis in psychology. Qualitative Research in Psychology 2006. DOI:10.1191/1478088706qp063oa.

'Brien BC, Harris IB, Beckman TJ, Reed DA, Cook DA. Standards for Reporting Qualitative Research Academic Medicine 2014; 89. DOI:10.1097/ACM.0000000000000388.

Guest G, Bunce A, Johnson L. How Many Interviews Are Enough?: An Experiment with Data Saturation and Variability. Field Methods 2006. DOI:10.1177/1525822X05279903.

Weaver K. Ethical sensitivity: State of knowledge and needs for further research. Nursing Ethics 2007. DOI:10.1177/0969733007073694.

Milliken A. Nurse ethical sensitivity: An integrative review. Nursing Ethics 2018. DOI:10.1177/0969733016646155.

American College of Nurse-Midwives. Core competencies for basic midwifery practice. American College of Nurse Midwives Core Competencies 2012; : 1-8.

International Confederation of Midwives. Philosophy and Model of Midwifery Care. 2014 https://www.internationalmidwives.org/assets/files/definitions-files/2018/06/eng-philosophy-andmodel-of-midwifery-care.pdf.

Newnham E, Kirkham M. Beyond autonomy: Care ethics for midwifery and the humanization of birth. Nursing Ethics 2019; 26: 2147-57.

Sanders P dr J, de Vries P dr R, Besseling S, Nieuwenhuijze PDM. 'Such a waste' - conflicting communicative roles of Dutch midwifery students in childbirth decision making. Midwifery 2018; 64: 115-21.

Haahr A, Norlyk A, Martinsen B, Dreyer P. Nurses experiences of ethical dilemmas: A review. Nursing Ethics 2020; 27. DOI:10.1177/0969733019832941.

Fox L, Onders R, Hermansen-Kobulnicky $\mathrm{CJ}$, et al. Teaching interprofessional teamwork skills to health professional students: A scoping review. Journal of Interprofessional Care. 2018. DOI:10.1080/13561820.2017.1399868. 


\section{"I'm sure we talked about it": Midwives experiences of ethics education and ethical dilemmas, a qualitative study|69}

26 McCarthy J, Gastmans C. Moral distress: A review of the argument-based nursing ethics literature. Nursing Ethics 2015. DOI:10.1177/0969733014557139.

27 Prentice TM, Gillam L, Davis PG, Janvier A. The use and misuse of moral distress in neonatology. Seminars in Fetal and Neonatal Medicine. 2018. DOI:10.1016/j.siny.2017.09.007. Burkemper JE, DuBois JM, Lavin MA, Meyer GA, McSweeney M. Ethics Education in MSN Programs: A Study of National Trends. Nursing Education Perspectives 2007; 28: 10-7. Peirce AG, Smith JA. The Ethics Curriculum for Doctor of Nursing Practice Programs. Journal of Professional Nursing 2008; 24: 270-4. International Confederation of Midwives. Essential Competencies for Midwifery Practice. 2019. Oelhafen S, Hölzli U, Häsänen M, et al. Increasing midwives' ethical competence: a European educational and practice development project. International Journal of Ethics Education 2017; 2: 147-60. and Women's Health. 2016. DOI:10.1111/jmwh.12520.

33 Penney DS. Midwifing the Student: Creating an Effective Learning Environment. Journal of Midwifery \& Women's Health 2016; 61: 7-10. Thompson SM, Nieuwenhuijze MJ, Low LK, de Vries R. “A powerful midwifery vision”: Dutch student midwives' educational needs as advocates of physiological childbirth. Women and Birth 2019. DOI:10.1016/j.wombi.2018.12.010. on how role models contribute to becoming a midwife: A qualitative study. Women and Birth 2019. DOI:doi.org/10.1016/j.wombi.2019.08.009. learning environments in becoming and being a physician: A position paper of the American college of physicians. Annals of Internal Medicine 2018; 168: 506-8. 
70|Chapter Four 


\section{CHAPTER 5}

\section{Essential components of midwifery ethics education: results of a Delphi study}

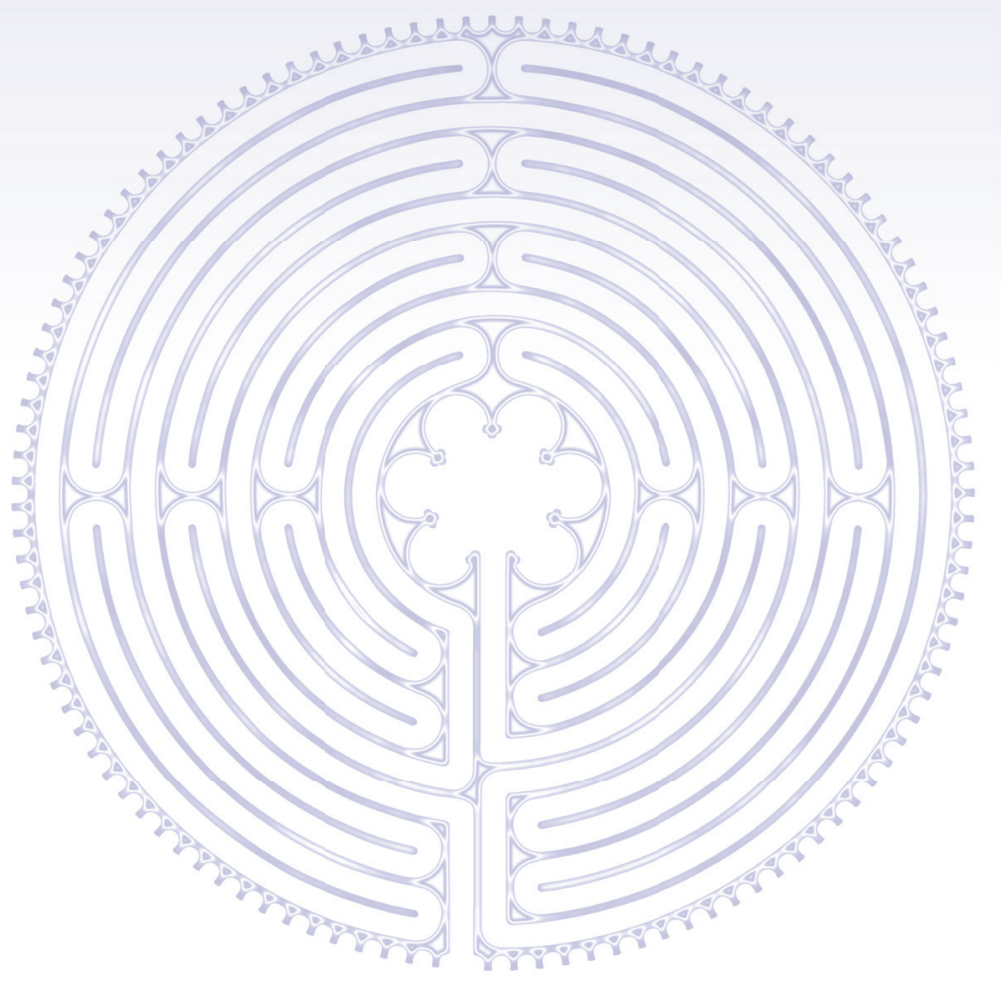

Michele Megregian, Lisa Kane Low, Cathy Emeis, Raymond de Vries, Marianne Nieuwenhuijze

Midwifery. 2021 May; 96:102946 


\title{
72 | Chapter Five
}

\begin{abstract}
Objective

Ethical dilemmas are an inevitable part of a midwife's experience in clinical care.

Midwifery educational programs have an obligation to provide students the opportunities to acquire the skills and knowledge to recognize and negotiate ethical dilemmas. Implementation of strategies for imparting ethical competencies and clinical ethics decision-making skills in formal midwifery curricula have been challenging and inconsistent. The purpose of this study was to gather information and opinions from midwifery educators and clinical preceptors about the essential components of ethics education for midwifery students in the United States (U.S.), aiming for consensus on key content, competencies, learning outcomes, and teaching strategies.
\end{abstract}

\section{Design}

This is an online Delphi study conducted in three rounds. Round 1 consisted of openended questions to explore and identify key content, competencies, learning outcomes, and teaching strategies for midwifery ethics education. In Rounds 2 and 3, experts rated statements on a 1 to 7 Likert scale, with positive consensus defined as $70 \%$ or more of the experts scoring $\geq 6$.

\section{Participants}

The panel included midwifery educators (midwifery program directors, faculty, and clinical preceptors) from the United States.

\section{Findings}

Of the 12 statements on key content of ethics education, midwives emphasized that content promoting an understanding of shared decision-making is essential for inclusion. Of the statements regarding competencies, learning outcomes, and teaching strategies, 20 of 21 statements met consensus, including those related to shared decision-making and ethical decision-making, as well as attributes such as compassion and courage. Midwives did not agree that an essential teaching strategy includes a validated assessment tool for evaluating students on any component of ethics learning (knowledge, skills, behaviour).

\section{Key Conclusions}

This Delphi study reveals what midwifery educators consider essential components of ethics education for midwifery students, with a particular focus on the professional attributes of shared decision-making.

\section{Implications for Practice}

Initial insights about optimal ways to incorporate the essential ethics education components into midwifery program curricula are provided, and more research is needed. 
Essential components of midwifery ethics education: results of a Delphi study $\mid 73$

\section{Keywords}

Midwifery Education, Ethics, Competency Education, Shared Decision-Making,

Professional Competence, Midwifery

\section{Highlights}

- Midwives did not endorse the use of an assessment tool for evaluating students

- Simulation and role-modelling ethics were viewed as important teaching strategies

- Key competency categories included critical thinking and shared decision-making

- Essential ethics content included shared decision-making and reproductive justice

- Compassion, respect, and awareness of bias were seen as key learning outcomes 


\section{4 |Chapter Five}

\section{Introduction}

A clinical encounter between midwives and women in their care carries the potential challenges related to ethics, or ethical dilemmas. Ethical dilemmas are "situations in which a midwife must make a decision and follow through with that decision by taking specific action, but the right action to take may be unclear". ${ }^{1}$ Ethical dilemmas are an inevitable part of maternity care, as midwives consistently face professional situations which challenge their personal and professional values and which strain interprofessional relationships. These ethical dilemmas may be unpredictable and fraught with uncertainty. They may range from specific situations where a woman refuses recommended care, e.g. screening for gestational diabetes, to general issues, e.g. the effect of implicit bias on health care disparities. As such, midwifery educational programs have an obligation to their students to foster ethical competency and acquisition of clinical ethics decisionmaking skills. ${ }^{2}$

The concept of ethical competence has been defined as the possession of ethical awareness, moral judgement skills, character strength, and willingness to do good. ${ }^{3}$ Clinical ethics decision-making requires recognizing and analysing an ethical dilemma when it occurs, reaching an appropriate conclusion, and taking appropriate action. ${ }^{4}$ While these components are intertwined, they may ask students to draw upon different skills, and one role of midwifery education is to provide the opportunities for students to be exposed to and acquire these skills. To achieve competency and effectively resolve ethical dilemmas, midwifery students need to develop critical thinking skills, reflective thinking skills, empathy, self-awareness, ethical awareness, communication skills and the ability to work well in high-functioning interprofessional teams. ${ }^{5,6}$ These competencies are broadly outlined in the International Confederation of Midwives (ICM) Global Standards for Midwifery Education and Essential Competencies for Midwifery Practice and in the American College of Nurse-Midwives (ACNM) Core Competencies for Basic Midwifery Practice. $^{7,8}$

Strategies for student acquisition of ethical competencies have been implemented in formal nursing and midwifery ethics education curricula, although implementation has been challenged by difficulty in identifying expected outcomes and inconsistency in how these outcomes are evaluated. ${ }^{6,9,10}$ While surveys of graduate nursing and midwifery programs found an overall commitment to the inclusion of ethics content, they also showed wide variation in the teaching methodology and specific ethics topics covered, indicating a lack of standardization. ${ }^{9,11,12}$ A 2015 Delphi study of ethics content for graduate nursing programs in the United States (U.S.) found that only the understanding of ethics terminology and a familiarity with the American Nursing Association's Code of Ethics reached consensus as essential concepts for foundational knowledge of ethics. ${ }^{12}$ These and other studies confirm the need for additional research into ethics curricular content, teaching methods, and strategies for evaluation. These studies also show that ideally ethics education should be based on evidence-based concepts, integrated into the overall curriculum, and designed as an iterative process that becomes increasingly complex as students gain clinical experience. ${ }^{10-14}$ 
Midwifery educational programs in the U.S. use a competency-based framework to guide curricular development, as per the Accreditation Commission for Midwifery Education (ACME). ${ }^{2}$ These standards represent essential professional knowledge, skills, and abilities to practice midwifery at an entry level. ${ }^{2}$ The content of the ACNM Core Competencies was developed to be congruent with other national and international midwifery standard-setting documents, including the International Confederation of Midwives (ICM) Essential Competencies for Midwifery Practice. While these competencies represent required components and outcomes of ethics education for midwives, the specific content, teaching methods, or evaluation methods are not proscribed, leading to a lack of standardization. ${ }^{9}$ It is unclear how midwifery programs accomplish the task of educating students to meet these competency requirements, if there is content that is emphasized or de-emphasized, or what specific learning exercises or teaching strategies are used that lead to knowledge and skill acquisition. As this aspect of ethics education in U.S. midwifery programs has not yet been examined, we sought to gather information and opinions from midwifery educators and clinical preceptors of student midwives about the essential components of ethics education for midwifery students. The aim of this Delphi study was to gain consensus regarding key content, competencies, learning outcomes, and teaching strategies for midwifery ethics education.

\section{Methods}

The purpose of this study was to develop expert consensus on essential content, expected competencies, key learning outcomes, and best teaching strategies for inclusion in an ethics curriculum for midwifery students. We conducted a Delphi study from September 2019 through February 2020. The Delphi technique is a method of consensus building and is particularly useful in situations where evidence may be scant, uncertain, or contradictory. ${ }^{15}$ Expert consensus can build upon professional knowledge by capturing and organizing information that that may otherwise be difficult to access or articulate. ${ }^{15,16}$ A Delphi study typically consists of a number of survey rounds. First, a limited number of expert participants are asked general question in order to generate ideas from which statements are created. In subsequent rounds participants are asked to agree or disagree with these statements until consensus is reached. ${ }^{17}$

In order to be consistent with the ACNM Core Competencies we chose a competency-based framework to develop the format of the initial questionnaire. A competency-based curricular design focuses on student demonstration and performance of acquired competencies. ${ }^{18}$ Program outcomes are clearly defined and learning activities and exercises are aligned to achieve these outcomes. ${ }^{18}$ For the purposes of the questionnaire, we defined competencies as broad curricular outcomes which form the frameworks for the knowledge, attitudes, and skills that students acquire and demonstrate during their education. Curricula learning outcomes were described as specific and definitive achievements that students complete by the end of the program and which are linked to specific learning activities that promote students' acquisition of required knowledge, attitudes, and skills. 


\section{6|Chapter Five}

\section{Expert Participants}

Program directors from the 37 accredited U.S. nurse-midwifery programs were recruited via direct email invitation and announcements at educators' meetings. Program directors were also invited to forward the email invitation to any faculty members involved in ethics and related education. Invitations were posted on the clinical educator, clinical preceptor, and academic educator list-servs that are available to members of ACNM. Experts in midwifery ethics education, curriculum development, and midwifery clinical education were also identified through key articles in the midwifery literature. Permission from ACNM to solicit members for participation in research was received. Research approval was also granted by the Institutional Review Board at Oregon Health and Science University, Portland, Oregon.

\section{Design and Data Collection}

This Delphi study consisted of three iterative online survey rounds. Participants were informed that all responses would be confidential. Completion of the survey indicated informed consent to participate.

\section{Round 1}

The first round consisted of an online survey of exploratory open-ended questions where midwives described ethics content, student competencies and skills, learning outcomes, and teaching strategies that should be included in an ethics curriculum for midwifery students. Content analysis of the midwives' answers was performed in an iterative process. ${ }^{19}$ From the content analysis, statements were created describing the broad themes of content topics, competencies, learning outcomes, and teaching methods. These broad themes provided a framework for the statements to be included in Round 2 . These categories included effective communication, shared decisions, respect, critical thinking, bias, knowledge, application to the midwifery role, compassion, and research.

\section{Round 2}

The goal of Round 2 was to reach consensus regarding statements generated from Round 1 on key components of ethics education for midwifery students. For the 12 statements regarding ethics content, midwives were asked to rank their top five choices of topics that were essential to be included in an ethics curriculum. The Round 2 questionnaire also consisted of 21 statements on student competencies, learning outcomes, and teaching methods that should be included in an ethics curriculum. Participants were asked to rate the 21 statements (on a 1 (completely disagree) to 7 (completely agree) Likert scale) on the importance of its inclusion into an ethics curriculum. A priori ${ }^{17}$, positive consensus was considered reached if $70 \%$ or more of participants scored that statement at $\geq 6$, less than $5 \%$ of participants scored the statement $\leq 3$, and the mean score was $\geq 6$. We chose the high mean score $(\geq 6)$ in order to assure consensus based on the explicit agreement of the participants. Negative consensus was reached if $70 \%$ or more of participants scored the statement as $\leq 2$, less than $5 \%$ of participants scored the statement at $\geq 5$, and the mean score was $\leq 2$. Participants were also invited to comment or elaborate on any of the statements or to suggest components that were missing. 


\section{Round 3}

The statements from Round 2 that did not reach clear consensus were included in Round 3. These statements were modified and redeveloped for clarity, using the written comments of the participants from Round 2. Participants were asked to rate the statements using the same Likert scale as used in Round 2, and we used the same parameters for positive and negative consensus. Participants were invited to comment or elaborate on any of the statements.

\section{Findings}

\section{Participant Demographics}

Twenty midwives agreed to participate in Round 1. Of the 37 midwifery programs in the U.S., five program directors participated in Round 1, with an additional six participants identifying as midwifery program faculty. Two midwives identified their primary role as researchers, and the remaining participants identified their primarily midwifery role as clinical preceptor. A total of 41 midwives participated in Round 2, with 12 midwifery program directors, 5 midwifery faculty, 16 preceptor midwives, and the remaining identifying their primarily role as researcher or as retired educator. Only the midwives who participated in Round 2 were asked to participate in Round 3, with a total of 14 midwives participating in that round. (Table 1 )

\begin{tabular}{|c|c|c|c|}
\hline Table 1 Participant Demographics & $\begin{array}{l}\text { Round } 1 \\
\mathrm{~N}=\mathbf{2 0}\end{array}$ & $\begin{array}{l}\text { Round } 2 \\
\mathrm{~N}=41\end{array}$ & $\begin{array}{l}\text { Round } 3 \\
\mathrm{~N}=14\end{array}$ \\
\hline \multicolumn{4}{|l|}{ Age } \\
\hline $18-24$ & $0(0 \%)$ & $1(2.4 \%)$ & $0(0 \%)$ \\
\hline $25-34$ & $1(5 \%)$ & $0(0 \%)$ & $0(0 \%)$ \\
\hline $35-44$ & $5(25 \%)$ & $12(29.3 \%)$ & $3(21.4 \%)$ \\
\hline $45-54$ & $7(35 \%)$ & $11(26.8 \%)$ & $3(21.4 \%)$ \\
\hline $55-64$ & $2(10 \%)$ & $11(26.8 \%)$ & $5(35.7 \%)$ \\
\hline $65+$ & $5(25 \%)$ & $6(14.6 \%)$ & $3(21.4 \%)$ \\
\hline \multicolumn{4}{|l|}{ Gender Identity } \\
\hline Female & $18(90 \%)$ & 39 (95\%) & $13(93 \%)$ \\
\hline Male & $1(5 \%)$ & $1(2.5 \%)$ & $1(7 \%)$ \\
\hline Transfemale & $0(0 \%)$ & $0(0 \%)$ & $0(0 \%)$ \\
\hline Transmale & $0(0 \%)$ & $0(0 \%)$ & $0(0 \%)$ \\
\hline Gender non-conforming & $0(0 \%)$ & $0(0 \%)$ & $0(0 \%)$ \\
\hline Another category & $0(0 \%)$ & $0(0 \%)$ & $0(0 \%)$ \\
\hline Prefer not to answer & $1(5 \%)$ & $1(2.5 \%)$ & $0(0 \%)$ \\
\hline \multicolumn{4}{|l|}{ Race / Ethnicity } \\
\hline American Indian / Alaska Native & $0(0 \%)$ & $1(2.5 \%)$ & $0(0 \%)$ \\
\hline Asian & $0(0 \%)$ & $0(0 \%)$ & $0(0 \%)$ \\
\hline Black / African American & $0(0 \%)$ & $0(0 \%)$ & $0(0 \%)$ \\
\hline Hispanic / Latinx & $0(0 \%)$ & $1(2.5 \%)$ & $0(0 \%)$ \\
\hline Middle Eastern / North African & $0(0 \%)$ & $0(0 \%)$ & $0(0 \%)$ \\
\hline Native Hawaiian / Pacifica Islander & $0(0 \%)$ & $0(0 \%)$ & $0(0 \%)$ \\
\hline White & $19(95 \%)$ & $34(82.9 \%)$ & $14(100 \%)$ \\
\hline Another category & $1(5 \%)$ & $2(4.9 \%)$ & $0(0 \%)$ \\
\hline Prefer not to answer & $0(0 \%)$ & $3(7.3 \%)$ & $0(0 \%)$ \\
\hline
\end{tabular}


78|Chapter Five

\begin{tabular}{|c|c|c|c|}
\hline \multicolumn{4}{|l|}{ Years as a Midwife } \\
\hline $1-9$ years & $4(20 \%)$ & $8(19.5 \%)$ & $2(14.2 \%)$ \\
\hline $10-19$ years & $5(25 \%)$ & $10(24.3 \%)$ & $2(14.2 \%)$ \\
\hline 20-29 years & $5(25 \%)$ & $13(31.7 \%)$ & $5(35.7 \%)$ \\
\hline $30-39$ years & $5(25 \%)$ & $8(19.5 \%)$ & $4(28.5 \%)$ \\
\hline $40+$ years & $1(5 \%)$ & $2(4.9 \%)$ & $1(7 \%)$ \\
\hline \multicolumn{4}{|l|}{ Primary Midwifery Role } \\
\hline Midwifery Program Director & $5(25 \%)$ & $12(29.3 \%)$ & $6(42.8 \%)$ \\
\hline Didactic faculty midwifery program & $3(15 \%)$ & $5(12.2 \%)$ & $1(7 \%)$ \\
\hline Research & $2(10 \%)$ & $2(4.9 \%)$ & $0(0 \%)$ \\
\hline Clinical Practice / Patient Care & $6(30 \%)$ & $16(39.0 \%)$ & $5(35.7 \%)$ \\
\hline Other & $4(20 \%)$ & $6(14.6 \%)$ & $2(14.2 \%)$ \\
\hline \multicolumn{4}{|l|}{ Years as a Clinical Preceptor } \\
\hline $1-9$ years & $5(25 \%)$ & $13(31.7 \%)$ & $3(21.4 \%)$ \\
\hline $10-19$ years & $8(40 \%)$ & $12(29.3 \%)$ & $2(14.2 \%)$ \\
\hline $20-29$ years & $3(15 \%)$ & $13(31.7 \%)$ & $7(50 \%)$ \\
\hline $30-39$ & $3(15 \%)$ & $3(7.3 \%)$ & $2(14.2 \%)$ \\
\hline $40+$ years & $1(5 \%)$ & $0(0 \%)$ & $0(0 \%)$ \\
\hline \multicolumn{4}{|c|}{ Percent of time working with students in Clinical Practice } \\
\hline $0-25 \%$ of the time & $11(55 \%)$ & $16(39 \%)$ & $6(42.8 \%)$ \\
\hline $26-50 \%$ of the time & $3(15 \%)$ & $6(14.6 \%)$ & $1(7 \%)$ \\
\hline $51-75 \%$ of the time & $3(15 \%)$ & $10(24.4 \%)$ & $4(28.5 \%)$ \\
\hline $76-100 \%$ of the time & $3(15 \%)$ & $9(22 \%)$ & $3(21.4 \%)$ \\
\hline \multicolumn{4}{|c|}{ Participate in Didactic Teaching of Ethics } \\
\hline Yes & $7(35 \%)$ & $18(43.9 \%)$ & $7(50 \%)$ \\
\hline No & $13(65 \%)$ & $23(56.1 \%)$ & $7(50 \%)$ \\
\hline
\end{tabular}

\section{Round 1 Results}

\section{Essential content}

In Round 1, essential content that was identified by the midwives included shared decision-making, communication skills, knowledge of ethics principles and philosophies, acknowledgement of bias, and the usefulness of reflective activities. Midwives also stated that midwifery professional values should be included, and specifically identified respectful maternity care and the Hallmarks of Midwifery, which are part of the ACNM Core Competencies and describe the fundamental tenets of ACNM's midwifery philosophy, e.g. "advocacy of non-intervention in physiologic processes in the absence of complications". ${ }^{8}$ Midwives highlighted the importance of using a reproductive justice framework when discussing respectful care, diversity and inclusion, values clarification, and awareness of bias. Specific ethical dilemmas or topics related to genetics, maternalfoetal conflict, surrogacy, and research integrity were also offered by the midwives.

\section{Competencies}

Midwives identified that students should be able to demonstrate competency in engaging in shared decision-making and informed consent processes, have good communication skills, possess a working knowledge of ethics principles, have an awareness of bias, and be able to reflect on their biases. The midwives also identified key personal attributes 
that they considered to be demonstrable competencies, including honesty, empathy, and kindness, as well as interpersonal skills that facilitate interprofessional relationships. The midwives stated that students should be able to demonstrate an application of ethical principles to decision-making in a manner that shows critical thinking analysis and skills. Some midwives emphasized the acquisition of skills related to confronting bias and disrespectful care and possessing and acting from an awareness of historical and current healthcare disparities. Midwives stated that students should be aware not only of their own biases, but also how those biases might affect their clinical and ethics decisions, as well as be able to provide care despite those biases. A few midwives commented on the difficulty in distinguishing between competencies and skills, which informed how we composed the statements for the Round 2.

\section{Learning outcomes}

Key learning outcomes of ethics education that were identified by the midwives reflected the above themes of shared decisions, awareness of bias, knowledge of ethics principles and their application to midwifery care and good communication and teamwork skills. They emphasized that students should have the confidence and skill to confront bias in others and in themselves. They also stated that students should emerge with a lifetime commitment to ethical conduct and a sustained interest in ethics and health policy.

\section{Teaching strategies}

Midwives stated that ethics should be taught through readings of ethics literature, exercises of personal reflection, participation in simulation and role-playing activities, and discussion of clinical cases (both paradigmatic and student-identified) via lectures and group discussions. One midwife stated that having a diverse cohort of midwifery students would be an important contribution to the ways in which ethics is learned. Other informal methods of learning ethics as suggested by the midwives were characterized by both active and passive methods. Passive methods included observation of clinical preceptors during ethical dilemmas and in their personal interactions and interprofessional discussions, along with being exposed to a variety of clinical sites. Active methods of informal learning that were suggested were participation in committees and professional organizational meetings, being in a mentoring relationship, interacting with a diversity of patients, and intentionally listening to interprofessional discussions. Midwives also stated that faculty modelling and mentorship are informal methods of ethics teaching.

\section{Round 2 Results}

Based on the responses in Round 1, we identified 12 statements (Table 2) describing essential content and 21 statements (Table 3 ) describing student competencies, learning outcomes, and teaching methods. In Round 2, midwives identified two statements as clearly essential to include as content in an ethics curriculum: 1) understanding shared decision-making and 2) adopting a framework of reproductive and social justice. Approximately one quarter of the participants prioritized the inclusion of the statement on building a knowledge base of key ethics concepts. Content related to research ethics, health policy, allocation of healthcare resources, and the differentiation between ethics and law received less interest. Some of the midwives commented that much of the 
content listed could, or should, be included elsewhere in the midwifery program, for example in a class on professional issues or research.

Table 2: Essential Components (topics, material, subject matter) of Ethics Education (ranked by the \% of inclusion)

1. Understanding of shared decision-making, particularly as it relates to supporting a woman's autonomy and ability to making informed decisions

2. Study of diversity, inclusion, health disparities, and racism, as viewed through the frameworks of social and reproductive justice

3. Fostering of self-awareness through reflection, which includes, for example, values clarification, awareness of cultural differences, and acknowledgement of bias

4. Building a knowledge base of key ethics concepts, including the principles of biomedical ethics (such as autonomy, beneficence, nonmaleficence, and justice), the principles of duty and obligation, ethics frameworks and philosophies

5. Study of reproductive coercion and mistreatment of women, as viewed through a framework of respectful maternity care

6. An understanding of the definition and components of ethical practice, and the way ethics principles impact the midwife's relationship with others, including women in their care

7. Skills-building in teamwork and interprofessional relationships, including collaborative and consulting relationships with other maternity care providers

8. Understanding of and appreciation for the complexities inherent in maternity care, particularly as the interests of woman and fetus may converge or diverge

9. Understanding the differentiation between ethics and law, and ethics and sociocultural norms or standard of care

10. An understanding of how ethics principles are applied to healthcare frameworks differently, such as health policy, biomedical frameworks, nursing frameworks, and midwifery frameworks

11. An understanding of ethics principles in research

12. Understanding of health care resource allocation, financial influences in health care, and health care costs

Six statements regarding competencies represented the themes of respect, shared decisions, bias, effective communication, critical thinking, and research. All six statements reached consensus, with a level of agreement between $88 \%$ and $100 \%$ and with mean scores ranging from 6.20-6.93. The statement about shared decisions, students promote effective decision-making, through an understanding of the elements of informed consent and refusal and skill in the shared decision-making process, achieved the highest mean score of 6.93, indicating it is considered a high-priority competency that must be included in ethics education. The statement regarding research ethics achieved the lowest mean score of 6.20. Several midwives commented that ethics should be incorporated into all components of midwifery education. One midwife expressed her scepticism that competency in effective communication and respect could be achieved through didactic means and indicated that these topics should not be isolated in an ethics curriculum.

Statements regarding key learning outcomes were comprised of 10 statements which described outcomes related to the themes of effective communication, shared decisions, respect, critical thinking, bias, knowledge, application to midwifery, midwifery role, compassion, and research. All 10 statements reached consensus, with a level of agreement between $95 \%$ and $100 \%$, and with a mean score ranging between 6.43 and 6.85 . While learning outcomes related to shared decision-making and respectful care tied 
for second in rank (mean score of $6.83,95 \%$ and $100 \%$ agreement, respectively), the statement regarding compassion ranked highest, with a mean score of 6.85 and $100 \%$ agreement. The statement, students possess the confidence and skill to recognize and acknowledge their own biases, and through reflection are aware of the potential impact of their bias on their ethical practice and clinical decision-making, providing ethical care even in situations of moral conflict or disagreement, was the only statement that received "somewhat disagree" and "strongly disagree" responses $(\mathrm{N}=2)$, although it still met consensus with a mean score of 6.50 and agreement of $95 \%$. Two midwives commented on the midwife's right to refuse care, based not only on a moral objection or due to moral distress, but also because the requested care may not be evidence-based. Because this statement received negative responses, we decided to amend the statement and include it in Round 3.

Statements regarding strategies for teaching ethics included five statements on the use of simulation/role-play, paradigmatic case studies, midwifery-specific case studies, faculty/preceptor modelling, and the use of a validated method of evaluation (such as Observed Structured Clinical Exam (OSCE)). Three statements met consensus, with the statement, modelling of ethical behaviour and respectful care by midwifery faculty and clinical preceptors, which should be intentionally highlighted, discussed, and debriefed, ranked the highest with a mean score of 6.80. The statement, focus on the application of ethical frameworks to cases and issues that particularly apply to or affect midwifery care or the midwifery profession (75.0\% agreement mean score 5.95), met consensus, although it had a lower mean score than other statements, with $20 \%$ marking "somewhat agree" and 5\% marking "somewhat disagree". Given the lower mean score, we decided to amend the statement and include it in Round 3. The statement, validated methods of evaluation of student competencies, such as OSCEs (57.5\% agreement, mean score 5.58) did not meet consensus. This statement was also included in Round 3, as we were interested to see if the specific mention of an OSCE was the reason why consensus was not reached. Comments from the participants did not directly speak to any disagreement with the statement about evaluation or midwifery-focused cases, though they did express the importance of students accessing their own experiences in bringing forth examples of ethical dilemmas. 


\section{2|Chapter Five}

\begin{tabular}{|c|}
\hline Category: Competencies \\
\hline $\begin{array}{l}\text { SHARED DECISIONS: Students promote } \\
\text { effective decision making, through an } \\
\text { understanding of the elements of informed } \\
\text { consent and refusal and skill in the shared } \\
\text { decision making process }\end{array}$ \\
\hline $\begin{array}{l}\text { CRITICAL THINKING: Students apply critical } \\
\text { thinking skills, based on a thorough knowledge } \\
\text { base of ethics theories, principles, and } \\
\text { frameworks, to ethical dilemmas and ethics } \\
\text { decision making }\end{array}$ \\
\hline $\begin{array}{l}\text { RESPECT: In their interactions with women and } \\
\text { their families, students will promote and } \\
\text { provide respectful care through the } \\
\text { demonstration of ethical conduct and cultural } \\
\text { literacy }\end{array}$ \\
\hline $\begin{array}{l}\text { BIAS: Students recognize, acknowledge, and } \\
\text { communicate their personal biases }\end{array}$ \\
\hline $\begin{array}{l}\text { EFFECTIVE COMMUNICATION: Students } \\
\text { demonstrate effective communication skills in } \\
\text { their interactions with peers, colleagues, and } \\
\text { women and their families }\end{array}$ \\
\hline $\begin{array}{l}\text { RESEARCH: Students understand and apply } \\
\text { established research ethics principles in their } \\
\text { midwifery role }\end{array}$ \\
\hline
\end{tabular}

\section{Category: Learning Outcomes}

COMPASSION: Students demonstrate behaviors consistent with compassionate care, including courage, empathy, honesty, kindness, and astute listening RESPECT: Through their interactions with women and their families, student behaviors reflect respectful care, including cultural literacy, awareness of discriminatory practices, and respect for reproductive choice

APPLICATION TO MIDWIFERY: Students demonstrate an understanding of such ethical issues as health disparities, surrogacy, unintended pregnancy, genetic screening, and maternal-fetal conflicts, particularly as they relate to the context of midwifery care MIDWIFERY ROLE: Students apply knowledge of ethics principles and frameworks to the midwifery role in clinical practice and health

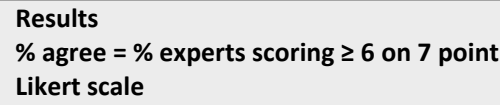

\begin{tabular}{l|l} 
Mean & 6.58
\end{tabular}

\begin{tabular}{l|l}
$\%$ agree & 87.5 \\
\hline
\end{tabular}

\begin{tabular}{l|r}
$\%$ disagree & 2.5 \\
\hline
\end{tabular}

Mean $\quad 6.20$

\section{Results}

$\%$ agree $=\%$ experts scoring $\geq 6$ on 7 point Likert scale

$\%$ disagree $=\%$ experts scoring $\leq 3$ on 7 point Likert scale

\begin{tabular}{l|r} 
\% agree & 100.0
\end{tabular}

\begin{tabular}{l|c}
\hline$\%$ disagree & 0.0
\end{tabular}

Mean $\quad 6.85$

\begin{tabular}{|l|l|}
\hline$\%$ agree & 100.0
\end{tabular}

\begin{tabular}{l|l} 
\% disagree & 0.0
\end{tabular}

\begin{tabular}{|l|r|}
\hline Mean & 6.83
\end{tabular}

\begin{tabular}{l|l}
\hline$\%$ agree & 100.0
\end{tabular}

\begin{tabular}{l|l}
\hline \% disagree & 0.0
\end{tabular}

\begin{tabular}{l|l} 
Mean & 6.75
\end{tabular}

\begin{tabular}{l|r}
\hline \% agree & 100.0
\end{tabular}

\begin{tabular}{l|l} 
\% disagree & 0.0
\end{tabular} 
policy, as demonstrated by promoting

Mean

6.70

autonomy, ensuring confidentiality, and

recognizing and resolving ethical dilemmas

CRITICAL THINKING: Students have the skills to

think critically about ethical dilemmas,

applying appropriate ethical principles, legal

concepts, and strategies for resolving ethical

dilemmas to the ethics decision making

$\%$ agree

$\%$ disagree

0.0

process, particularly in the context of

midwifery care

KNOWLEDGE: Students possess a

comprehensive knowledge base of ethics,

including familiarity with the ACNM Code of

Ethics, definitions of ethics terms, principles of ethics, and the importance of ethics to the midwifery profession

SHARED DECISIONS: Students will use a shared decision making framework as the primary strategy in risk communication and in counseling women and their families through the decision making process, balancing clinical expectations with the interests of women and their families

EFFECTIVE COMMUNICATION: Through their

interactions with colleagues, in routine

situations and during conflicts or

disagreements with others, students

demonstrate ethical conduct, including the use

of non-discriminatory language, and work with

others as a team to resolve ethical dilemmas

BIAS: Students possess the confidence and skill to recognize and acknowledge their own biases, and through reflection are aware of the potential impact of their bias on their ethical practice and clinical decision making, providing ethical care even in situations of moral conflict or disagreement

RESEARCH: Students demonstrate an

Mean

\begin{tabular}{|l|r|}
\hline \% agree & 97.5 \\
\hline \% disagree & 0.0 \\
\hline Mean & 6.73 \\
\hline
\end{tabular}

\begin{tabular}{|l|r|}
\hline$\%$ agree & 95.0 \\
\hline \% disagree & 0.0 \\
\hline Mean & 6.83 \\
\hline \% agree & 95.0 \\
\hline
\end{tabular}

\begin{tabular}{l|l}
\hline disagree & 0.0
\end{tabular}

\begin{tabular}{l|l} 
Mean & 6.73
\end{tabular}

\begin{tabular}{l|r}
\hline \% agree & 95.0
\end{tabular}

\begin{tabular}{l|r}
\hline \% disagree & 5.0
\end{tabular}

\begin{tabular}{l|l} 
Mean & 6.50
\end{tabular}

understanding of established ethics principles in human subject research, including the role of the Institutional Review Board, the informed consent process, appropriate collection and management of date, and the protection of vulnerable populations, as well as an understanding of public accountability in reporting and publication of results

\section{Category: Teaching Strategies}

\begin{tabular}{l|r}
\hline \% agree & 95.0
\end{tabular}

\begin{tabular}{l|l}
\hline \% disagree & 0.0
\end{tabular}

Mean

Modeling of ethical behavior and respectful care by midwifery faculty and clinical preceptors, which should be intentionally highlighted, discussed, and debriefed Simulation and role play exercises, during which students have the opportunity to

\begin{tabular}{|c|c|}
\hline \multicolumn{2}{|c|}{$\begin{array}{l}\text { Results } \\
\% \text { agree }=\% \text { experts scoring } \geq 6 \text { on } 7 \text { point } \\
\text { Likert scale } \\
\% \text { disagree }=\% \text { experts scoring } \leq 3 \text { on } 7 \text { point } \\
\text { Likert scale }\end{array}$} \\
\hline$\%$ agree & 100.0 \\
\hline$\%$ disagree & 0.0 \\
\hline Mean & 6.80 \\
\hline$\%$ agree & 92.5 \\
\hline$\%$ disagree & 0.0 \\
\hline
\end{tabular}




\begin{tabular}{|c|c|c|}
\hline $\begin{array}{l}\text { participate in real-time, structured ethical } \\
\text { scenarios }\end{array}$ & Mean & 6.48 \\
\hline \multirow{3}{*}{$\begin{array}{l}\text { Opportunities to study and analyze } \\
\text { paradigmatic, real-world cases with faculty } \\
\text { and students through group presentations, } \\
\text { debates, thought experiments, and written } \\
\text { reflections, with the goal of understanding the } \\
\text { ethical principles at stake and the decision } \\
\text { making processes of the providers involved }\end{array}$} & $\%$ agree & 87.5 \\
\hline & $\%$ disagree & 0.0 \\
\hline & Mean & 6.25 \\
\hline \multirow{3}{*}{$\begin{array}{l}\text { Focus on the application of ethical frameworks } \\
\text { to cases and issues that particularly apply to or } \\
\text { affect midwifery care or the midwifery } \\
\text { profession }\end{array}$} & $\%$ agree & 75.0 \\
\hline & $\%$ disagree & 5.0 \\
\hline & Mean & 5.95 \\
\hline \multirow{3}{*}{$\begin{array}{l}\text { Validated methods of evaluation of student } \\
\text { competencies, such as Observed Structured } \\
\text { Clinical Exams (OSCEs) }\end{array}$} & $\%$ agree & 57.5 \\
\hline & $\%$ disagree & 20.0 \\
\hline & Mean & 5.58 \\
\hline
\end{tabular}

\section{Round 3 Results}

Round 3 consisted of four statements. In the learning outcomes category, the statement about bias was amended and divided into two distinct statements. The first statement reflects the provision of ethical care, even in situations of moral conflict. The second statement also reflects the provision of ethical care in situations of ethical conflict, but also includes the phrase students possess the confidence and skill to reflect on their own moral distress and the moral distress of others. The two statements from Round 2 regarding teaching strategies were amended. First, we deleted the reference to OSCE in the statement about the use of a validated evaluation method. Second, we altered the statement regarding strategies that focus on ethical frameworks as applied to midwiferyspecific cases and changed the focus to include a narrower statement about using a midwifery-focused framework such as the ACNM Code of Ethics.

In Round 3, both of the amended statements regarding bias as a learning outcome reached consensus. The statement, students possess the skill to provide ethical care, even in situations of moral conflict or disagreement had a mean score of 6.40 and $86 \%$ agreement with no disagreement. The second statement, students possess the confidence and skill to reflect on their own moral distress and the moral distress of others, to decide on providing ethical care, even in situations of ethical conflict or disagreement, with a mean score of 6.27 and $86 \%$ agreement, but with $13.33 \%(\mathrm{~N}=2)$ of midwives choosing the option somewhat disagree. (Table 4)

The amended statement regarding the use of ethical frameworks was revised to state, use of a midwifery-focused ethics framework, such as the American College of Nurse-Midwives Code of Ethics, with an emphasis on cases and issues that affect midwifery care or the midwifery profession reached consensus with a mean score of 6.13 and $80 \%$ agreement (no disagreements and one neutral vote). The amended statement regarding the use of a validated method of evaluation did not meet consensus in Round 3 with 59\% agreement, and in fact had a lower mean score compared to Round 2 (5.26 compared to 5.58). 


\begin{tabular}{|c|c|c|}
\hline Category: Learning Outcomes & \multicolumn{2}{|c|}{$\begin{array}{l}\text { Results } \\
\% \text { agree }=\% \text { experts scoring } \geq 6 \text { on } 7 \text { point } \\
\text { Likert scale } \\
\% \text { disagree }=\% \text { experts scoring } \leq 3 \text { on } 7 \text { point } \\
\text { Likert scale }\end{array}$} \\
\hline \multirow{3}{*}{$\begin{array}{l}\text { Students possess the confidence and skill to } \\
\text { reflect on their own moral distress and the } \\
\text { moral distress of others, to decide on } \\
\text { providing ethical care, even in situations of } \\
\text { ethical conflict or disagreement }\end{array}$} & $\%$ agree & 86.6 \\
\hline & $\%$ disagree & 13.3 \\
\hline & Mean & 6.27 \\
\hline \multirow{3}{*}{$\begin{array}{l}\text { Students possess the skill to provide ethical } \\
\text { care, even in situations of moral conflict or } \\
\text { disagreement. }\end{array}$} & $\%$ agree & 86.3 \\
\hline & $\%$ disagree & 0.0 \\
\hline & Mean & 6.40 \\
\hline Category: Teaching Strategies & \multicolumn{2}{|c|}{$\begin{array}{l}\text { Results } \\
\% \text { agree }=\% \text { experts scoring } \geq 6 \text { on } 7 \text { point } \\
\text { Likert scale } \\
\% \text { disagree }=\% \text { experts scoring } \leq 3 \text { on } 7 \text { point } \\
\text { Likert scale }\end{array}$} \\
\hline \multirow{3}{*}{$\begin{array}{l}\text { Use of a midwifery-focused ethics framework, } \\
\text { such as the American College of Nurse- } \\
\text { Midwives Code of Ethics, with an emphasis on } \\
\text { cases and issues that affect midwifery care or } \\
\text { the midwifery profession }\end{array}$} & $\%$ agree & 80.0 \\
\hline & $\%$ disagree & 0.0 \\
\hline & Mean & 6.10 \\
\hline \multirow{3}{*}{$\begin{array}{l}\text { The use of a validated method of evaluation } \\
\text { of student performance. }\end{array}$} & $\%$ agree & 60.0 \\
\hline & $\%$ disagree & 13.2 \\
\hline & Mean & 5.26 \\
\hline
\end{tabular}

\section{Discussion}

We conducted a three-round Delphi study to identify what midwifery educators currently consider to be key content, competencies, learning outcomes and teaching strategies for ethics education for midwifery students. The essential components identified in this Delphi reflect and further elucidate the broad ethics competencies outlined by ICM and ACNM, particularly in the commitment to the promotion of respectful, person-centred care. ${ }^{7,8}$ For example, the understanding and active promotion of the process of shared decision-making was seen as critically important. Midwives also highlighted the importance of certain personal or professional attributes, such as an understanding and active awareness of their own biases, as well as critical-thinking and decision-making skills. While midwives identified role-modelling as the most important strategy for achieving these competencies and learning outcomes, they did not agree that a validated method for evaluating students is an essential teaching strategy.

Midwives commented on the importance of integrating a reproductive justice framework into an ethics curriculum. Based on the human rights movement, the term reproductive justice was introduced in the mid-1990s to highlight and address the historical social, economic, and racial factors that contribute to and perpetuate reproductive discrimination. ${ }^{20,21}$ It incorporates not only the right to self-determination with regards to childbearing, but also adds context to the experiences of women related 


\section{6|Chapter Five}

to barriers to receiving person-centred reproductive care, including access to contraception, abortion care, and routine preventive care. ${ }^{21,22}$ While there has been progress in the incorporation of some aspects of reproductive justice into midwifery education in general, for example through the development of equity focus-based professional competencies by the Equity Agenda Guideline framework, further research, understanding, and strategies for implementation of a reproductive justice framework into a midwifery ethics curriculum is needed..$^{23,24}$

\section{Shared Decision-Making}

Shared decision-making was seen by the midwives in this Delphi study as not only the vehicle for effective communication, but also as the primary means of promoting autonomy. This view of shared decision-making as a critical component of negotiating ethical dilemmas is consistent with the findings of previously published studies on midwives' and nurses' experiences with ethical dilemmas. ${ }^{25,26}$ The midwives also viewed shared decision-making primarily through a principle-based lens, emphasizing the preservation and amplification of an individual's autonomy and agency. While they acknowledged the awareness of bias and its potential to influence or corrupt the midwife-woman relationship via power differentials, misunderstandings, or poor communication, they did not make a specific link between bias and the risk to the process of shared decision-making. The use of other philosophical frameworks, particularly care ethics, in teaching the process of shared decision-making, will help call attention to the effect of bias and other contributors to discrimination. Care ethics is an ethical framework that fits particularly well to the midwifery philosophy as it emphasizes individualized care and the trusting partnership between midwife and woman, and is comprised of attentiveness, responsibility, competence, and responsiveness. ${ }^{27-29} \mathrm{~A}$ care ethics framework has the potential to mitigate the harms done to midwives and women by institutional regulations and structured discrimination. ${ }^{27-29}$

Despite widespread support for the routine use of shared decision-making in clinical encounters, interventions that aim to increase providers' use of shared decisionmaking have shown minimal success. ${ }^{30}$ While organized training activities for students and providers have shown potential for providing the knowledge and skills to successfully engage in shared decision-making and are viewed as important for increasing implementation, the best methods for achieving this are unclear. ${ }^{31,32}$ In addition, the evidence on the outcomes of provider training, both in terms of provider behavioural change and in terms of the health outcomes of their patients, is lacking. ${ }^{30,31,33}$

\section{The dual purpose of ethics education}

In the categories of competencies and learning outcomes, statements related to personal behaviours (e.g. treating women with respect) and analytical skills (e.g. critical thinking) were closely ranked. This close ranking reflects two primary aims of ethics education. First, ethics education aims to enhance the personal, professional or behavioural attributes midwives are expected to possess (e.g. compassion). The focus of a valuesbased curricular framework is on character-building, emphasizing the idea that if one possesses particular moral attributes and one acts in alignment with those attributes, then one will be a good provider. ${ }^{34-37}$ Embodiment of the professional values of 
midwifery is a marker of a midwife's socialization into that group, and represents one of the goals of midwifery education, i.e. creating good midwives. However, what constitutes a "good midwife" has been an elusive concept, made more complicated by the idea that what midwives themselves believe is a good midwife may not be congruent with what women prefer or value in their midwifery care. ${ }^{38,39}$ While studies identify professional attributes such as professional caring, wisdom, and a commitment to physiologic birth as key components of exemplar midwifery care, studies with women show that they value midwifery care that is flexible, encouraging, and supportive of women as unique individuals. ${ }^{40,41}$ The midwives in our study echo both of these perspectives by the high ranking of ethics competencies and learning outcomes statements regarding compassionate care, respectful care, and support of individual choice through shared decision-making.

Second, ethics education aims to provide the deliberative and decision-making skills needed to recognize, analyse and negotiate ethical dilemmas. This framework for ethics education focuses on teaching moral reasoning, or ethical decision-making. ${ }^{10,42}$ Ethical sensitivity, knowledge of ethical theories, and critical thinking skills are essential components needed for ethics decision-making. ${ }^{3,26,42} \mathrm{~A}$ midwife's approach to ethics decision-making may be grounded in the values of the midwifery profession. For example, in midwifery, the high value placed on promoting physiologic birth is the lens through which an ethical dilemma may be viewed, negotiated, and resolved. ${ }^{43,44}$ While there are a number of ethics assessment processes that guide midwives through ethical decisionmaking, not all midwifery programs include them in their ethics curricula. ${ }^{9}$ In addition, some midwives may struggle to identify an ethical dilemma. ${ }^{6,45}$ While acquisition of ethics decision-making skills is strongly endorsed by the midwives in this study, the success of midwifery programs in conferring these skills is unclear.

\section{The evaluation conundrum}

The midwives in this Delphi study did not have a positive response to the statement regarding the use of a validated measure for evaluating student competencies. Unfortunately, the midwives did not offer any commentary in their survey responses, leaving the nature of their objections unclear. OSCEs are a well-established method of assessing clinical competencies and have been used widely in nursing education to assess student skills in areas such as obstetric emergencies, pharmacology, and lactation. ${ }^{46-48}$ While an OSCE may include criteria related to professional behaviours (such as active listening), the use and evaluation of an OSCE specifically involving assessment of ethics competencies and ethical decision-making have not been widely studied. ${ }^{48,49}$ The use of other validated tools for measuring specific aspects of ethics competency, such as ethical sensitivity, have been developed by educators and validated in undergraduate nursing and midwifery education programs to guide curricular development. ${ }^{13,42,50,51}$ However, these tools have not been used widely, and it is not clear that using them would have an impact on learning outcomes, knowledge, or student confidence to recognize and negotiate ethical dilemmas. Other teaching methods such as simulation and role-play rely primarily on self-reflection and debriefing to assist students in integrating knowledge and skills. ${ }^{52-54}$ However, midwifery educators describe purposefully avoiding any evaluation of student performance during simulation exercises in order to decrease stress and improve 


\section{8}

Chapter Five

acquisition of new skills. ${ }^{55}$ The use of other methods of assessment that focus on student collaboration, debriefing, critical self-reflection, such as authentic assessment, may be more acceptable to both educators and students. ${ }^{42,56}$

\section{Limitations}

The primary limitation of this study was the number of participants. Although all of the current program directors of accredited midwifery programs in the U.S. were invited, participation was limited to just 5 of 37 program directors in Round 1. In general, workload burden can be a significant limitation of the Delphi method, contributing to a low rate of participation and can increase bias, and we may have underestimated this burden. ${ }^{57}$ In addition, this may not be a representative sample of midwifery educators and clinical preceptors, as participants self-identified as experts and expertise may have varied.

\section{Conclusion}

Acquisition of critical thinking skills in ethics decision-making and nurturing of professional attributes such as compassion and courage were identified as essential competencies and learning outcomes, highlighting the dual aims of midwifery ethics education. Improved understanding of how these dual aims overlap and contribute differently to the professionalization of midwifery students and to their ethics competencies can assist midwifery educators in developing evidence-based ethics curricula. While shared decision-making was seen as an essential aspect of ethics education across all categories, midwifery programs should also consider including an exploration of care ethics when teaching about autonomy and shared decision-making. Further research is also needed to better understand how to achieve learning outcomes related to ethics education, including the best approaches for confirming that students have acquired and incorporated ethics knowledge and skills. 


\section{References}

1. Butts JB, Rich KL. Nursing Ethics: Across the Curriculum and into Practice. 4th Ed. Jones \& Bartlett Learning; 2016.

2. Phillippi JC, Avery MD. The 2012 American college of nurse-midwives core competencies for basic midwifery practice: History and revision. Journal of Midwifery and Women's Health. 2014;59(1):82-90. doi:10.1111/jmwh.12148

3. Kulju K, Stolt M, Suhonen R, Leino-Kilpi H. Ethical competence: A concept analysis. Nursing Ethics. 2016;23(4):401-412. doi:10.1177/0969733014567025

4. Jonsen AR, Siegler M, Winslade WJ. Clinical Ethics: A Practical Approach to Ethical Decisions in Clinical Medicine. 7th Ed. McGraw-Hill Medical; 2010.

5. Carrese JA, Malek J, Watson K, et al. The essential role of medical ethics education in achieving professionalism: The romanell report. Academic Medicine. 2015;90(6):744-752. doi:10.1097/ACM.0000000000000715

6. Lechasseur K, Caux C, Dollé S, Legault A. Ethical competence: An integrative review. Nursing Ethics. 2018;25(6):694-706. doi:10.1177/0969733016667773

7. International Confederation of Midwives. Essential Competencies for Midwifery Practice.; 2019.

8. American College of Nurse-Midwives. ACNM Core Competencies for Basic Midwifery Practice.; 2020.

9. Megregian M. Ethics Education in Midwifery Education Programs in the United States. Journal of Midwifery and Women's Health. 2016;61(5):586-592. doi:10.1111/jmwh.12462

10. Campbell A v., Chin J, Voo T-C. How can we know that ethics education produces ethical doctors? Medical Teacher. 2007;29(5):431-436. doi:10.1080/01421590701504077

11. Burkemper JE, DuBois JM, Lavin MA, Meyer GA, McSweeney M. Ethics Education in MSN Programs: A Study of National Trends. Nursing Education Perspectives. 2007;28(1):10-17.

12. Laabs CA. Toward a Consensus in Ethics Education for the Doctor of Nursing Practice. Nursing Education Perspectives. 2015;36(4):249-251. doi:10.5480/13-1195

13. Oelhafen S, Hölzli U, Häsänen M, et al. Increasing midwives' ethical competence: a European educational and practice development project. International Journal of Ethics Education. 2017;2(2):147-160. doi:10.1007/s40889-017-0033-3

14. Woods M. Nursing ethics education: Are we really delivering the good(s)? Nursing Ethics. 2005;12(1):518. doi:10.1191/0969733005ne754oa

15. Humphrey-Murto S, Varpio L, Wood TJ, et al. The Use of the Delphi and Other Consensus Group Methods in Medical Education Research: A Review. Academic Medicine. 2017;92(10):1491-1498. doi:10.1097/ACM.0000000000001812

16. Holey EA, Feeley JL, Dixon J, Whittaker VJ. An exploration of the use of simple statistics to measure consensus and stability in Delphi studies. BMC Medical Research Methodology. 2007;7(1):52. doi:10.1186/1471-2288-7-52

17. Keeney S, Hasson F, Mckenna H. The Delphi Technique in Nursing and Health Research. John Wiley \& Sons; 2011. doi:10.1002/9781444392029

18. Iwasiw C, Andrusyszyn M-A, Goldenberg D. Curriculum Development in Nursing Education. Fourth ed. Jones \& Bartlett Learning; 2020.

19. Spencer L, Ritchie J, O'Connor W, Morrell G, Ormston R. Analysis in Practice. In: Ritchie J, Lewis J, McNaughton Nicholls C, Ormston R, eds. Qualitative Research Practice. 2nd Editio. Sage Publications; 2014:295-346.

20. Chrisler JC. A Reproductive justice approach to women's health. Analyses of Social Issues and Public Policy. 2014;14(1):205-209. doi:10.1111/asap.12056

21. Gilliam ML, Neustadt A, Gordon R. A call to incorporate a reproductive justice agenda into reproductive health clinical practice and policy. Contraception. 2009;79(4):243-246. doi:10.1016/j.contraception.2008.12.004

22. Agénor M. A reproductive justice approach to patient-centered, structurally competent contraceptive care among diverse sexual minority US women. American Journal of Public Health. 2019;109(12):16261627. doi:10.2105/AJPH.2019.305382

23. Walker K, Arbour M, Waryold J. Educational Strategies to Help Students Provide Respectful Sexual and Reproductive Health Care for Lesbian, Gay, Bisexual, and Transgender Persons. Journal of Midwifery and Women's Health. 2016;61(6):737-743. doi:10.1111/jmwh.12506

24. Effland KJ, Hays K, Ortiz FM, Blanco BA. Incorporating an Equity Agenda into Health Professions Education and Training to Build a More Representative Workforce. Journal of Midwifery \& Women's Health. 2020;65(1):149-159. doi:10.1111/jmwh.13070 


\section{0|Chapter Five}

25. Monroe HA. Nurses' professional values: Influences of experience and ethics education. Journal of Clinical Nursing. 2019;28(9-10):2009-2019. doi:10.1111/jocn.14806

26. Oelhafen S, Monteverde S, Cignacco E. Exploring moral problems and moral competences in midwifery: A qualitative study. Nursing Ethics. 2019;26(5):1373-1386. doi:10.1177/0969733018761174

27. MacLellan J. Claiming an Ethic of Care for midwifery. Nursing Ethics. 2014;21(7):803-811. doi:10.1177/0969733014534878

28. Newnham E, Kirkham M. Beyond autonomy: Care ethics for midwifery and the humanization of birth. Nursing Ethics. 2019;26(7-8):2147-2157. doi:10.1177/0969733018819119

29. Nieuwenhuijze M. Doing good: Ethics of decision-making in midwifery care. In: Jefford E, Jefford E, Jomeen J, eds. Empowering Decision-Making in Midwifery. Routledge; 2019. doi:10.4324/9780429398179

30. Légaré F, Stacey D, Turcotte $S$, et al. Interventions for improving the adoption of shared decision making by healthcare professionals. Cochrane Database of Systematic Reviews. 2014;2014(9). doi:10.1002/14651858.CD006732.pub3

31. Müller E, Strukava A, Scholl I, et al. Strategies to evaluate healthcare provider trainings in shared decision-making (SDM): a systematic review of evaluation studies. BMJ Open. 2019;9(6):e026488. doi:10.1136/bmjopen-2018-026488

32. Rusiecki J, Schell J, Rothenberger S, Merriam S, McNeil M, Spagnoletti C. An Innovative Shared DecisionMaking Curriculum for Internal Medicine Residents: Findings from the University of Pittsburgh Medical Center. Academic Medicine. 2018;93(6):937-942. doi:10.1097/ACM.0000000000001967

33. Begley K, Daly D, Panda S, Begley C. Shared decision-making in maternity care: Acknowledging and overcoming epistemic defeaters. Journal of Evaluation in Clinical Practice. 2019;25(6):1113-1120. doi:10.1111/jep.13243

34. Eckles RE, Meslin EM, Gaffney M, Helft PR. Medical Ethics Education: Where Are We? Where Should We Be G... : Academic Medicine. 2005;80(12):1143-1152. doi:10.1097/00001888-200512000-00020

35. McLean C. The yellow brick road: A values based curriculum model. Nurse Education in Practice. 2012;12(3):159-163. doi:10.1016/j.nepr.2011.11.002

36. Kennedy HP. A MODEL OF EXEMPLARY MIDWIFERY PRACTICE: RESULTS OF A DELPHI STUDY. J Midwifery Womens Health. 2000;45:4-19.

37. Bryan CS, Babelay AM. Building Character: A Model for Reflective Practice. Acad Med. 2009;84:12831288.

38. Borrelli SE. What is a good midwife? Insights from the literature. Midwifery. 2014;30(1):3-10. doi:10.1016/j.midw.2013.06.019

39. Nicholls $L$, Webb C. What makes a good midwife? An integrative review of methodologically-diverse research. Journal of Advanced Nursing. 2006;56(4):414-429. doi:10.1111/j.1365-2648.2006.04026.x

40. Borrelli SE, Spiby H, Walsh D. The kaleidoscopic midwife: A conceptual metaphor illustrating first-time mothers' perspectives of a good midwife during childbirth. A grounded theory study. Midwifery. 2016;39:103-111. doi:10.1016/j.midw.2016.05.008

41. Feijen-de Jong El, Kool L, Peters LL, Jansen DEMC. Perceptions of nearly graduated fourth year midwifery students regarding a 'good midwife' in the Netherlands. Midwifery. 2017;50:157-162. doi:10.1016/j.midw.2017.04.008

42. Robinson EM, Lee SM, Zollfrank A, Jurchak M, Frost D, Grace P. Enhancing moral agency: Clinical ethics residency for nurses. Hastings Center Report. 2014;44(5):12-20. doi:10.1002/hast.353

43. Ménage D. Part 2: A model for evidence-based decision-making in midwifery care. British Journal of Midwifery. 2016;24(2):137-143. doi:10.12968/bjom.2016.24.2.137

44. Megregian M. Ethics and Professionalism: The Whole Is More Than the Sum of Its Parts. Journal of Midwifery \& Women's Health. 2019;64(5):526-528. doi:10.1111/jmwh.13016

45. Megregian M, Low LK, Emeis C, de Vries R, Nieuwenhuijze M. "I'm sure we talked about it": Midwives experiences of ethics education and ethical dilemmas, a qualitative study. Women and Birth. Published online 2020. doi:10.1016/j.wombi.2019.12.005

46. Solà-Pola M, Morin-Fraile V, Fabrellas-Padrés N, et al. The usefulness and acceptance of the OSCE in nursing schools. Nurse Education in Practice. 2020;43. doi:10.1016/j.nepr.2020.102736

47. Daniels VJ, Pugh D. Twelve tips for developing an OSCE that measures what you want. Medical Teacher. 2018;40(12):1208-1213. doi:10.1080/0142159X.2017.1390214

48. Smith V, Muldoon K, Biesty L. The Objective Structured Clinical Examination (OSCE) as a strategy for assessing clinical competence in midwifery education in Ireland: A critical review. Nurse Education in Practice. 2012;12(5):242-247. doi:10.1016/j.nepr.2012.04.012 


\section{Essential components of midwifery ethics education: results of a Delphi study|91}

49. Singer PA, Robb A, Cohen R, Norman G, Turnbull J. Performance-based Assessment of Clinical Ethics Using an Objective Structured Clinical Examination. Academic Medicine. 1996;71(5):495-498.

50. Cannaerts N, Gastmans C, Casterlé BD de. Contribution of ethics education to the ethical competence of nursing students. Nursing Ethics. 2014;21(8):861-878. doi:10.1177/0969733014523166

51. Yeom H-A, Ahn S-H, Kim S-J. Effects of ethics education on moral sensitivity of nursing students. Nursing Ethics. 2017;24(6):644-652. doi:10.1177/0969733015622060

52. Ryall T, Judd BK, Gordon CJ. Simulation-based assessments in health professional education: A systematic review. Journal of Multidisciplinary Healthcare. 2016;9:69-82. doi:10.2147/JMDH.S92695

53. Cooper S, Cant R, Porter J, et al. Simulation based learning in midwifery education: A systematic review. Women and Birth. 2012;25(2):64-78. doi:10.1016/j.wombi.2011.03.004

54. Rutherford-Hemming T, Nye C, Coram C. Using Simulation for Clinical Practice Hours in Nurse Practitioner Education in The United States: A Systematic Review. Nurse Education Today. 2016;37:128-135. doi:10.1016/j.nedt.2015.11.006

55. Buxton M, Phillippi JC, Collins MR. Simulation: A New Approach to Teaching Ethics. Journal of Midwifery and Women's Health. 2015;60(1):70-74. doi:10.1111/jmwh.12185

56. Wu XV, Heng MA, Wang W. Nursing students' experiences with the use of authentic assessment rubric and case approach in the clinical laboratories. Nurse Education Today. 2015;35(4):549-555. doi:10.1016/j.nedt.2014.12.009

57. Keeney S, Hasson F, McKenna H. Consulting the oracle: Ten lessons from using the Delphi technique in nursing research. Journal of Advanced Nursing. 2006;53(2):205-212. doi:10.1111/j.1365-

2648.2006.03716.x 
92|Chapter Five 


\section{CHAPTER 6}

\section{The impact of shared decision-making in perinatal care, a scoping review}

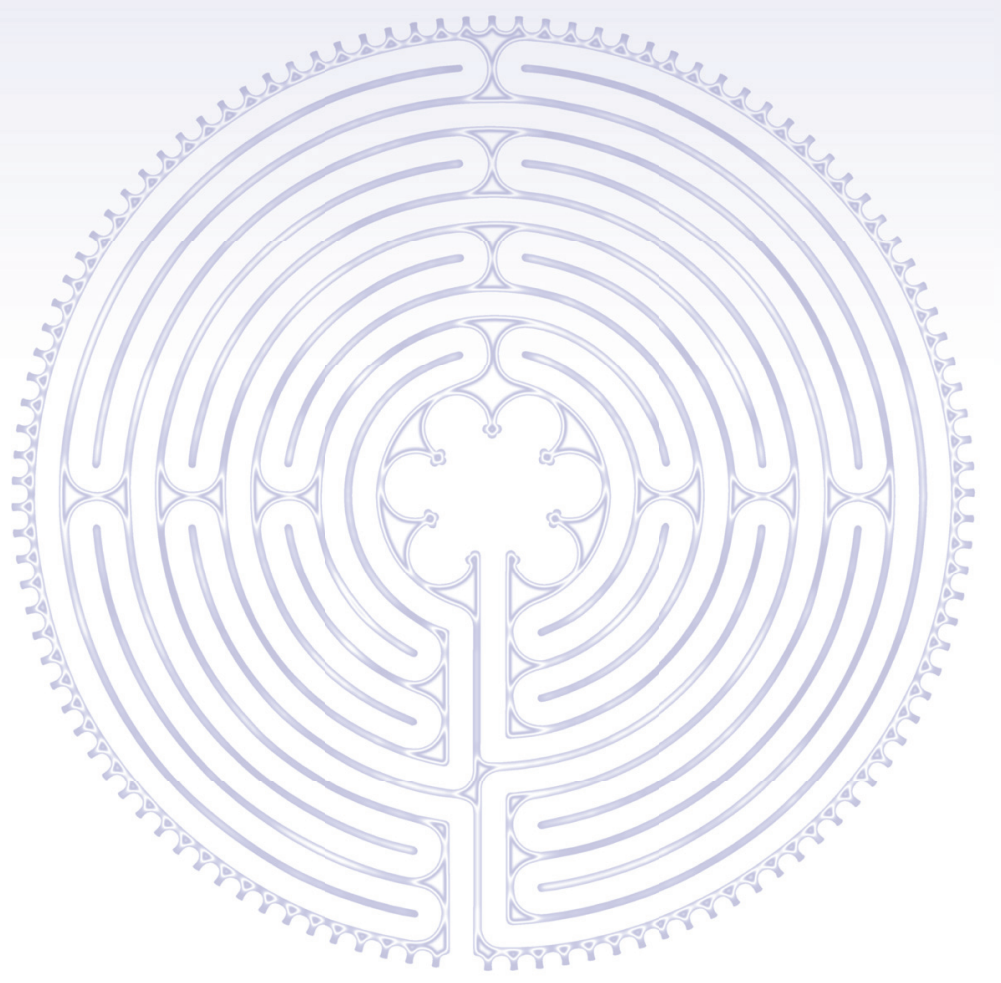

Michele Megregian, Cathy Emeis, Marianne Nieuwenhuijze

Journal of Midwifery \& Women's Health. 2020 Aug 7 


\title{
$94 \mid$ Chapter 6
}

\section{Precis}

This scoping review shows limited studies that examine the impact of shared decision making strategies in perinatal care, with no studies occurring in the intrapartum setting.

\begin{abstract}

\section{Introduction}

Shared decision making is considered to be a key aspect of woman-centered care and a strategy to improve communication, respect, and satisfaction. This scoping review aims to identify studies that use a shared decision making support strategy as the primary intervention in the context of perinatal care.
\end{abstract}

\section{Methods}

A literature search of PubMed, CINAHL, Cochrane Library, PsycInfo, and SCOPUS databases was completed for English-language studies conducted from January 2000 through November 2019 that examined the impact of a shared decision making support strategy on a perinatal decision (such as choice of mode of birth after prior cesarean birth). Studies that only examined the use of a decision aid were excluded. Nine studies met inclusion criteria and were examined for the nature of the shared decision making intervention as well as outcome measures such as decisional evaluation, including decisional conflict, decisional regret, and certainty.

\section{Results}

The 9 included studies were heterogeneous in shared decision making interventions, measured outcomes, and were performed in different countries and in a variety of perinatal situations, such as women facing the choice of mode of birth after prior cesarean birth. The impact of a shared decision making intervention on women's perception of shared decision making and on their experiences of the decision making process were mixed. There may be a decrease in decisional conflict and regret related to feeling informed, but no change in decisional certainty.

\section{Discussion}

Despite the call to increase the use of shared decision making in perinatal care, there are few studies which have examined the effects of a shared decision making support strategy. Further studies which include antepartum and intrapartum settings, and which include common perinatal decisions such as induction of labor are needed. In addition, clear guidance and strategies for successfully integrating shared decision making and practice recommendations would help women and midwives navigate these complex decisions.

\section{Keywords}

Shared decision making, pregnancy, decision support techniques, patient centered communication 
The impact of shared decision-making in perinatal care, a scoping review|95

\section{Quick Points}

- Implementation of a shared decision making strategy may decrease women's perceptions of decisional conflict. The communication of accurate, evidencebased information has the potential to decrease decisional conflict

- Shared decision making strategies may have less of an impact on women's feelings of certainty in their decision.

- Midwives have an opportunity to contribute to further research on the impact of a shared decision making strategy and to the integration of shared decision making and evidence-based clinical guidelines. 


\section{$96 \mid$ Chapter 6}

\section{Introduction}

Patient centered care is an approach to healthcare that uses a holistic framework to address a person's health and wellbeing, and has been linked to improved patient satisfaction, provider-patient communication, and health outcomes. ${ }^{1}$ While variation in how patient-centered care is defined and measured remains a potential barrier to effective implementation, patient-centered care highlights the importance of effective provider-patient communication as well as the pursuit of harmony between an individual's values and the proposed health intervention. ${ }^{2,3}$ Shared decision making is considered to be a key aspect of patient-centered care and a strategy to improve communication, respect, and satisfaction. ${ }^{4}$

Shared decision making is a collaborative process in which a provider and patient engage with one another to make health care decisions, using respectful communication and basing their decisions on the best available evidence and the patient's preferences, values, and goals. ${ }^{5}$ The shared decision making process attempts to balance the principles of beneficence and autonomy through the clear and thorough exchange of information and the exploration and clarification of the patient's values and their understanding of risk. ${ }^{6}$ Effective and respectful communication has been linked to women's satisfaction with their maternity care and experience of childbirth. ${ }^{3,7}$ Recent articles describing the mistreatment of women in childbirth as a global phenomenon emphasize the need for improved understanding of the dynamic process of shared decision making, communication, risk perception and informed consent. ${ }^{8,9}$ In addition, lack of shared decision making has also been linked to health care disparities in the United States (U.S.). ${ }^{10}$ A study of women's perceptions of shared decision making regarding obstetric procedures during labor demonstrated that women who were from racial/ethnic minority groups, who were less educated, or who lacked private insurance reported lower levels of shared decision making. ${ }^{10}$

Consistent implementation of and engagement in the shared decision making process in maternity care has been identified as critical to improved perinatal outcomes and is considered and essential component to high quality maternity care. ${ }^{11,12}$ Shared decision making has been included in policy initiatives that aim to promote a meaningful partnership with women, to promote physiologic birth and to reduce primary cesarean births. ${ }^{13,14}$ Perinatal guidelines and studies, including randomized controlled trials, now call upon providers to integrate research findings into a shared decision making framework when discussing such decisions as induction of labor ${ }^{15}$, delivery options in the setting of late-preterm preeclampsia ${ }^{16}$, and unknown group B Streptococcus colonization status ${ }^{17}$. Systematic reviews have examined the effect of decision aids alone on outcomes such as treatment adherence and decision evaluation. ${ }^{18}$ However, a shared decision making process is, or should be, more than just the provision of a decision aid. Despite current encouragement to adopt shared decision making, there is limited evidence of the true effect of shared decision making on treatment adherence, clinical outcomes, or the experience of decision making for both women and providers in the perinatal context. The aim of this scoping review was to examine the range of current research in perinatal care on the potential impact of shared decision making, to summarize the findings when a 
shared decision making support strategy is implemented, and to identify gaps in the research. ${ }^{19}$

\section{Methods}

A scoping review is a rigorous method used to evaluate the extent of the evidence of a particular subject. ${ }^{20}$ While a systematic review seeks to synthesize the evidence to answer a specific clinical question, the breadth of a scoping review allows an examination of the range of evidence and identification of research gaps. ${ }^{20}$ In addition, a scoping review offers the opportunity to determine if a full systematic review would be appropriate. ${ }^{19,21}$ For this scoping review, a literature search procedure was performed according to the Preferred Reporting Items for Systematic Reviews and Meta-Analyses extension for scoping reviews (PRISMA-ScR) guidelines. ${ }^{20,22}$ Search terms were formulated based on the Population Intervention Comparison Outcome (PICO) framework. ${ }^{21}$ The literature search was conducted between September and November 2019 using the databases PubMed, SCOPUS, Cochrane Library, Psyclnfo, and CINAHL. Search terms included "maternity care", "pregnancy", "shared decision making", and "informed choice" in combination. The final search was limited to articles published between January 2000 and November 2019, as a preliminary search demonstrated that there were few studies published on this topic prior to 2000 .

Inclusion criteria included articles presenting outcomes of original quantitative, qualitative, and mixed-methods studies reporting on the use of shared decision making strategies as an intervention for either women and/or maternity care providers. Exclusion criteria comprised studies published in a non-English language, studies published prior to 2000, studies that evaluated a decision aid alone, and studies that described preferences or experiences of shared decision making but did not include shared decision making as the primary intervention. (Table 1) Review article, opinion pieces, protocol descriptions, and quality improvement process articles were excluded, although their reference lists were reviewed for additional potential studies.

\begin{tabular}{|c|c|}
\hline Inclusion Criteria & Exclusion Criteria \\
\hline $\begin{array}{l}\text { - } \quad \text { English Language } \\
\text { - } \quad \text { quantitative, mixed methods or } \\
\text { - } \quad \text { Shared decision making intervention } \\
\text { - } \quad \text { Published after } 1999 \\
\quad \text { Clinical context includes any aspect of } \\
\text { perinatal or maternity care, including } \\
\text { antepartum, intrapartum, postpartum }\end{array}$ & $\begin{array}{l}\text { - } \quad \text { Non-English Language } \\
\text { Reviews, opinions, quality improvement } \\
\text { protocols or process descriptions, } \\
\text { research protocols } \\
\text { Evaluation of decision aid as the sole aim } \\
\text { of the study } \\
\text { Examination of women's or providers' } \\
\text { preferences where shared decision } \\
\text { making was not the intervention } \\
\text { Published prior to } 2000 \\
\text { Clinical context is outside maternity care, } \\
\text { including other aspects of reproductive } \\
\text { health care such as breast cancer } \\
\text { Clinical context is outside maternity care, } \\
\text { including other aspects of reproductive } \\
\text { health care such as breast cancer }\end{array}$ \\
\hline
\end{tabular}


The literature search and description of studies is presented in Figure 1. After duplicates were removed, 609 publications were evaluated. (Figure 1) Titles and abstracts were screened for inclusion. If inclusion criteria were met, then the full text was retrieved and reviewed. A data abstraction form was developed specifically for this review, including author name, title, date of publication, journal, location of study, study design, and specific type of shared decision-making intervention. Information on study results and the measurement tools used by the study researchers were also recorded. Extracted data were entered into a spreadsheet for organization. Studies were organized into three primary categories which represent the potential influence of shared decision making on women's experiences of decision making, perinatal outcomes, and providers. As the aim of this review was to describe the scope of this topic in the literature, the methodological quality of the individual studies was not a focus of the review, and a pooled analysis was not performed.

\section{Figure 1: PRISMA-ScR Flow Chart}

Liberati A, Altman DG, Tetzlaff J, et al. The PRISMA statement for reporting systematic reviews and meta-analyses of studies that evaluate health care interventions: explanation and elaboration. Journal of Clinical Epidemiology; 2009. doi:10.1016/j.jclinepi.2009.06.006

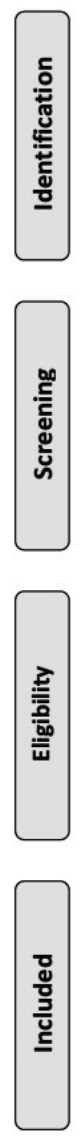

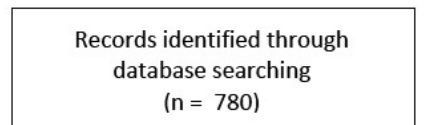
$(\mathrm{n}=780)$
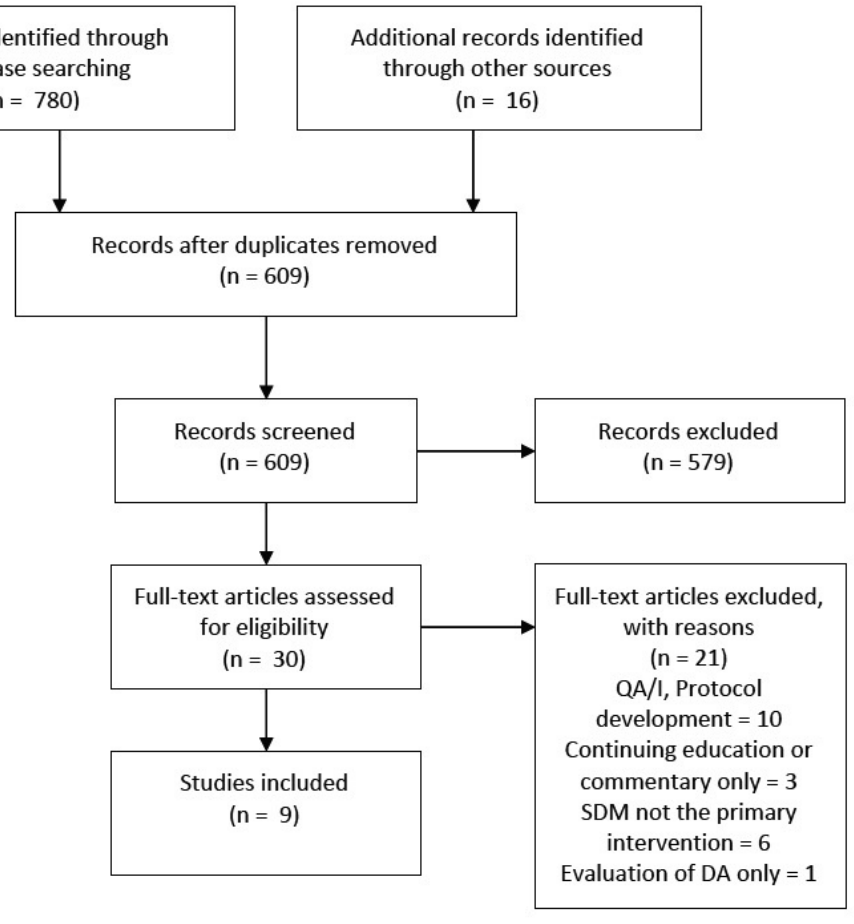


\section{Results}

Thirty full text articles were reviewed and ultimately 9 were included in the scoping review (Table 2). ${ }^{23-31}$ Three were from the Netherlands ${ }^{23,24,31}, 2$ from the United State ${ }^{25,29}$, and the others were from Australia ${ }^{26}$, Canada $^{27}$, Iran ${ }^{28}$, and $\operatorname{Japan}^{30}$. Three studies used a mixed methods design ${ }^{23,25,30}, 3$ studies used a quasi-experimental design ${ }^{27-}$ ${ }^{29}$, a randomized controlled trial $(R C T)^{31}$, and a secondary analysis of the same $R_{C T}{ }^{24}$. Two of the studies evaluated shared decision making regarding mode of delivery after prior cesarean birth. ${ }^{26,30}$ Two studies used the same data set to evaluate couples' decisionmaking with respect to single embryo transfer (versus double embryo transfer in the setting of invitro fertilization (IVF). ${ }^{24,31}$ The remaining studies involved women and families faced with treatment decisions regarding severe pregnancy or postpartum complications $^{23}$, care options for pregnant women with substance use disorder ${ }^{25}$, care options for women and families facing a potential delivery complicated by extreme prematurity ${ }^{27}$, options regarding termination or continuation of pregnancy for women whose fetuses were affected by ß-thalassemia major ${ }^{28}$, and decisions regarding opioid prescriptions for women after cesarean birth. ${ }^{29}$

\begin{tabular}{|c|c|c|c|c|c|}
\hline \multicolumn{6}{|c|}{$\begin{array}{l}\text { Table } 2 \\
\text { Summary of } 9 \text { Articles Included in Scoping Review }\end{array}$} \\
\hline $\begin{array}{l}\text { Author } \\
\text { Date }\end{array}$ & $\begin{array}{l}\text { Population } \\
\text { and Setting }\end{array}$ & Study Aim & $\begin{array}{l}\text { Study Design } \\
\text { Evaluation Tool }\end{array}$ & $\begin{array}{l}\text { Intervention } \\
\text { / Comparator }\end{array}$ & Key Outcomes \\
\hline $\begin{array}{l}\text { Baijens et } \\
\text { al. }^{23} 2018 \\
\text { Netherlan } \\
\text { ds }\end{array}$ & $\begin{array}{l}\text { Pre- } \\
\text { Intervention } \\
\text { Group =33; } \\
\text { Intervention } \\
\text { Group = 29; } \\
4 \text { interviews } \\
\text { Providers } \\
\text { not included }\end{array}$ & $\begin{array}{l}\text { Evaluate the } \\
\text { feasibility } \\
\text { and } \\
\text { effectiveness } \\
\text { of } 3 \\
\text { questions } \\
\text { intervention } \\
\text { in clinical } \\
\text { inpatient } \\
\text { setting }\end{array}$ & $\begin{array}{l}\text { Mixed methods } \\
\text { Quantitative } \\
\text { pre/post survey, } \\
\text { qualitative interviews } \\
\text { SDM-Q-9 to measure } \\
\text { perceived level of } \\
\text { shared decision } \\
\text { making; Preferences } \\
\text { about their } \\
\text { involvement in } \\
\text { decision making and } \\
\text { information } \\
\text { provision }\end{array}$ & $\begin{array}{l}\text { Intervention } \\
\text { group given } \\
\text { 3-questions } \\
\text { card, } \\
\text { encouraged } \\
\text { to use the } \\
\text { questions } \\
\text { during ward } \\
\text { rounds } \\
\text { Pre- } \\
\text { intervention } \\
\text { group did not } \\
\text { receive } 3 \\
\text { questions } \\
\text { during first } 3 \\
\text { weeks of } \\
\text { study }\end{array}$ & $\begin{array}{l}\text { Mean score of } \\
\text { SDM-Q-9 not } \\
\text { statistically } \\
\text { significant between } \\
\text { groups; Majority in } \\
\text { both groups } \\
\text { preferred doctor to } \\
\text { make decision after } \\
\text { explicitly } \\
\text { considering the } \\
\text { woman's } \\
\text { preferences }\end{array}$ \\
\hline $\begin{array}{l}\text { Brabers et } \\
\text { al. }^{24} 2016 \\
\text { Netherlan } \\
\text { ds }\end{array}$ & $\begin{array}{l}5 \text { hospitals; } \\
222 \text { couples } \\
(I=109 \text {, } \\
\text { C=113); } \\
\text { beginning of } \\
\text { first IVF, } \\
\text { excluded } \\
\text { couples who } \\
\text { only had } 1 \\
\text { embryo }\end{array}$ & $\begin{array}{l}\text { Examine the } \\
\text { hypothesis } \\
\text { that shared } \\
\text { decision } \\
\text { making } \\
\text { reduces } \\
\text { variation in } \\
\text { medical } \\
\text { practice, } \\
\text { with an }\end{array}$ & $\begin{array}{l}\text { Secondary analysis of } \\
\text { Randomized } \\
\text { Controlled Trial }\end{array}$ & $\begin{array}{l}\text { Evidence } \\
\text { based } \\
\text { Decision Aid, } \\
\text { support of } \\
\text { IVF nurse } \\
\text { (decision } \\
\text { coach) } \\
\text { provided } \\
\text { before the } \\
\text { standard }\end{array}$ & $\begin{array}{l}\text { Strategy to promote } \\
\text { shared decision } \\
\text { making reduced } \\
\text { variation in single } \\
\text { embryo transfer or } \\
\text { double embryo } \\
\text { transfer choice } \\
\text { between hospitals } \\
\text { but not within the } \\
\text { same hospital }\end{array}$ \\
\hline
\end{tabular}




\begin{tabular}{|c|c|c|c|c|c|}
\hline & $\begin{array}{l}\text { available, } \\
\text { those } \\
\text { already } \\
\text { pregnant or } \\
\text { who never } \\
\text { started IVF } \\
\text { Providers } \\
\text { not included }\end{array}$ & $\begin{array}{l}\text { increase in } \\
\text { Single } \\
\text { embryo } \\
\text { transfer vs } \\
\text { Double } \\
\text { embryo } \\
\text { transfer }\end{array}$ & & $\begin{array}{l}\text { counseling } \\
\text { session and } \\
\text { IVF care } \\
\text { Standard } \\
\text { counseling } \\
\text { and IVF care }\end{array}$ & \\
\hline $\begin{array}{l}\text { van } \\
\text { Peperstrat } \\
\text { en et al. }{ }^{31} \\
2010 \\
\text { Netherlan } \\
\text { ds }\end{array}$ & $\begin{array}{l}\text { Couples } \\
\text { with first } \\
\text { IVF or first } \\
\text { after } \\
\text { previously } \\
\text { successful } \\
\text { IVF, } \\
\text { age<40yo; } \\
\mathrm{N}=152 \\
\text { intervention } \\
\text { group; } \\
\mathrm{N}=156 \\
\text { control } \\
\text { group } \\
\text { Providers } \\
\text { not included }\end{array}$ & $\begin{array}{l}\text { A } \\
\text { multifaceted } \\
\text { empowerme } \\
\text { nt strategy } \\
\text { would } \\
\text { encourage } \\
\text { the use of } \\
\text { single } \\
\text { embryo } \\
\text { transfer and } \\
\text { reduce the } \\
\text { number of } \\
\text { twin } \\
\text { pregnancies } \\
\text { in a cost } \\
\text { effective way }\end{array}$ & $\begin{array}{l}\text { Randomized } \\
\text { Controlled Trial, } 3 \\
\text { questionnaires } \\
\text { (inclusion, after } \\
\text { intervention but } \\
\text { before treatment, } 5 \\
\text { weeks after embryo } \\
\text { transfer), measuring } \\
\text { decision making } \\
\text { outcomes and } \\
\text { knowledge } \\
\text { General self-efficacy } \\
\text { scale; actual } \\
\text { knowledge } 11 \text { item } \\
\text { multiple choice test; } \\
\text { decision evaluation } \\
\text { scores } \\
\text { (satisfaction/uncertai } \\
\text { nty, informed choice, } \\
\text { decision control) 15 } \\
\text { item questionnaire; } \\
\text { state trait anxiety } \\
\text { inventory; Beck } \\
\text { depression inventory }\end{array}$ & $\begin{array}{l}\text { Evidence } \\
\text { based DA, } \\
\text { support of } \\
\text { IVF nurse } \\
\text { (decision } \\
\text { coach), } \\
\text { reimburseme } \\
\text { nt for } \\
\text { additional IVF } \\
\text { if choosing } \\
\text { single } \\
\text { embryo } \\
\text { transfer } \\
\text { decreased } \\
\text { chance of } \\
\text { pregnancy, } \\
\text { provided } \\
\text { before the } \\
\text { standard } \\
\text { counseling } \\
\text { session and } \\
\text { IVF care } \\
\text { Standard } \\
\text { counseling } \\
\text { and IVF care }\end{array}$ & $\begin{array}{l}\text { Couples choosing } \\
\text { single embryo } \\
\text { transfer: } \\
\text { intervention } \\
\text { group=43\%, control } \\
\text { group=32\%; the } \\
\text { proportion of } \\
\text { couples in } \\
\text { intervention group } \\
\text { who wanted to } \\
\text { decide for } \\
\text { themselves the } \\
\text { number of embryos } \\
\text { increased from } 77 \% \\
\text { to } 91 \%, \text { remained } \\
73 \% \text { in control } \\
\text { group; Decision } \\
\text { evaluation scale not } \\
\text { significant in } \\
\text { satisfaction/uncerta } \\
\text { inty or control but } \\
\text { intervention group } \\
\text { reported a better } \\
\text { informed choice. No } \\
\text { difference in } \\
\text { anxiety or } \\
\text { depression. }\end{array}$ \\
\hline $\begin{array}{l}\text { Howard \& } \\
\text { Clark }^{25} \\
2017 \\
\text { United } \\
\text { States }\end{array}$ & $\begin{array}{l}\text { Prenatal } \\
\text { healthcare } \\
\text { providers } \\
\mathrm{N}=45 \\
\text { Women not } \\
\text { included }\end{array}$ & $\begin{array}{l}\text { Training for } \\
\text { providers on } \\
\text { de- } \\
\text { stigmatizatio } \\
\text { n of SUD in } \\
\text { pregnancy, } \\
\text { using SDM to } \\
\text { increase } \\
\text { screening for } \\
\text { substance } \\
\text { use and to } \\
\text { provide info } \\
\text { about } \\
\text { treatment } \\
\text { and } \\
\text { resources }\end{array}$ & $\begin{array}{l}\text { Mixed Methods: } \\
\text { Online pre/post } \\
\text { survey targeting } \\
\text { attitudes, practices, } \\
\text { stigma reduction, } \\
\text { knowledge, and SDM } \\
\text { practice } \\
\text { Developed } \\
\text { questionnaire } \\
\text { specifically for this } \\
\text { training }\end{array}$ & $\begin{array}{l}\text { Provider } \\
\text { training } \\
\text { Pre/post } \\
\text { training } \\
\text { surveys }\end{array}$ & $\begin{array}{l}\text { Post-training } \\
\text { providers had } \\
\text { increased } \\
\text { knowledge about } \\
\text { child welfare laws } \\
\text { and there was } \\
\text { stigma reduction. } \\
\text { An increase in } \\
\text { intent to use SDM } \\
\text { in visits with } \\
\text { pregnant with } \\
\text { substance use } \\
\text { disorder, but not } \\
\text { statistically } \\
\text { significant }\end{array}$ \\
\hline $\begin{array}{l}\text { Miller \& } \\
\text { Holdaway } \\
{ }^{6} 2019 \\
\text { Australia }\end{array}$ & $\begin{array}{l}\text { Women age } \\
>18 \text { years, } \\
\text { not } \\
\text { currently }\end{array}$ & $\begin{array}{l}\text { Investigate } \\
\text { how } \\
\text { variations in } \\
\text { risk } \\
\text { communicati }\end{array}$ & $\begin{array}{l}2 \times 2 \times 2 \text { experimental } \\
\text { design; } 8 \\
\text { experimental } \\
\text { conditions; random } \\
\text { allocation and }\end{array}$ & $\begin{array}{l}\text { Exposure to } \\
\text { vignettes that } \\
\text { manipulated } \\
\text { decision- } \\
\text { making } \\
\end{array}$ & $\begin{array}{l}\text { Decision making } \\
\text { role (choice vs } \\
\text { compliance) did not } \\
\text { predict childbirth } \\
\text { preference }\end{array}$ \\
\hline
\end{tabular}


The impact of shared decision-making in perinatal care, a scoping review|101

\begin{tabular}{|c|c|c|c|c|c|}
\hline & $\begin{array}{l}\text { pregnant; } \\
\mathrm{N}=669 \\
\text { Providers } \\
\text { not included }\end{array}$ & $\begin{array}{l}\text { on } \\
\text { (information } \\
\text { selectivity, } \\
\text { absolute vs } \\
\text { relative risk, } \\
\text { role in } \\
\text { decision } \\
\text { making) } \\
\text { influenced } \\
\text { choice of } \\
\text { mode of } \\
\text { birth }\end{array}$ & $\begin{array}{l}\text { blinded; Online } \\
\text { survey } \\
\text { SDM measured via } \\
\text { questions that } \\
\text { assessed decisional } \\
\text { certainty, perception } \\
\text { of risk, perceived } \\
\text { freedom to choose; } \\
\text { perceived } \\
\text { involvement in } \\
\text { decision making, } \\
\text { encouragement to } \\
\text { participate in } \\
\text { decision making by } \\
\text { provider }\end{array}$ & $\begin{array}{l}\text { conditions; } \\
\text { Preference } \\
\text { for mode of } \\
\text { birth } \\
\text { assessed } \\
\text { Selective vs } \\
\text { non-selective } \\
\text { information; } \\
\text { absolute vs } \\
\text { relative risk } \\
\text { communicati } \\
\text { on; } \\
\text { compliance } \\
\text { vs choice } \\
\text { (role of } \\
\text { decision } \\
\text { making). } \\
\text { Choice } \\
\text { created by } \\
\text { emphasizing } \\
\text { freedom to } \\
\text { choose, } \\
\text { control over } \\
\text { the dm } \\
\text { process, } \\
\text { encourageme } \\
\text { nt to } \\
\text { participate }\end{array}$ & \\
\hline $\begin{array}{l}\text { Moore et } \\
\text { al. }{ }^{27} 2017 \\
\text { Canada }\end{array}$ & $\begin{array}{l}\text { Parents } \\
\text { facing } \\
\text { potential } \\
\text { delivery at } \\
23-24 \text { weeks } \\
\text { gestational } \\
\text { age, } \mathrm{N}=15 ; \\
\text { Convenienc } \\
\text { e sample } \\
4 \\
\text { neonatologi } \\
\text { sts trained } \\
\text { as decision } \\
\text { coaches } \\
\text { through } \\
\text { online } \\
\text { course and } \\
\text { workshop }\end{array}$ & $\begin{array}{l}\text { Field-test } \\
\text { decision } \\
\text { coaching } \\
\text { with DA } \\
\text { developed } \\
\text { by study } \\
\text { team to } \\
\text { determine } \\
\text { effect on } \\
\text { decisional } \\
\text { conflict }\end{array}$ & $\begin{array}{l}\text { Quantitative surveys } \\
\text { of women and } \\
\text { decision coaches } \\
\text { Satisfaction with } \\
\text { SDM rating tool; } \\
\text { modified Genetic } \\
\text { Counselling } \\
\text { Satisfaction Scale; } \\
\text { Low literacy } \\
\text { Decisional Conflict } \\
\text { Scale; Choice } \\
\text { Predisposition Scale; } \\
\text { Decision coaches } \\
\text { filled a satisfaction } \\
\text { questionnaire based } \\
\text { on experience with } \\
\text { DA and decisional } \\
\text { coaching }\end{array}$ & $\begin{array}{l}\text { Trained } \\
\text { neonatologist } \\
\text { provided } \\
\text { decision } \\
\text { coaching and } \\
\text { DA } \\
\text { Standard } \\
\text { consultation } \\
\text { with } \\
\text { neonatologist } \\
\text { who did not } \\
\text { receive } \\
\text { training as } \\
\text { decision } \\
\text { coach; no DA }\end{array}$ & $\begin{array}{l}89 \% \text { would } \\
\text { recommend } \\
\text { decision coaching } \\
\text { plus DA; total } \\
\text { decisional conflict } \\
\text { score decreased } \\
\text { significantly; } \\
\text { Participants' choice } \\
\text { predisposition } \\
\text { carried through to } \\
\text { actual choice. }\end{array}$ \\
\hline $\begin{array}{l}\text { Moudi et } \\
\text { al. }{ }^{28} 2018 \\
\text { Iran }\end{array}$ & $\begin{array}{l}\text { Fetus } \\
\text { diagnosed } \\
\text { with } \beta-T M ; \\
\mathrm{N}=40 \\
\text { control } \\
\text { group; } \mathrm{N}=40\end{array}$ & $\begin{array}{l}\text { Study the } \\
\text { effect of } \\
\text { SDM on } \\
\text { decisional } \\
\text { conflict } \\
\text { scores } \\
\text { immediately }\end{array}$ & $\begin{array}{l}\text { Quasi experimental } \\
\text { Decisional Conflict } \\
\text { Scale; Decision } \\
\text { Regret Scale }\end{array}$ & $\begin{array}{l}90 \text { min } \\
\text { counseling } \\
\text { session based } \\
\text { on SDM with } \\
\text { study } \\
\text { member }\end{array}$ & $\begin{array}{l}\text { Statistically } \\
\text { significant lower } \\
\text { scores of decisional } \\
\text { conflict and } \\
\text { decisional regret }\end{array}$ \\
\hline
\end{tabular}




\section{2|Chapter 6}

\begin{tabular}{|c|c|c|c|c|c|}
\hline & $\begin{array}{l}\text { Intervention } \\
\text { group } \\
\text { Providers } \\
\text { not included }\end{array}$ & $\begin{array}{l}\text { after } \\
\text { consultation, } \\
\text { determine } \\
\text { the impact } \\
\text { of SDM on } \\
\text { decisional } \\
\text { regret in first } \\
3 \text { months } \\
\text { following } \\
\text { decision to } \\
\text { terminate } \\
\text { pregnancy }\end{array}$ & & $\begin{array}{l}\text { trained in } \\
\text { SDM } \\
\text { Routine care } \\
\text { (termination } \\
\text { recommende } \\
\text { d, one-way } \\
\text { flow of } \\
\text { information) }\end{array}$ & \\
\hline $\begin{array}{l}\text { Prabhu et } \\
\text { al. }^{29} \\
2017 \\
\text { United } \\
\text { States }\end{array}$ & $\begin{array}{l}\mathrm{N}=50 \text {, } \\
\text { women who } \\
\text { had } \\
\text { cesarean } \\
\text { birth } \\
\text { Providers } \\
\text { not included }\end{array}$ & $\begin{array}{l}\text { Assess the } \\
\text { effect of } \\
\text { interactive } \\
\text { SDM session } \\
\text { with two } \\
\text { trained } \\
\text { providers } \\
\text { using a DA } \\
\text { on a tablet } \\
\text { helping } \\
\text { women } \\
\text { choose the } \\
\text { number of } 5 \\
\text { mg } \\
\text { oxycodone } \\
\text { tablets to be } \\
\text { prescribed at } \\
\text { discharge }\end{array}$ & $\begin{array}{l}\text { Post-intervention } \\
\text { questionnaire, } \\
\text { medical record } \\
\text { review of } \\
\text { prescription refill } \\
\text { requests } \\
\text { Review of medical } \\
\text { records for } \\
\text { prescriptions; } \\
\text { questionnaire } \\
\text { measuring } \\
\text { satisfaction with } \\
\text { outpatient pain } \\
\text { management }\end{array}$ & $\begin{array}{l}10 \text { minute } \\
\text { SDM session } \\
\text { with clinician } \\
\text { who } \\
\text { reviewed } \\
\text { information } \\
\text { verbally while } \\
\text { the woman } \\
\text { viewed tablet } \\
\text { based DA; } \\
\text { women } \\
\text { chose the } \\
\text { number of } \\
\text { tablets (0-40) } \\
\text { of oxycodone } \\
\text { Routine care }\end{array}$ & $\begin{array}{l}\text { Fewer refill } \\
\text { requests, } 90 \% \text { of } \\
\text { women reported } \\
\text { being satisfied with } \\
\text { outpatient pain } \\
\text { management }\end{array}$ \\
\hline $\begin{array}{l}\text { Torigoe \& } \\
\text { Shorten }^{30} \\
2018 \\
\text { Japan }\end{array}$ & $\begin{array}{l}\mathrm{N}=33, \\
\text { currently } \\
\text { pregnant } \\
\text { women } \\
\text { eligible for } \\
\text { vaginal birth } \\
\text { after } \\
\text { cesarean } \\
\text { (VBAC) } \\
\text { Providers } \\
\text { not included }\end{array}$ & $\begin{array}{l}\text { Translate } \\
\text { and } \\
\text { culturally } \\
\text { adapt a } \\
\text { decision aid } \\
\text { for use in } \\
\text { Japan and } \\
\text { integrate it } \\
\text { into a } \\
\text { decision } \\
\text { coaching } \\
\text { strategy for } \\
\text { use with } \\
\text { decisions } \\
\text { about mode } \\
\text { of delivery }\end{array}$ & $\begin{array}{l}\text { Mixed methods: } \\
\text { quantitative } \\
\text { measures for } \\
\text { knowledge and } \\
\text { decisional conflict; } \\
\text { qualitative interviews } \\
\text { and thematic } \\
\text { analysis exploring } \\
\text { women's experience } \\
\text { of decision making } \\
\text { Decisional Conflict } \\
\text { Scale Japanese } \\
\text { version; Knowledge } \\
\text { Score; Birth } \\
\text { Preference Scale }\end{array}$ & $\begin{array}{l}\text { Birth Choices } \\
\text { DA plus } \\
\text { decision } \\
\text { guide for } \\
\text { assessment } \\
\text { and decision } \\
\text { discussions } \\
\text { (one-page } \\
\text { interview } \\
\text { guide) } \\
\text { Routine care }\end{array}$ & $\begin{array}{l}\text { Number of women } \\
\text { with high decisional } \\
\text { conflict scores } \\
\text { decreased; } \\
\text { knowledge scores } \\
\text { increased overall; } \\
\text { mean value for } \\
\text { strength of } \\
\text { woman's birth } \\
\text { preference before } \\
\text { and after } \\
\text { intervention } \\
\text { increased; However } \\
\text { mean decision } \\
\text { score remained } \\
\text { high and there was } \\
\text { no significant } \\
\text { change in feelings } \\
\text { of certainty }\end{array}$ \\
\hline
\end{tabular}


Interventions included the use of the Three Questions Intervention (1)"What are my options?", 2) "What are the possible benefits and harms of those options?", and 3) "How likely are each of those benefits and harm to happen to me?") ${ }^{23}$, an online survey that used different scenarios to gauge involvement in and encouragement of shared decision making ${ }^{26}$, and multi-faceted decision support strategies. ${ }^{24,27-31}$

Decision support strategies consisted of one-on-one decision coaching sessions with a provider or research team member who had prior training in decision support as well as a decision aid that was designed or adapted for the particular situation. Howard and Clark's was the only study that focused on provider training in shared decision making as the primary intervention. ${ }^{25}$

While the included studies shared a similar purpose (to evaluate the effectiveness of their specific shared decision-making strategy), the measured effects and outcomes varied. The studies examined 3 primary areas: first, the impact on women, including their perception of shared decision making ${ }^{23,26,29}$, and their experience of making decisions, in terms of decisional control, decisional conflict, and decisional regret ${ }^{27,28,31}$; second, the impact on perinatal outcomes, such as mode of birth, continuation of pregnancy, or choices regarding embryo transfer during in-vitro fertilization ${ }^{28,30,31}$; and third, the impact on providers, including changes in medical practice variation ${ }^{24}$, and providers' satisfaction with the implementation of a shared decision-making strategy ${ }^{25,27}$.

\section{Impact of Shared Decision Making: Women's Experiences Perception of Shared Decision Making}

The one study that evaluated women's perceptions of shared decision making did not show statistically significant results after a specific shared decision making strategy was implemented. ${ }^{23}$ Baijens et al. introduced the Three Questions Intervention to women who were admitted to inpatient obstetric wards for pregnancy or postpartum complications. ${ }^{23}$ Women were given cards with the 3 questions written down and the women were asked to use the prompt to ask questions during ward rounds. The researchers used the Shared Decision Making Questionnaire (SDM-Q-9) to evaluate the women's perceptions of shared decision making during their interactions with their obstetric providers. The SDM-Q-9 is a validated tool that has good acceptance, consistency and reliability, and asks 9 questions relevant to shared decision making such as "My doctor made it clear that a decision needs to be made". ${ }^{32}$ While the use of the 3 questions did stimulate women to seek more, and more specific information, Baijens et al. found that the SDM-Q-9 scores were not statistically different between the women in the intervention and control groups, indicating that perception of shared decision making was unaffected by use of the three question strategy.

\section{Decisional Evaluation}

Four of the studies ${ }^{27,28,30,31}$ examined women's experiences of decision making, including decisional conflict and decisional regret. Van Peperstraten et al. evaluated what they termed a "multi-faceted empowerment strategy" based on decision coaching and a shared decision making framework. They used multiple surveys which measured selfefficacy, knowledge, satisfaction/uncertainty of decision making, informed choice, 


\section{4|Chapter 6}

decision control, anxiety and depression. ${ }^{31, ~ p .2}$ Scores of decision control (defined as feelings of regret, anxiety, and fright at making a decision) and satisfaction/uncertainty (defined as feeling satisfied or doubtful with their decision) showed no difference between couples who received the empowerment strategy and those who did not. Couples in the intervention group did report feeling more informed compared with the control group.

Moore et al., Moudi et al., and Torigoe et al. used the validated Decision Conflict Scale ${ }^{33}$ to explore perceptions of uncertainty about options, including feeling uninformed, uncertainty related to personal values, and feelings of lack of support in decision making. In Moore et al.'s survey of women at risk for extreme preterm birth, the women who received a decision coaching session with a neonatologist trained in decision coaching had decreased decisional conflict across all subdomains. ${ }^{27}$ The greatest difference in decisional conflict scores occurred in the subdomain of feeling informed. Moudi et al.'s evaluation of women whose fetuses were diagnosed with ß-Thalassemia Major and who received a decision coaching session showed statistically significantly lower mean decisional conflict scores compared with women who did not receive decisional coaching. ${ }^{28}$ The largest difference was in the subdomain of feeling informed, similar to Moore et al.'s findings. In addition, while women in the intervention group had lower decisional regret scores overall, there were a few women in the intervention group who expressed significant decisional regret and would not choose the same option (termination of pregnancy) again. Reasons for their regret included issues such as concerns for future fertility and adverse physical experiences but did not include lack of information or feeling uninformed. Torigoe et al. also used the Decision Conflict Scale to examine decision making for women facing the choice of mode of birth after prior cesarean birth, with the intervention group participating in a shared decision making support session. In this study, there was a statistically significant decrease in overall decisional conflict scores after the shared decision making session. As with the Moudi et al. and Moore et al. studies, the greatest decrease occurred in the subdomain of feeling informed. However, there was no significant change in the subdomain of feeling certainty, suggesting that feelings of doubt remained despite an increase in knowledge.

\section{Impact of Shared Decision Making: Outcomes Perinatal Outcomes and Practice Variation}

Six studies $24,26,27,29-31$ included discussion of the perinatal outcome related to the decision being made. Although most of the studies were not necessarily designed to measure change in a particular outcome, they showed minimal, if any, effect on actual perinatal outcomes. Miller and Holdaway's study and Torigoe and Shorten's study looked at birth preference for mode of birth after prior cesarean birth. ${ }^{26,30}$ While neither study looked directly at the number of women who, in the end, actually had a VBAC or cesarean birth, the potential rates of VBAC or planned repeat cesarean birth were essentially unchanged. Miller and Holdaway used hypothetical scenarios to demonstrate that while women's preferences for mode of birth was influenced by risk perception (and therefore by providers' risk communication) the decision-making role assumed by the woman did not influence her choice of mode of birth. ${ }^{26}$ Torigoe and Shorten showed that, while the strength of the woman's birth method preference increased after the shared decision 
making intervention, there was minimal change in the number of women desiring VBAC versus planned cesarean birth. ${ }^{30}$

Moore et al. used the Choice Predisposition Scale ${ }^{34}$ to measure participants' propensity for a particular option before and after the shared decision making intervention. ${ }^{27}$ Choice predisposition represents a person's leaning towards selecting a particular option. ${ }^{34}$ They also collected data on the actual choice made by the parents, either intensive care or palliative care for their preterm neonate. They showed that the couples' choice predisposition carried through to the actual choice. The same number of parents who were predisposed to choose palliative care actually did so; there were no changes in this particular perinatal outcome.

Van Peperstraten et al. and Brabers et al. used the same data set to look at the outcome of single embryo transfer versus double embryo transfer for couples seeking invitro fertilization (IVF). ${ }^{24,31}$ Both study teams hypothesized that the shared decisionmaking intervention would reduce the number of double embryo transfers; Van Peperstraten et al. through the lens of perinatal complications associated with double embryo transfers, and Brabers et al. through the lens of provider practice variation. In the van Peperstraten et al. study, $43 \%$ of the intervention group chose single embryo transfer, compared to $32 \%$ in the control group, which was statistically significant, indicating that the shared decision making strategy has a potential effect on this particular perinatal outcome. ${ }^{31}$ In contrast, Brabers et al. found that the shared decision making strategy did not have as great of an effect on practice variation between hospitals. ${ }^{24}$

Prabhu et al. used a decision aid plus decision coaching to review what to expect with regards to pain after a cesarean birth, with the hope that women would choose the lesser amount, and thereby reduce the amount of leftover oxycodone in their community. They demonstrated a statistically significant decrease in the number of oxycodone tablets chosen by women after the shared decision making intervention, while also maintaining a low refill request rate. ${ }^{29}$

\section{Impact of Shared Decision Making: Providers}

Two studies looked at the experience of the providers who participated in or facilitated the shared decision making intervention. ${ }^{25,27}$ In Howard and Clark's study, maternity care providers received a training on shared decision making model for engaging with pregnant women with substance use disorder. ${ }^{25}$ The number of participants who responded that they do use shared decision making ("sometimes" or "yes") increased post training, although this was not statistically significant. ${ }^{25}$ In Moore et al.'s study, 4 neonatologists received training in decision coaching and developed a decision support tool and decision coach guide specifically for their study. The neonatologists completed a satisfaction questionnaire after each consultation $(\mathrm{N}=11)$, and all recommended this shared decision making intervention for any neonatologist who might be supporting women through decision making in the setting of extreme prematurity. ${ }^{27}$ 


\section{6|Chapter 6}

\section{Discussion}

Despite the call to increase the use of shared decision making in maternity care, there are very few studies designed to examine the potential or actual effects of a shared decision making support strategy. Only 9 studies were identified that met the inclusion criteria for this study. These studies involved a diverse array of perinatal situations, examined different aspects shared decision making, and explored different potential effects of shared decision making on women, providers and perinatal outcomes. While they embodied the spirit of shared decision making through their descriptions of women's empowerment through inclusion and support in decision making, particularly through values clarification and information sharing, the studies were not specific in their definition(s) of shared decision making. Different methodologies and tools were used to evaluate the perception of shared decision making and decision-making experiences. In addition, the studies were performed across an international spectrum of healthcare systems. These heterogenous elements contribute to the potential difficulty in performing a systematic review, and highlights the need for better understanding of how to successfully implement shared decision making and what the goal of shared decision making should be.

Our scoping review identified a number of gaps in current research on shared decision making in perinatal care. None of the studies took place during the intrapartum period. Facilitation of person-centered care via shared decision making during labor is inherently challenging, as decisions may need to be made urgently and where the experience of labor may pull a woman's focus away from personal interactions. ${ }^{35}$ In addition, the shared decision making process may need to be more flexible and the providers more nimble in their assessments of the situation and the woman's ability to participate in the shared decision making process during labor. ${ }^{36}$ And yet labor is also a critically important time to assure the inclusion of shared decision making as part of a larger framework encompassing women's satisfaction with their birth experiences, respect for women in birth, and support of an overall culture of safety in perinatal care. Despite these challenges, further research is needed into how shared decision making may be optimally operationalized in the intrapartum setting.

In addition, none of the studies identified involved common perinatal decisionmaking situations such as induction of labor, antenatal fetal surveillance for women more than 35 years of age. Studies, including Miller and Holdaway's study, clearly demonstrate the strong influence of the provider's method of information and risk communication on a woman's choice of mode of birth, and women's reliance upon their providers for accurate, evidence-based information. ${ }^{11,26,37}$ Unfortunately, opportunities for implementing shared decision making are often missed. ${ }^{4,38}$ A study that looked at interactions between maternity care providers and women demonstrated that in the majority of decisions only one option was discussed, indicating that no choice was actually offered. ${ }^{39}$ Research into the development of evidence-based shared decision making strategies that work in conjunction with updated clinical guidelines, which include but are not limited to a decision aid alone, is critical for both providers and women as decisions in maternity care increase in complexity and providers are implored to use such strategies. 
In the studies included in this scoping review, shared decision making appeared to have a positive effect on decisional conflict and decisional regret, but less so on decisional certainty. Decisional conflict represents a state of uncertainty regarding decision making, and may be exacerbated by feeling uninformed, feeling unclear about one's personal values, or feeling unsupported or pressured to make a choice. These cognitive factors are independent of the complexity or difficulty of the decision choice itself. ${ }^{33}$ As seen in these studies, the communication of accurate, evidence-based information has the potential to significantly decrease decisional conflict. Studies examining women's satisfaction in birth consistently demonstrate the importance of the respectful communication of accurate, unbiased information $37,40,41$

However, shared decision making strategies may have less of an impact on the subdomain of certainty, a feeling of having made the right decision. These studies shed light on the complexity of the emotional experiences inherent in these decisions and which continues to evolve over time, as well as the inability to predict with absolute certainty a clinical outcome. Fundamentally, shared decision making is a process, one that should be repeated and recycled as much or as often as women need, with the hope of minimizing the potential adverse effects of decisional conflict and regret. Research studies that use the same measures for evaluating women's experiences of decisional conflict, decisional regret, and certainty are needed. In particular, tools are needed that are validated for the use in maternity care and which may be used across countries and in different healthcare systems.

This scoping review had several limitations. Despite the use of broad search terms, the inclusion criteria was narrowed to only allow studies that clearly used a shared decision-making strategy as the intervention, which may have excluded some relevant studies. In addition, if the abstract or title described only a decision aid as the intervention, then it was excluded and the full text was not reviewed. This may have excluded relevant studies that used a multi-faceted decision support strategy that was not clearly articulated. The exclusion of non-English language studies may have cause some articles not to be included, particularly as at least one of the measurement tools used (SDM-Q-9) has been translated into and validated in multiple languages. Last, we were unable identify studies which explicitly articulated or examined the involvement of midwives in the shared decision making intervention strategy. This may have excluded relevant studies involving midwives or midwifery care.

\section{Conclusion}

Shared decision making is process through which women and midwives exchange information, explore preferences, and make choices. It has great potential to assist midwives and women to negotiate medically and emotionally complex perinatal decisions. Implementation of a shared decision making strategy may reduce decisional conflict and regret, although more studies are needed to better understand the impact of such strategies. In the studies included in this scoping review, the perception of feeling informed was the most studied outcome of shared decision making interventions, highlighting the importance of sharing accurate, evidence-based information with women. However, the studies were limited and did not include common perinatal situations such 


\section{$108 \mid$ Chapter 6}

as decisions regarding induction of labor, nor did the studies occur in the intrapartum setting. This highlights the need for more research into the development of clearly defined goals of shared decision making interventions, including specific perinatal outcomes and impact on costs. In addition, more research is needed that examines and includes the use of tools and scales that have been validated for maternity care settings. Clear guidance and strategies for successfully integrating shared decision making and practice recommendations are needed. 


\section{The impact of shared decision-making in perinatal care, a scoping review|109}

References

1. Håkansson Eklund J, Holmström IK, Kumlin T, et al. "Same same or different?" A review of reviews of person-centered and patient-centered care. Patient Education and Counseling. 2019;102(1):3-11. doi:10.1016/J.PEC.2018.08.029

2. Winn K, Ozanne E, Sepucha K. Measuring patient-centered care: An updated systematic review of how studies define and report concordance between patients' preferences and medical treatments. Patient Education and Counseling. 2015;98(7):811-821. doi:10.1016/J.PEC.2015.03.012

3. Rowe RE, Garcia J, Macfarlane AJ, Davidson LL. Improving communication between health professionals and women in maternity care: A structured review. Health Expectations. Published online 2002. doi:10.1046/j.1369-6513.2002.00159.x

4. Pollard S, Bansback N, Bryan S. Physician attitudes toward shared decision making: A systematic review. Patient Education and Counseling. Published online 2015. doi:10.1016/j.pec.2015.05.004

5. American College of Nurse-Midwives. Shared Decision Making in Midwifery Care.; 2016. http://midwife.org/ACNM/files/ACNMLibraryData/\%ODUPLOADFILENAME/000000000305/SharedDecision-Making-in-\%0DMidwifery-Care-10-13-17.pdf. December 2016.

6. Elwyn G, Frosch D, Thomson R, et al. Shared decision making: A model for clinical practice. Journal of General Internal Medicine. 2012;27(10):1361-1367. doi:10.1007/s11606-012-2077-6

7. Declercq ER, Sakala C, Corry MP, Applebaum S, Herrlich A. Listening to mothers III: Pregnancy and birth. Journal of Perinatal Education. Published online 2014. doi:10.1891/1058-1243.23.1.9

8. Bohren MA, Vogel JP, Hunter EC, et al. The Mistreatment of Women during Childbirth in Health Facilities Globally: A Mixed-Methods Systematic Review. PLoS Medicine. Published online 2015. doi:10.1371/journal.pmed.1001847

9. Koblinsky M, Moyer CA, Calvert C, et al. Beyond too little, too late and too much, too soon: a pathway towards evidence-based, respectful maternity care worldwide. The Lancet. Published online 2016. doi:10.1016/S0140-6736(16)31333-2

10. Attanasio LB, Kozhimannil KB, Kjerulff KH. Factors influencing women's perceptions of shared decision making during labor and delivery: Results from a large-scale cohort study of first childbirth. Patient Education and Counseling. 2018;101(6):1130-1136. doi:10.1016/j.pec.2018.01.002

11. Moore JE. Women's voices in maternity care: The triad of shared decision making, informed consent, and evidence-based practices. Journal of Perinatal and Neonatal Nursing. 2016;30(3):218-223. doi:10.1097/JPN.0000000000000182

12. Coates D, Thirukumar P, Spear V, Brown G, Henry A. What are women's mode of birth preferences and why? A systematic scoping review. Women and Birth. Published online 2019. doi:10.1016/j.wombi.2019.09.005

13. National Partnership for Women \& Families. Blueprint for Advancing High-Value Maternity Care Through Physiologic Childbearing.; 2018. Accessed February 15, 2020.

https://www.nationalpartnership.org/our-work/resources/health-care/maternity/blueprint-foradvancing-high-value-maternity-care.pdf

14. Birth Tools. Reducing Primary Cesareans. Accessed February 15, 2020. https://www.birthtools.org/Shared-Decision-Making

15. Grobman W. A randomized trial of elective induction of labor at 39 weeks compared with expectant management of low-risk nulliparous women. The American Journal of Obstetrics \& Gynecology. 2018;218(1):S601. doi:10.1016/j.ajog.2017.12.016

16. Chappell LC, Brocklehurst P, Green ME, et al. Planned early delivery or expectant management for late preterm pre-eclampsia (PHOENIX): a randomised controlled trial. The Lancet. Published online 2019. doi:10.1016/S0140-6736(19)31963-4

17. American College of Obstetricians and Gynecologists. Prevention of Group B Streptococcal Early-Onset Disease in Newborns: ACOG Committee Opinion, Number 782. Obstetrics and Gynecology. 2019;134(1):E19-E40. doi:10.1097/AOG.0000000000003334

18. Vlemmix F, Warendorf JK, Rosman AN, et al. Decision aids to improve informed decision-making in pregnancy care: A systematic review. BJOG: An International Journal of Obstetrics and Gynaecology. 2013;120(3):257-266. doi:10.1111/1471-0528.12060

19. Arksey H, O'Malley L. Scoping studies: Towards a methodological framework. International Journal of Social Research Methodology: Theory and Practice. 2005;8(1):19-32. doi:10.1080/1364557032000119616

20. Peters MDJ, Godfrey CM, Khalil H, Mclnerney P, Parker D, Soares CB. Guidance for conducting systematic scoping reviews. International Journal of Evidence-Based Healthcare. 2015;13(3):141-146. doi:10.1097/XEB.0000000000000050 


\section{0|Chapter 6}

21. Tricco AC, Lillie E, Zarin W, et al. PRISMA extension for scoping reviews (PRISMA-ScR): Checklist and explanation. Annals of Internal Medicine. 2018;169(7):467-473. doi:10.7326/M18-0850

22. Liberati A, Altman DG, Tetzlaff J, et al. The PRISMA statement for reporting systematic reviews and metaanalyses of studies that evaluate health care interventions: explanation and elaboration. Journal of clinical epidemiology. 2009;62(10):e1-e34. doi:10.1016/j.jclinepi.2009.06.006

23. Baijens SWE, Huppelschoten AG, van Dillen J, Aarts JWM. Improving shared decision-making in a clinical obstetric ward by using the three questions intervention, a pilot study. BMC Pregnancy and Childbirth. 2018;18(1). doi:10.1186/s12884-018-1921-z

24. Brabers AEM, van Dijk L, Groenewegen PP, van Peperstraten AM, de Jong JD. Does a strategy to promote shared decision-making reduce medical practice variation in the choice of either single or double embryo transfer after in vitro fertilisation? A secondary analysis of a randomised controlled trial. BMJ Open. 2016;6(5). doi:10.1136/bmjopen-2015-010894

25. Howard H, Clark K. Interprofessional Shared Decision Making for Pregnant Women with Opioid Use: Results from a Provider Training. Current Women's Health Reviews. 2017;13(2):121-129. doi:10.1001/jama.1991.03460120043033

26. Miller YD, Holdaway W. How communication about risk and role affects women's decisions about birth after caesarean. Patient Education and Counseling. Published online 2019. doi:10.1016/j.pec.2017.09.015

27. Moore GP, Lemyre B, Daboval T, et al. Field testing of decision coaching with a decision aid for parents facing extreme prematurity. Journal of Perinatology. 2017;37(6):728-734. doi:10.1038/jp.2017.29

28. Moudi Z, Phanodi Z, Ansari H, Zohour MM. Decisional conflict and regret: Shared decision-making about pregnancy affected by $\beta$-thalassemia major in Southeast of Iran. Journal of Human Genetics. Published online 2018. doi:10.1038/s10038-017-0379-6

29. Prabhu M, McQuaid-Hanson E, Hopp S, et al. A Shared Decision-Making Intervention to Guide Opioid Prescribing after Cesarean Delivery. Obstetrics and Gynecology. 2017;130(1):42-46. doi:10.1097/AOG.0000000000002094

30. Torigoe I, Shorten A. Using a pregnancy decision support program for women choosing birth after a previous caesarean in Japan: A mixed methods study. Women and Birth. 2018;31(1):e9-e19. doi:10.1016/j.wombi.2017.06.001

31. van Peperstraten A, Nelen W, Grol R, et al. The effect of a multifaceted empowerment strategy on decisionmaking about the number of embryos transferred in in vitro fertilisation: Randomised controlled trial. BMJ (Online). 2010;341(7775):712. doi:10.1136/bmj.c2501

32. Kriston L, Scholl I, Hölzel L, Simon D, Loh A, Härter M. The 9-item Shared Decision Making Questionnaire (SDM-Q-9). Development and psychometric properties in a primary care sample. Patient Education and Counseling. 2010;80(1):94-99. doi:10.1016/j.pec.2009.09.034

33. O'Connor AM. User Manual - Decisional Conflict Scale.; 1993. doi:10.1177/0272989X9601600114

34. O'Connor AM. User Manual - Measure of Decision/Choice Predisposition.

35. Nieuwenhuijze MJ, Korstjens I, de Jonge A, de Vries R, Lagro-Janssen A. On speaking terms: A Delphi study on shared decision-making in maternity care. BMC Pregnancy and Childbirth. 2014;14(1):1-11. doi:10.1186/1471-2393-14-223

36. Nieuwenhuijze MJ, Low LK, Korstjens I, Lagro-Janssen T. The role of maternity care providers in promoting shared decision making regarding birthing positions during the second stage of labor. Journal of Midwifery and Women's Health. 2014;59(3):277-285. doi:10.1111/jmwh.12187

37. Bringedal $\mathrm{H}$, Aune I. Able to choose? Women's thoughts and experiences regarding informed choices during birth. Midwifery. 2019;77:123-129. doi:10.1016/j.midw.2019.07.007

38. Declercq ER, Cheng ER, Sakala C. Does maternity care decision-making conform to shared decisionmaking standards for repeat cesarean and labor induction after suspected macrosomia? Birth. 2018;45(3):236-244. doi:10.1111/birt.12365

39. Garrard F, Ridd M, Narayan H, Montgomery AA. Decisions, choice and shared decision making in antenatal clinics: An observational study. Patient Education and Counseling. 2015;98(9):1106-1111. doi:10.1016/j.pec.2015.04.004

40. Mattison CA, Dion ML, Lavis JN, Hutton EK, Wilson MG. Midwifery and obstetrics: Factors influencing mothers' satisfaction with the birth experience. Birth. 2018;45(3):322-327. doi:10.1111/birt.12352

41. Lou S, Hvidman L, Uldbjerg N, et al. Women's experiences of postterm induction of labor: A systematic review of qualitative studies. Birth. Published online 2019. doi:10.1111/birt.12412 
The impact of shared decision-making in perinatal care, a scoping review|111 
112|Chapter 6 


\section{CHAPTER 7}

Choosing to Decline: Finding Common Ground through the Perspective of Shared Decision Making

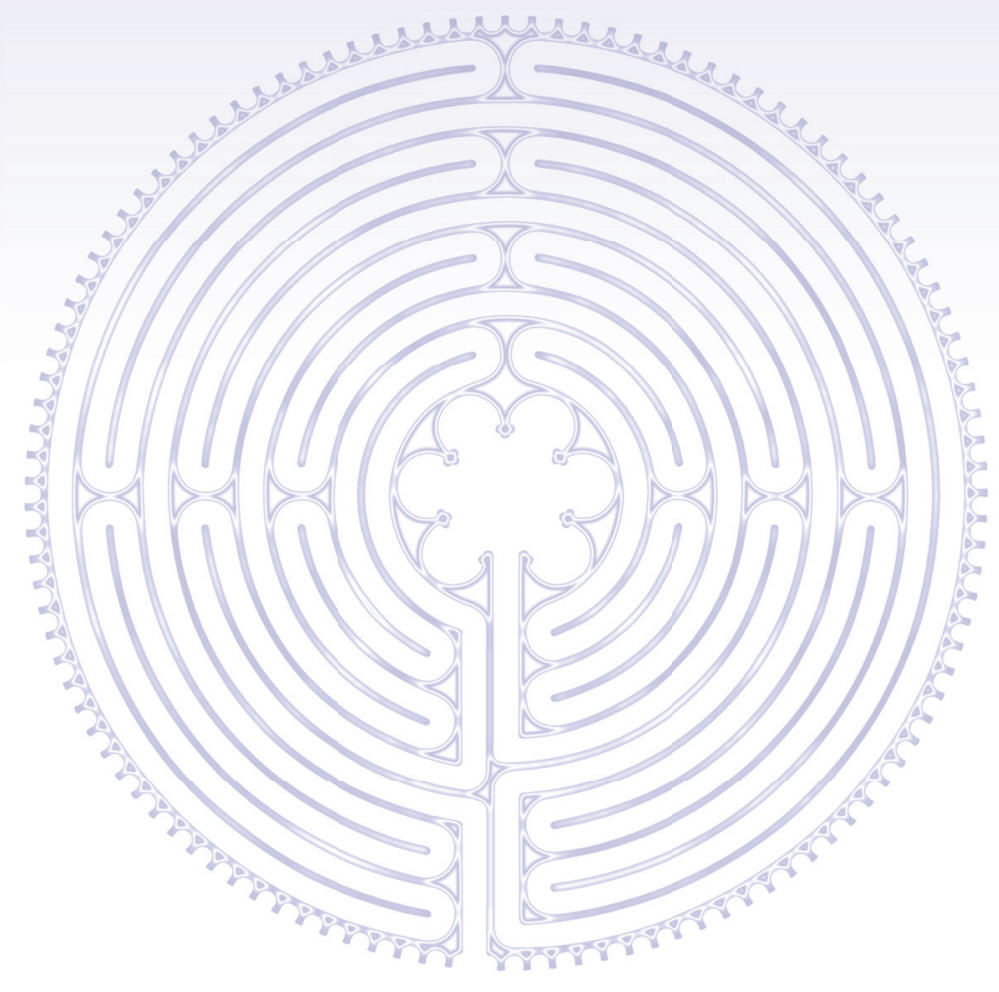

Michele Megregian, Marianne Nieuwenhuijze

Journal of Midwifery \& Women's Health. 2018 May;63(3):340-346 


\title{
$114 \mid$ Chapter Seven
}

\begin{abstract}
Respectful communication is a key component of any clinical relationship. Shared decision-making is the process of collaboration that occurs between a health care provider and patient in order to make healthcare decisions based upon the best available evidence and the individual's preferences. A midwife and woman (and her support persons), engage together to make healthcare decisions, using respectful communication that is based upon the best available evidence and the woman's preferences, values, and goals. Supporting a woman's autonomy, however, can be particularly challenging in maternity care when recommended treatments or interventions are declined. In the past, the real or perceived increased risk to a woman's health or that of her fetus as a result of that choice has occasionally resulted in coercion. Through the process of shared decisionmaking, the woman's autonomy may be supported, including the choice to decline interventions. The case presented here demonstrates how a shared decision-making framework can support the provider-patient relationship in the context of informed refusal.
\end{abstract}

\section{Keywords}

patient refusal, informed refusal, informed consent, shared decision-making, patientcentered communication, midwifery, maternity care 


\section{Case}

AJ was a 38-year-old gravida 1 para 0 woman at 26 weeks gestation being seen for routine prenatal care. She was healthy and did not have a history of major illnesses or other obstetric risk factors. Her pre-pregnant BMI was $29 \mathrm{~kg} / \mathrm{m}^{2}$. She consumed a vegetarian diet and completed a marathon the year prior to pregnancy. At the 26-week prenatal visit the midwife recommended testing for gestational diabetes (GDM). The midwife discussed the test recommendations per the International Association of Diabetes and Pregnancy Study Group (IADPSG), consisting of a 2-hour oral glucose tolerance test (OGTT). ${ }^{1}$ The midwife reviewed information about the risks and benefits for testing and treatment of GDM, and gave AJ a pamphlet about the topic. After discussing the recommendation with the midwife and her family, AJ declined GDM testing, as she did not believe she was at risk for GDM due to her healthy lifestyle and lack of risk factors. She expressed concerns about the accuracy of the test and she related an objection to ingesting the glucose drink. The midwife presented the evidence for the IADPSGrecommended testing, explored $A J^{\prime}$ 's understanding of GDM testing and treatment, her values, preferences, and goals related to GDM testing, and the midwife reiterated her recommendation in favor of testing. AJ again declined, and her decision and rationale for declining GDM testing was reviewed at subsequent prenatal visits and documented in the electronic health record. Her pregnancy course continued without complications, with appropriate weight gain, fundal height measurements, and fetal growth. AJ was admitted to the hospital for induction of labor at 41 3/7 weeks' gestation, with a Bishop score of 4 . After a multi-day induction of labor that included multiple doses and methods of cervical ripening followed by oxytocin infusion, AJ gave birth to a female who weighed 8 pounds 4 ounces, via primary cesarean birth that was performed secondary to arrest of dilatation at $8 \mathrm{~cm}$ dilatation. (This case report is a composite of elements from different patients.)

\section{Introduction}

Collaboration through a shared decision-making process is a fundamental component of the interaction between clients and health care providers. A midwife and woman (and her support persons), engage together to make healthcare decisions, using respectful communication that is based upon the best available evidence and the woman's preferences, values, and goals. ${ }^{2}$ Shared decision-making is a model for decision-making in situations where the choice of intervention is determined by the preference of the patient. Shared decision-making seeks to improve the decision-making process by attempting to balance provider beneficence and patient autonomy through the clear and thorough transmission of information, exploration and clarification of a patient's values and preferences, and understanding of risk. In the end, the patient has the ultimate decisional authority. ${ }^{3}$ Shared decision-making, informed consent and related terms are defined in Table 1. 


\begin{tabular}{|c|c|}
\hline \multicolumn{2}{|c|}{$\begin{array}{l}\text { Table } 1 \\
\text { Definitions of Key Concepts }\end{array}$} \\
\hline Informed Consent & $\begin{array}{l}\text { A competent individual's intentional and voluntary authorization of a medical } \\
\text { intervention, given through a process where a provider discloses information } \\
\text { regarding the risks and benefits of the proposed intervention }{ }^{7}\end{array}$ \\
\hline Informed Refusal & $\begin{array}{l}\text { The corollary to informed consent, whereby the individual declines to provide } \\
\text { authorization for a proposed medical intervention }{ }^{4}\end{array}$ \\
\hline Informed Choice & $\begin{array}{l}\text { A deliberative process by which an individual makes a decision for or against a } \\
\text { proposed intervention based upon good knowledge and understanding, with } \\
\text { little or no decisional conflict and consistent with their values }{ }^{34}\end{array}$ \\
\hline Shared Decision-Making & $\begin{array}{l}\text { A deliberative process of active engagement and collaboration between a } \\
\text { provider and individual, which explores the available options of medical } \\
\text { interventions for a particular condition, in order to implement a plan based } \\
\text { upon the best available evidence and congruent with the individual's } \\
\text { preferences, values, and needs }{ }^{8}\end{array}$ \\
\hline $\begin{array}{l}\text { Preference-Sensitive } \\
\text { Condition }\end{array}$ & $\begin{array}{l}\text { A condition which has more than one clinically appropriate option. The choice } \\
\text { to be implemented is determined by the patient's values, goals, and } \\
\text { preferences. }\end{array}$ \\
\hline Situation of Equipoise & $\begin{array}{l}\text { The situation in which preference-sensitive conditions are conveyed by the } \\
\text { provider in an open manner, where the provider does not have a clear } \\
\text { preference about the choice of intervention. }{ }^{35}\end{array}$ \\
\hline
\end{tabular}

When a woman declines recommended evaluations or treatments during the course of prenatal care, the clinical relationship between the midwife and woman can be challenged. ${ }^{4}$ The process of shared decision-making, in these situations, can be further challenged by the uncertainty that accompanies recommendations which are based on limited evidence. A 2011 analysis of Practice Bulletins published by the American College of Obstetricians and Gynecologists (ACOG) found that, for obstetric recommendations, only $25.5 \%$ were assigned Category A, good evidence to support the recommendation. Almost $40 \%$ of recommendations were based on Category B evidence (fair evidence to support the recommendation), and almost $35 \%$ were based on insufficient evidence. ${ }^{5}$ In addition, decision-making often centers on the choice of expectant management versus interventions aimed at decreasing risk of potential adverse outcomes. The relative risks of these two options, and differences in fetal/neonatal risks or maternal consequences related to these risks may be difficult to compare. ${ }^{6}$ Shared decision-making, in situations of both certain and uncertain evidence, can help to uphold a woman's autonomous choice to accept or decline interventions, and the risks of coercion, bullying or abandonment mitigated. The case presented here offers the opportunity to examine the manner in which the framework of shared decision-making can help to alleviate potential ethical threats to both a woman's autonomy and the midwife's professional integrity.

\section{Autonomy, Informed Consent, and Informed Refusal}

A core philosophical belief in patient-centered care is the respect for autonomy, defined as recognition of the undeniable right of a legally competent person to accept or decline medical care or intervention. ${ }^{7}$ Informed consent is considered the embodiment of respect for autonomy. ${ }^{8}$ As medical conditions and treatment options have become increasingly 
complex, so has the process of informed consent. Incidental findings, complex medical concepts that can be difficult to understand, and individual risk perception are some of the elements that contribute to the complexity of the informed consent process. ${ }^{4}$ In addition, when the process of deliberating about a medical intervention is termed informed consent, there is an underlying assumption that consent will be the outcome of the process.

\section{Informed Refusal}

Situations in which competent individuals decline medical care that is recommended to advance or preserve their well-being can be especially complex or challenging when values, opinions, emotions and interests between health care providers and clients diverge. Informed refusal may be viewed simply as the corollary to informed consent. (Table 1) The same process is involved - the woman receives information about the risks, benefits and alternatives, and instead of accepting an intervention, the woman declines. However, the processes of informed consent and informed refusal may not, in fact, be symmetric. ${ }^{9}$ The way in which information is presented may be influenced by the provider's anticipation of consent or refusal. When a woman reveals her intention to decline an intervention, the health care provider may frame risks differently or deemphasize alternatives. ${ }^{9}$

\section{Coercion}

The ramifications of accepting or declining a particular intervention can have long-term effects on the health and wellbeing of the individual, and in maternity care, the fetus or newborn may also be affected. ${ }^{4}$ Although maternity care providers have a professional obligation to support maternal autonomy, perceived increased risk to the fetus by the woman's choice has led to forced compliance with providers' recommendations, including forced incarceration and surgery. ${ }^{10}$ In a review of legal databases in the United States, Paltrow et al found 413 cases between 1973-2005 in which a woman's pregnancy was the primary reason for the compromise of her autonomy..$^{10} \operatorname{In} 2014$, the case of a woman with a history of two cesarean births who desired a subsequent vaginal birth and instead had a forced repeat cesarean birth garnered media attention. ${ }^{11}$ This and other incidents of forced or coerced procedures have brought increased attention to obstetrical violence globally. ${ }^{12,13}$

Even without the extreme circumstances of forced cesarean birth or incarceration, the lines between forced compliance, coercive counseling, and respectful persuasion can be blurred. The ACOG Committee Opinion on refusal of care explicitly states that coercion is ethically impermissible. ${ }^{4}$ But what constitutes coercion may be a matter of perspective. For example, in the case presented here, the midwife, by revisiting $A J$ 's declination of GDM screening at each visit, may think she is honoring AJ's autonomy, as well as offering her an opportunity to change in her decision. AJ, however, may view the midwife's efforts as not respecting her decision, or could feel like badgering, a coercive effort to diminish AJ's autonomy. 
During prenatal care, when a woman refuses recommended care, the midwife may feel vulnerable, both medico-legally and personally. A recommended medical intervention (including a screening test, diagnostic test, or procedure), presented in good faith, represents the midwife's perception of the best interests of woman and her fetus, based on the midwife's clinical reasoning, which consists of a mélange of evidence-based knowledge, experience, and prevailing guidelines. ${ }^{14} \mathrm{~A}$ study involving Australian midwives and obstetricians reported feelings of anxiety and stress related to the potential consequences, in terms of medico-legal liability and poor outcomes, of continuing to provide care to women who declined recommended interventions. ${ }^{15}$ Some of the midwives interviewed spoke not only about their support of maternal autonomy and choice despite the increased stressors, but also described the limitations of that support. They expressed a commitment to maternal autonomy but compromised that autonomy through the messaging that access to care was conditional upon compliance with their recommendations. ${ }^{15}$ The experiences of midwives in the United States in caring for women who decline recommended interventions has not yet been examined.

\section{Shared Decision-Making}

The concept of shared decision-making evolved from the research and quality assurance arenas and was first defined in a 1982 report by the Presidents Commission for the Study of Ethical Problems in Medicine and Biomedical and Behavioral Research as a dialog between providers and patients regarding a course of treatment, emphasizing the importance of and mutual respect for their individual perspectives. ${ }^{16}$ In the process of shared decision-making, the provider shares high quality, evidence-based information and supports the patient through the decision-making process. The patient shares preferences, values, and goals related to the current medical situation and choices to be made. Shared decision making is a dynamic process that includes allowing for and support of a patient's reaction to information and deliberation of choices. ${ }^{3}$ This process emphasizes the role of autonomy as a counter to the history of paternalism and lack of patient involvement in their own healthcare. ${ }^{16}$

Shared decision-making consists of three elements: first, the patient should meet the clinical criteria for the test or intervention proposed. Second, a decision aid for values and preference clarification should be used if available. A decision aid is a tool developed specifically to assist the decision-making process through values clarification, with detailed focus on options and outcomes. ${ }^{17}$ A 2014 Cochrane Collaboration review on the effect of decision aids for persons facing healthcare decisions found that the use of decision aids increased the accuracy of risk perception, increased the likelihood that choices would be made in congruence with patient's values, improved patient-provider communication, decreased decisional conflict, and decreased passive decision-making. ${ }^{17}$ Lastly, the condition should be preference sensitive, where multiple options for treatment are clinically appropriate and the expected outcomes are analogous. This is also described as a situation of equipoise.$^{18}$ When these criteria are met, the framework of shared decision-making creates the opportunity for the woman's preferences to determine which option is chosen. 
As initially conceived, the shared decision-making process was based upon the idea that the essential outcomes would likely be equivalent. In this type of situation, the available options are clinically appropriate, allowing the individual's preference to determine the choice of intervention, even as the interventions may carry different risks or side effects. For example, for a woman who desires contraception (and is clinically appropriate), the choice between the copper intrauterine device versus the levonorgestrel-releasing intrauterine system may be based upon her acceptance or rejection of the possible side effects, while both devices provide the equivalent long-term outcome of contraception.

Despite an overall acceptance of the concept of shared decision-making, practical implementation has lagged due to a number of barriers, including a perception that is difficult to achieve due to lack of time in the clinical encounter and that the clinical workflow is not conducive to its implementation. ${ }^{19}$ In addition, clinicians and policy makers express concerns regarding increased healthcare costs, compatibility with current practice guidelines, and the actual extent to which people desire to participate in the process. ${ }^{20}$

As the concept of shared decision-making has evolved, it has become both broader and more refined..$^{21}$ The initial focus of shared decision-making concentrated on information exchange -- information about options from the provider and information about preferences from the woman. As shared decision-making has become more widely promoted, the relationship and dialog between the woman and provider have become more central, as have ideas regarding what is being shared and decided, the manner of sharing, and the nature of decisional support. ${ }^{21,22}$ When the choices for intervention are no longer in equipoise, for example when one option is inferior with regard to clinical criteria but may be more congruent with the woman's values or life context, then shared decision-making may provide the framework to support meaningful discussions. ${ }^{23}$ Shared decision-making's focus on the elements of conversation allows for the ideas of emotional influence, reassessment of goals and perspectives over time, continued support, and lack of decision as a viable decision, to have an increased presence in the midwife-woman dialog. ${ }^{23}$

\section{Shared Decision-Making in the Setting of Recommended Interventions}

$\mathrm{AJ}^{\prime} \mathrm{s}$ case demonstrates an opportunity to utilize shared decision-making, but without a true situation of equipoise. The recommendation to test for gestational diabetes (GDM) may not be seen as a preference-sensitive intervention. Instead, it is based on clinical evidence that shows a benefit in favor of determining if a woman has GDM. ACOG, the U.S. Preventive Services Task Force (USPSTF), the American Diabetes Association, and the Endocrine Society recommend universal testing for GDM testing for all pregnant women after 24 weeks of gestation. ${ }^{24}$ The evidence for this recommendation is based on increasing evidence of adverse pregnancy outcomes associated with hyperglycemia. ${ }^{24}$ Women diagnosed with GDM have a higher risk of developing preeclampsia and developing diabetes later in life. ${ }^{25}$ In addition, studies have demonstrated that fetal 
exposure to maternal diabetes increases the risk of diabetes and obesity later in life. ${ }^{25}$ When viewed through the lens of potential adverse perinatal outcomes, the options of testing or not may not have equivalent results. If AJ declines testing for GDM, but develops undiagnosed, and therefore untreated GDM, then the perinatal outcomes for herself and her fetus may be very different than if she pursued testing, received a diagnosis of GDM, and engaged in recommended treatment.

The midwife may have the opportunity to engage a multidisciplinary approach to her discourse with AJ, referring her for a consultation with a nutritionist, maternal-fetal medicine specialist, or other member of the healthcare team. ${ }^{4}$ Care must be taken in this case, however, to assure that such an approach enhances communication and collaboration. Referral to another provider should not be viewed by the woman to be coercive nor putative, with the other provider's focus on persuading AJ where the midwife could not. An additional challenge may exist if continuation of the midwife's care is conditional upon AJ's consent for GDM testing. Policies may dictate the extent of the midwife's care under the circumstances of an existing diagnosis of GDM, and this may extend to include women who decline GDM testing. AJ's choice and autonomy may be constrained by these potential limitations.

Although the recommendation for testing for GDM is evidence-based and may not be preference-sensitive ${ }^{24}$, the process of shared decision-making can still be applied because it provides a framework for open communication between AJ and the midwife, which acknowledges the midwife's expertise and guards AJ's choice without coercion. By exploring $\mathrm{AJ}^{\prime}$ 's understanding of the testing, her assessment of her own risk factors, and her motivations, fears, and goals, the midwife could support AJ in finding and exercising her autonomous voice, even if her choice is to decline a recommendation that is supported by the best available evidence.

\section{Shared Decision-Making in the Setting of Uncertainty}

While the recommendation for testing for GDM is based upon clear evidence, the best method of testing has not been determined. Providers may offer a two-step testing strategy that first screens by measuring the plasma glucose level after ingestion of a 50gram glucose beverage then follows with a 3-hour glucose tolerance test if the screening plasma glucose level exceeds a pre-determined cut off value, or the one-step IADPSG testing criteria that measures plasma glucose two hours after ingestion of a 75-gram glucose beverage. No studies have directly compared the two approaches, nor is there consensus regarding the most appropriate diagnostic thresholds for the different glucose tests. ${ }^{25,26}$

For women who are unable to tolerate the 50- or 75-gram glucose load, guidelines for testing and diagnostic thresholds are based on limited data. ${ }^{25}$ There are studies which have assessed food alternatives to the glucose beverage, including a candy bar $^{26}$, candy licorice twists ${ }^{27}$, and jelly beans ${ }^{28}$, although these methods are not considered reliable for detecting hyperglycemia. ${ }^{26}$ Other alternatives include checking a random fasting blood glucose, continuous glucose monitoring, or engaging in one week of self-capillary blood glucose monitoring (SCBG) four times daily. ${ }^{29}$ These 
recommendations, however, are based on expert opinion for the care of women who have had prior bariatric surgery, and it may be difficult to extrapolate the results to a different population. ${ }^{30}$ Thus, for women who are intolerant of the traditional glucose beverage, or who, like AJ, decline the glucose drink, there is a paucity of evidence to guide midwives and women toward appropriate alternatives. This gap in medical knowledge leaves the woman and fetus vulnerable to the adverse effects of hyperglycemia.

The circumstances of AJ's decision to decline GDM testing, and the rationale for her decision, also highlight the challenge of determining which test (or method of testing) should, or could, be presented by the midwife as appropriate. Does the midwife's obligation to inform extend to the provision of detailed information about every possible testing option, including those without clinical evidence to support them? It could be argued that such a disclosure, for example, offering the use of a high-carbohydrate meal as a substitute for the glucose beverage, empowers AJ to make the most informed decision, consistent with her goals. Alternatively, one could argue that inundating women with information and options, without the benefit of the midwife's expertise and discernment, risks abandoning the woman and reinforcing her position of vulnerability. ${ }^{31}$

The process of shared decision-making in the context of unclear evidence, including when the outcome is informed refusal, may demand different skills from midwives. Open, meaningful communication is necessary, but it is also important to consider that clinical uncertainty can cause anxiety for both the midwife and the woman, as the limits of medical knowledge and fragility of predictions are recognized in the shared decision-making process. ${ }^{23}$ The positive predictive value of medical interventions is difficult to apply to individuals. For example, poor outcomes may be over-predicted due to a bias for intervention or under-predicted due to personal optimism. ${ }^{9}$ Midwives may also be asked by women to offer recommendations based upon their experience or upon anecdotal evidence. In this situation, however, the midwife should be clear regarding the basis for the recommendation and open in communication. The limits of clinical evidence require midwives to engage with women in a reflective way, as sharing the burden of decision-making and providing opportunities for debriefing, particularly as the physical, psychological or emotional effects related to the decision may not be initially evident. ${ }^{22}$ Under conditions of uncertain evidence, the dichotomous outcomes of informed consent versus informed refusal may need to be discarded in favor of a more nuanced, complex process of shared decision-making. ${ }^{23}$

\section{Frameworks for Shared Decision-Making Conversations}

Frameworks for respectful patient communication and shared decision-making have been developed. ${ }^{32,33}$ Elwyn et al developed the Three-Talk model to guide shared decisionmaking conversations. Team Talk consists of working together to explore choices and goals. Options Talk explores alternatives utilizing the principles of risk communication. Lastly, Decision Talk implements the decision based upon preferences. ${ }^{19}$ Throughout this process, active listening and space for deliberation play key roles. ${ }^{19}$ Using this framework, 
the midwife and $\mathrm{AJ}$ are partners in exploring the recommendations, alternatives, and evidence regarding GDM testing and methods of testing. They discuss AJ's values, goals, and tolerance for risk, and they endeavor to implement decisions based on AJ's preferences, while supporting $\mathrm{AJ}^{\prime} \mathrm{s}$ autonomy in declining a medically recommended intervention and in making choices when information may be lacking.

Other patient-centered interview techniques, such as the RESPECT model and the 5step Patient-centered Interview endeavor to create an environment of openness and trust, and to balance the differing power positions of the midwife and woman. ${ }^{33}$ The RESPECT model, which stands for rapport, empathy, support, partnership, explanations, cultural competence, and trust, promotes cultural humility and provider awareness of their own biases as methods to establish rapport. ${ }^{33}$

The 5-step patient-centered interview technique is a strategy for enhancing the provider's communication skills through showing comfort and acceptance of discussing difficult topics, and by demonstrating an understanding of the woman's point of view through responsiveness and empathy. ${ }^{33}$ Table 2 provides resources for implementation of shared decision-making. In our case, the midwife can utilize these communication frameworks to set the stage for her conversations with AJ. Through active listening and thoughtful deliberation, the midwife engages $A J$ in a dialog about her hopes related to her pregnancy and birth, how her concerns about the glucose drink stem from the context of her life, and her worries and goals surrounding her decision to decline GDM testing. The midwife carefully and thoroughly documents their conversations in the electronic health record, including $\mathrm{AJ}^{\prime}$ s rationale behind her decision-making. Because they have established trust and rapport over the course of their prenatal visits, they are able to cope with the uncertainty and vulnerability that may accompany her decision. If the outcome of $\mathrm{AJ}^{\prime} \mathrm{s}$ decision is different than her expectation, or has an impact upon herself or her neonate, the midwife will be able to support her through debriefing.

\begin{tabular}{|l|l|l|}
\hline $\begin{array}{l}\text { Table } 2 \\
\text { Shared Decision-Making Resources }\end{array}$ & Source \\
\hline Resource & Description & $\begin{array}{c}\text { American College of } \\
\text { Obstetricians and } \\
\text { Gynecologists. Committee }\end{array}$ \\
\hline The RESPECT Model & $\begin{array}{l}\text { Promotes cultural humility and } \\
\text { awareness of biases }\end{array}$ & $\begin{array}{l}\text { Opinion No. 587: Effective } \\
\text { patient-physician }\end{array}$ \\
& & communication. Obstet \\
& & Gynecol. 2014; 123(2 Pt \\
\hline $5-S t e p s$ of patient interviewing & Fosters caring communication & 1):389-393. \\
\hline skills & & American College of \\
& & Obstetricians and \\
& & Gynecologists. Committee \\
& & Opinion No. 587: Effective \\
& & patient-physician \\
communication. Obstet \\
\end{tabular}




\begin{tabular}{|l|l|l|}
\hline $\begin{array}{l}\text { ACNM Position Statement on } \\
\begin{array}{l}\text { Shared Decision-Making in } \\
\text { Midwifery Care }\end{array}\end{array}$ & $\begin{array}{l}\text { Position statement that affirms } \\
\text { Shared Decision-Making as } \\
\text { congruent with the philosophy of } \\
\text { ACNM }\end{array}$ & $\begin{array}{l}\text { http://midwife.org/ACNM/files/ } \\
\text { ACNMLibraryData/UPLOADFIL } \\
\text { ENAME/00000000305/Share } \\
\text { d-Decision-Making-in- } \\
\text { Midwifery-Care-10-13-17.pdf }\end{array}$ \\
\hline $\begin{array}{l}\text { Ottawa Decision Support } \\
\text { Framework }\end{array}$ & $\begin{array}{l}\text { An evidence-based theory for } \\
\text { guiding patients in making } \\
\text { decisions. Offers a library of } \\
\text { patient decision aids and a shared } \\
\text { decision-making implementation } \\
\text { toolkit }\end{array}$ & $\begin{array}{l}\text { https:/decisionaid.ohri.ca/impl } \\
\text { ement.html }\end{array}$ \\
\hline $\begin{array}{l}\text { The SHARE Approach, by the } \\
\text { Agency for Healthcare Research \& } \\
\text { Quality }\end{array}$ & $\begin{array}{l}\text { Provides a 5-step process for } \\
\text { shared decision-making. Offers a } \\
\text { workshop curriculum for } \\
\text { implementation }\end{array}$ & $\begin{array}{l}\text { https://www.ahrq.gov/profession } \\
\text { als/education/curriculum- } \\
\text { tools/shareddecisionmaking/inde } \\
\text { x.html }\end{array}$ \\
\hline
\end{tabular}

\section{Conclusion}

Situations in which women decline to follow clinical recommendations can be complicated, as the autonomy and best interests of those involved seek balance and are viewed against the relief of certain versus uncertain clinical evidence. The open, honest communication promoted in the shared decision-making process can mitigate the risk of coercion. The framework of shared decision-making, enhanced by skilled communication, empathy, and acceptance of vulnerability, offers midwives and women the opportunity to engage in meaningful dialog without compromising professional integrity or a woman's autonomy. 


\section{4|Chapter Seven}

References

1. International Association of Diabetes and Pregnancy Study Groups Consensus Panel. International Association of Diabetes and Pregnancy Study Groups Recommendations on the Diagnosis and Classification of Hyperglycemia in Pregnancy. Diabetes Care. 2010;33(3). doi:10.2337/dc09-1848

2. American College of Nurse-Midwives. Shared Decision Making in Midwifery Care.; 2016. http://midwife.org/ACNM/files/ACNMLibraryData/\%ODUPLOADFILENAME/000000000305/SharedDecision-Making-in-\%0DMidwifery-Care-10-13-17.pdf. December 2016. Accessed December 26, 2017.

3. Elwyn G, Frosch D, Thomson R, et al. Shared decision making: A model for clinical practice. Journal of General Internal Medicine. 2012;27(10):1361-1367. doi:10.1007/s11606-012-2077-6

4. American College of Obstetricians and Gynecologists. Committee Opinion No. 664. Obstetrics \& Gynecology. 2016;127(6). doi:10.1097/AOG.0000000000001485

5. Wright JD, Pawar N, Gonzalez JSR, et al. Scientific Evidence Underlying the American College of Obstetricians and Gynecologists' Practice Bulletins. Obstetrics \& Gynecology. 2011;118(3):505-512. doi:10.1097/AOG.0b013e3182267f43

6. Nieuwenhuijze MJ, Low LK, Korstjens I, Lagro-Janssen T. The role of maternity care providers in promoting shared decision making regarding birthing positions during the second stage of labor. Journal of Midwifery and Women's Health. 2014;59(3):277-285. doi:10.1111/jmwh.12187

7. Beauchamp TL, Childress JF. Principles of Biomedical Ethics. 6th ed. Oxford University Press; 2009; pages 117-121.

8. Barry MJ, Edgman-Levitan S. Shared decision making - The pinnacle of patient-centered care. New England Journal of Medicine. Published online 2012. doi:10.1056/NEJMp1109283

9. Dickens BM, Cook RJ. Patients' refusal of recommended treatment. International Journal of Gynecology \& Obstetrics. 2015;131(1). doi:10.1016/j.ijgo.2015.07.001

10. Paltrow LM, Flavin J. Arrests of and Forced Interventions on Pregnant Women in the United States, 1973-2005: Implications for Women's Legal Status and Public Health. Journal of Health Politics, Policy and Law. 2013;38(2). doi:10.1215/03616878-1966324

11. Hartocollis A. Mother accuses doctors of forcing a C-section and files suit. The New York Times. https://www.nytimes.com/2014/05/17/nyregion/mother-accuses-doctors-of-forcing-a-c-section-andfiles-suit.html. Published May 16, 2014. Accessed December 18, 2017.

12. World Health Organization. The Prevention and Elimination of Disrespect and Abuse during FacilityBased Childbirth.; 2015. Accessed February 12, 2018. https://apps.who.int/iris/bitstream/handle/10665/134588/WHO_RHR_14.23_eng.pdf?sequence=1

13. Deshpande N, Oxford C. Management of pregnant patients who refuse medically indicated cesarean delivery. Rev Obstet Gynecol. 2012;5(3-4):e144-e150.

14. Ménage D. Part 2: A model for evidence-based decision-making in midwifery care. British Journal of Midwifery. 2016;24(2):137-143. doi:10.12968/bjom.2016.24.2.137

15. Jenkinson B, Kruske S, Stapleton H, Beckmann M, Reynolds M, Kildea S. Women's, midwives' and obstetricians' experiences of a structured process to document refusal of recommended maternity care. Women and Birth. 2016;29(6). doi:10.1016/j.wombi.2016.05.005

16. Makoul G, Clayman ML. An integrative model of shared decision making in medical encounters. Patient Education and Counseling. 2006;60(3). doi:10.1016/j.pec.2005.06.010

17. Stacey $D$, Légaré $F$, Col NF, et al. Decision aids for people facing health treatment or screening decisions. Cochrane Database of Systematic Reviews. Published online 2014. doi:10.1002/14651858.CD001431.pub4

18. Elwyn G, Dehlendorf C, Epstein RM, Marrin K, White J, Frosch DL. Shared decision making and motivational interviewing: Achieving patient-centered care across the spectrum of health care problems. Annals of Family Medicine. Published online 2014. doi:10.1370/afm.1615

19. Elwyn G, Durand MA, Song J, et al. A three-talk model for shared decision making: multistage consultation process. BMJ. Published online November 6, 2017. doi:10.1136/bmj.j4891

20. Légaré $F$, Thompson-Leduc $P$. Twelve myths about shared decision making. Patient Education and Counseling. 2014;96(3). doi:10.1016/j.pec.2014.06.014

21. Entwistle VA, Cribb A, Watt IS. Shared decision-making: enhancing the clinical relevance. Journal of the Royal Society of Medicine. 2012;105(10). doi:10.1258/jrsm.2012.120039

22. Nieuwenhuijze M, Low L. Facilitating women's choice in maternity care. J Clin Ethics. 2013;24(3):276282.

23. Berger Z. Navigating the Unknown: Shared Decision-Making in the Face of Uncertainty. Journal of General Internal Medicine. 2015;30(5):675-678. doi:10.1007/s11606-014-3074-8 


\section{Choosing to Decline: Finding Common Ground through the Perspective of Shared}

Decision Making $\mathbf{1 2 5}$

24. Moyer VA. Screening for Gestational Diabetes Mellitus: U.S. Preventive Services Task Force Recommendation Statement. Annals of Internal Medicine. 2014;160(6). doi:10.7326/M13-2905

25. American College of Obestricians and Gynecologists. ACOG Practice Bulletin No. 190. Obstetrics \& Gynecology. 2018;131(2). doi:10.1097/AOG.0000000000002501

26. Farrar D, Duley L, Dowswell T, Lawlor DA. Different strategies for diagnosing gestational diabetes to improve maternal and infant health. Cochrane Database of Systematic Reviews. 2017;8(8). doi:10.1002/14651858.CD007122.pub4

27. Racusin DA, Antony K, Showalter L, Sharma S, Haymond M, Aagaard KM. Candy twists as an alternative to the glucola beverage in gestational diabetes mellitus screening. American Journal of Obstetrics and Gynecology. 2015;212(4). doi:10.1016/j.ajog.2014.11.010

28. Lamar ME, KuehI TJ, Cooney AT, Gayle LJ, Holleman S, Allen SR. Jelly beans as an alternative to a fiftygram glucose beverage for gestational diabetes screening. American Journal of Obstetrics and Gynecology. 1999;181(5). doi:10.1016/S0002-9378(99)70099-2

29. American College of Obstetricians and Gynecologists. ACOG Practice Bulletin No. 105: Bariatric Surgery and Pregnancy. Obstetrics \& Gynecology. 2009;113(6). doi:10.1097/AOG.0b013e3181ac0544

30. Wax JR, Pinette MG, Cartin A, Blackstone J. Female Reproductive Issues Following Bariatric Surgery. Obstetrical \& Gynecological Survey. 2007;62(9). doi:10.1097/01.ogx.0000279291.86611.46

31. Spector-Bagdady K, de Vries R, Harris LH, Kane Low L. Stemming the Standard-of- Care Sprawl: Clinician Self-Interest and the Case of Electronic Fetal Monitoring. Hastings Center Report. 2017;47(6):16-24. doi:10.1002/hast.781

32. Mostow C, Crosson J, Gordon S, et al. Treating and Precepting with RESPECT: A Relational Model Addressing Race, Ethnicity, and Culture in Medical Training. Journal of General Internal Medicine. 2010;25(S2). doi:10.1007/s11606-010-1274-4

33. American College of Obestricians and Gynecologists. Committee Opinion No. 587. Obstetrics \& Gynecology. 2014;123(2, PART 1). doi:10.1097/01.AOG.0000443279.14017.12

34. Lewis $\mathrm{C}$, Hill M, Chitty LS. Offering non-invasive prenatal testing as part of routine clinical service. Can high levels of informed choice be maintained? Prenatal Diagnosis. 2017;37(11). doi:10.1002/pd.5154

35. Elwyn G, Edwards A, Kinnersley P, Grol R. Shared Decision Making and the Concept of Equipoise: The Competences of Involving Patients in Healthcare Choices. Br J Gen Pract . 2000;50(460):892-899. 
126|Chapter Seven 


\section{CHAPTER 8}

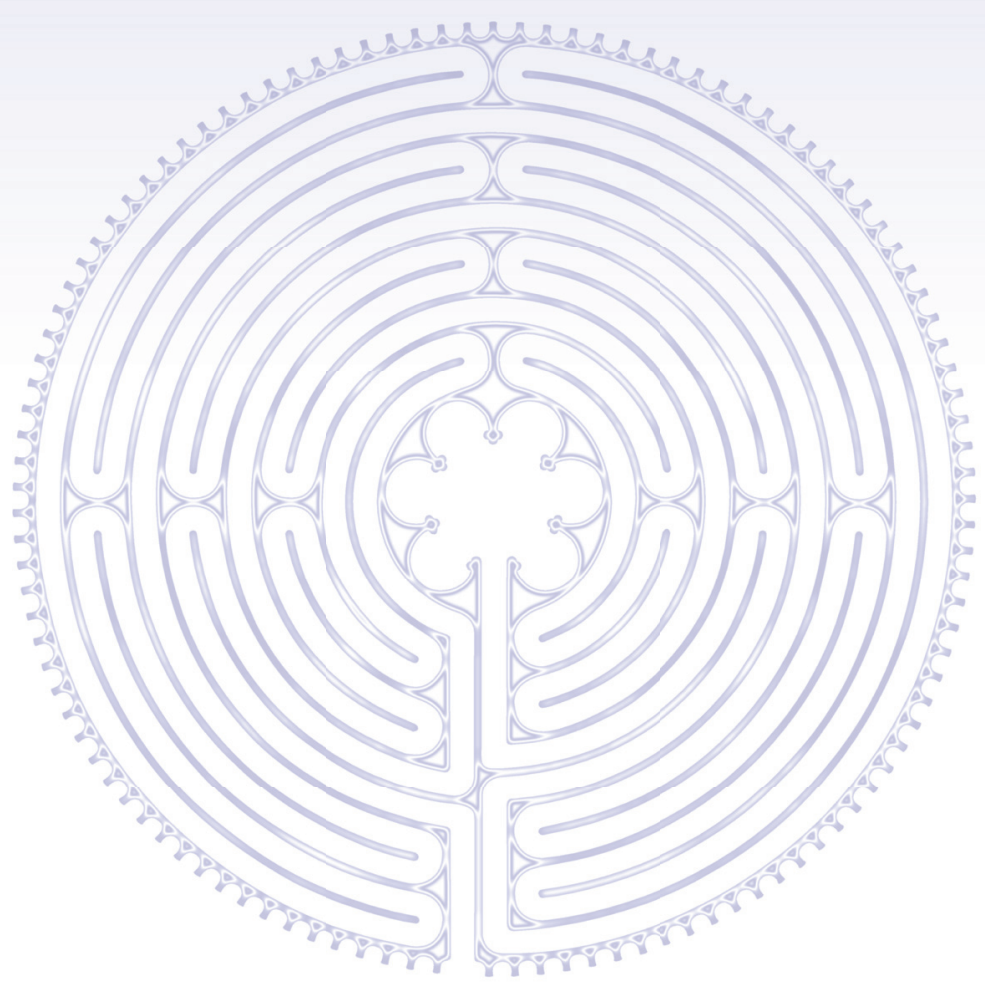




\section{Introduction}

The central aim of this thesis is to contribute to the optimization of ethics education in midwifery programs and to offer a framework which can guide ethics education in midwifery programs, based on insights into the experiences of student midwives, practicing midwives and midwifery educators. In order to assess the current state of ethics education in the United States, and to identify potential gaps in that education, we began our program of research with a survey of midwifery program directors, allowing us to assess the place of ethics in their curricula (Chapter 2). We then engaged midwifery students in focus groups, soliciting their opinions about the ethics content in their current midwifery program and asking them about ethical dilemmas they experienced (Chapter 3). Next we interviewed individual midwives in order to learn how their midwifery program prepared them to recognize and negotiate ethical dilemmas in clinical practice and to gain insight into their experiences with ethical dilemmas (Chapter 4). Building on our findings from students and midwives, we returned to midwifery educators (midwifery program directors, faculty, and clinical preceptors) to create the foundation for a competency-based model of a midwifery ethics curriculum. Using the Delphi method, we sought consensus on essential content, competencies, learning outcomes and teaching strategies that were identified as essential for an ethics curriculum (Chapter 5). Given the overall emphasis placed on the role of informed choice and shared decision-making in promoting autonomy and facilitating communication, we performed a scoping review of current literature to assess the effect of shared decision-making on outcomes in maternity care (Chapter 6 ). Finally, to explore the value of our work in a clinical setting, we examine a case highlighting the use of the shared decision-making process to enhance the midwife-woman relationship under the strain of disagreement (Chapter 7).

In this chapter we present an overview of the main findings, discuss the implications of our work for midwifery education, review the strengths and limitations of our research. We conclude with suggestions for further research in midwifery education and midwifery practice.

\section{Main Findings}

We heard from midwifery students, experienced midwives, and midwifery educators about the ethical dilemmas they face in providing reproductive care, what they consider to be best practices in ethics education, and what they see as the role of midwifery educational programs in preparing students to face these challenges. Through our studies we were able to identify key components of midwifery ethics education and offer a framework for midwifery educators to consider.

Ethics content in midwifery education programs: current status and future opportunities Our survey of midwifery program directors revealed a lack of standardization in ethics training for midwifery students (Chapter 2). In order to be accredited by ACME, programs must facilitate knowledge of biomedical ethics and foster a commitment to personcentered care, informed choice, and shared decision-making. The ways by which these accreditation criteria are met are left to the individual programs, so it is not surprising to 
see a wide variation in the topics covered, the time spent on ethics, the formats used to convey information, and the methods of evaluating students. Of the 25 participating midwifery programs, three had a stand-alone ethics class in their curriculum; otherwise ethics content was integrated into other classes, most commonly a class on midwifery professionalism. The majority of the programs reported the inclusion of content related to informed consent; about half reported the inclusion of content related to an overview of ethics principles and ethics theories.

Building on this information and on the input from stakeholders, students and midwives, (Chapter 3 and Chapter 4), we invited midwifery educators to participate in a Delphi study. Our goal was to elicit consensus on essential content, competencies, learning outcomes and teaching strategies that should be included in a midwifery ethics curriculum (Chapter 5). Educators emphasized the inclusion of content related to shared decision-making, specifically the communication skills needed to successfully promote the shared decision-making process. Consensus was reached on 20 of 21 statements regarding competencies, learning outcomes, and teaching strategies. Competencies related to shared decision-making and ethical decision making skills were ranked highly and student demonstration of particular behaviors, specifically courage and compassion, were deemed very important. Role-play / simulation activities and exercises in reflection were identified as key teaching strategies. The educators did not reach consensus on strategies for evaluating students, disagreeing with the statement that a validated method for evaluating ethics competencies is an essential teaching strategy. This is also reflected in our initial survey of program directors (Chapter 2), where the majority of participating programs reported relying on faculty observation and student class participation for evaluating ethics knowledge and behavior, methods that carry limited ability to assure competency.

\section{Student and midwives' experiences of ethical dilemmas and ethics education}

In order to gain insight into the needs of students and midwives with regard to the skills and support needed to recognize, negotiate, and cope with the complex ethical challenges present in clinical care, we conducted focus groups with midwifery students (Chapter 3) and did individual interviews with experienced midwives (Chapter 4).

Midwifery students expressed mixed, and somewhat conflicted, feelings about ethics content and methods for teaching ethics. They relied primarily upon their clinical preceptors for ethics learning and role modeling of ethics behaviors, despite the lack of explicit acknowledgement or awareness that ethics learning was occurring. Students assumed that their clinical preceptors received training in ethics, although in our interviews with midwives (Chapter 4 ) and midwifery preceptors (Chapter 5 ) most clinical preceptors were not formally prepared for this role. In addition, the student experiences with their clinical preceptors were fraught with mixed messages and power differentials that sometimes impeded their learning process. The students expressed a strong commitment to advocating for women's autonomy in choice and decision making, even if they did not agree with the woman's choice or if the woman's choice was not in alignment with their own midwifery philosophy. We characterized this as resolute autonomy, the fierce sense of duty to protect and advocate for autonomy as the highest 
priority. They followed the examples of their midwifery preceptor role models, who supported women's choices sometimes to the point of undermining other members of the healthcare team. They emulated these examples even as they viewed the midwives as powerless actors in a large, unfriendly system. Students in our focus groups emphasized the need for improved skills among clinical educators, particularly with regard to ethics education, communication and feedback skills. These findings reflect the results of our prior projects, highlighting that variation in the approach to ethics education may not necessarily contribute to achieving intended learning outcomes.

Interviews with experienced clinical midwives revealed similar complex relationships and a strong commitment to shared decision-making and informed choice. They described the wide range of ethical dilemmas experienced in clinical care, primarily related to strained interprofessional relationships and to protecting or promoting women's autonomous decisions. While some of the midwives struggled to define and articulate what they considered to be ethical dilemmas, many of the midwives identified ethical dilemmas by a sense of contextual unease. This sense of unease came about when they were uncertain about the right action to be taken, when they felt that the right action was known but they were constrained from following through with that action, or in reflection on the situation. They relied on their own role models and clinical preceptors for their ethics learning during their midwifery education, and reported a minimum of classroom time dedicated to ethics learning. They expressed a desire for intentional inclusion of ethics content and deliberately crafted learning exercises that explicitly highlight ethics learning. It also reflects a call for improved collaboration between midwifery program faculty, clinical preceptors, and students to coordinate and integrate ethics learning.

\section{A focus on shared decision-making}

Shared decision-making is a key aspect of woman-centered care and a strategy to improve communication, respect, and women's satisfaction with maternity care. ${ }^{1}$ The understanding of shared decision-making as a process and possessing the skills necessary to participate in this process were emphasized as key elements of competency in ethics by stakeholders in our projects. Given the emphasis on shared decision-making and its potential to improve maternity care outcomes, maternity care providers are regularly called on to use shared decision-making when discussing evidence-based care recommendations, particularly recommendations that represent new, emerging, or potentially controversial findings, or when there is a gap in evidence. We performed a scoping review to identify studies that used a shared decision-making support strategy in maternity care, beyond the use of just a decision aid, as the primary intervention. We found only 9 studies that met criteria. These studies were heterogenous in their shared decision-making interventions, tools for evaluating the intervention, measured outcomes, settings and perinatal situations. None of the studies included interventions in the intrapartum setting. We found that participants commonly described decreased decisional conflict related to feeing informed, although participants did not demonstrate changes in feelings of decisional certainty. 
To explore the shared decision-making process in the clinical setting, the understanding of which was identified as an essential component of ethics education, we present a clinical case that uses a shared decision-making framework when negotiating and coping with a challenging interaction with a patient, in this case a woman who declined a recommended test during pregnancy (Chapter 7). Using a principle-based framework, we described the tensions between supporting a woman's autonomy and compliance with medically appropriate and recommended interventions. In addition, we highlighted that the shared decision-making process is optimally situated to assist midwives and women in negotiating the uncertainty present in many clinical decisions.

\section{A framework for ethics education in midwifery}

With the input of students, midwives, and midwife educators, we developed a broad framework for midwifery ethics education. The framework is based on the following ideas: 1) ethics should be integrated with clinical learning throughout the midwifery program; 2) clinical preceptors are role models that are integral as a source of ethics learning; and 3) ethics, professionalization, and socialization of midwifery students are distinct yet overlapping elements that serve to form midwifery identity. In addition, we identified broad competencies that should be considered as part of a competency-based ethics curriculum. We use the image of a camera lens to bring focus to ethics learning. (Figure 1)

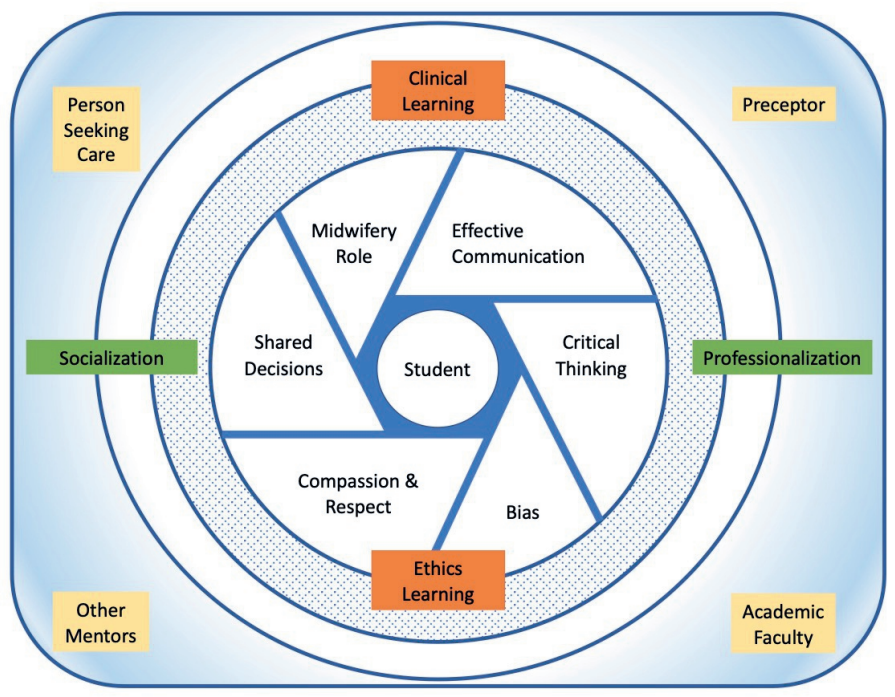




\section{Figure 1: Framework for Ethics Education in Midwifery}

- The student is represented at the center of learning.

- The competencies identified by stakeholders surround the student, informed by both clinical and ethics learning.

- The rings of ethics and clinical learning are interconnected, highlighting the idea that they should occur concurrently and should be integrated into everyday learning, but should also be promoted individually

- The outer rings show the influence of socialization and professionalization of midwifery students, which contribute to clinical and ethics learning and to the formation and ongoing evolution of a midwife's identity

- The main influencers of student learning are in orbit - the academic faculty, clinical preceptor, other mentors, and the person engaged with them in care

\section{The integration of clinical and ethics learning}

Through the input from our participants, it is clear that ethics content and learning should be intentional, it should be highlighted when it occurs, and it should be integrated in to standard clinical learning environment. Ethics teaching should be intentional in that it should be deliberately included as part of the overall midwifery curriculum in conjunction with clinical learning. With intentionality also comes highlighting: as ethic teaching is being performed or role-modeled, the educator should be explicit that it is occurring and that one purpose for the learning activity is ethics learning. For example, when a preceptor prepares to demonstrate the best method for performing a vaginal exam during labor to determine cervical dilation, instead of just highlighting the psychomotor skills involved, the midwife can call attention to her method of discussing the purpose of the exam as part of informed consent or shared decision-making. In addition, ethics should be integrated throughout the midwifery curriculum, running its own track parallel to clinical content, with its own knowledge base and skills, but connected through the relationships that are central to clinical encounters. (Figure 2)

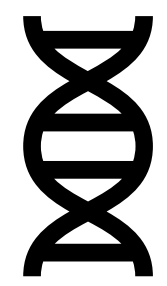

Figure 2: The DNA double helix represents the parallel yet connected tracks of clinical and ethics learning.

As students progress from novice to proficient learners, clinical content and case examples (for example, the case presented in Chapter 7) are designed to match their progress, increasing in difficulty and complexity over time in order to challenge and develop clinical reasoning skills. Clinical cases provide examples of standard medical decision-making that assist novice learners in grasping broad concepts, synthesizing them 
and applying them appropriately to specific cases. In our framework, exemplar cases in ethics serve a similar purpose - the cases clearly demonstrate ethics principles or decision-making in a manner that may be grasped by novice learners. Exemplar ethics cases also center around topics that may be controversial or debated in journals or popular media, such as abortion or choice of birth setting. While the use of exemplar cases contributes to students' broad understanding of concepts and principles, the integration of ethics content into the clinical curriculum allows for students to recognize, understand, and experience the ethical aspects that underlay everyday clinical encounters. This has the potential to increase midwives' ethical awareness, which was identified by midwives in our interviews as a gap in their education (Chapter 4).

Our survey (Chapter 2) showed that the content included in midwifery ethics curricula varies widely. While it may not be necessary to include every topic within the program, using both controversial and common cases may increase ethical awareness and provide the skills needed to negotiate both familiar and unfamiliar situation. However, by including exemplar cases that highlight challenges in the maternal-fetal relationship and common cases that highlight challenges in confidentiality, the student will gain the skills needed to negotiate such a case when encountered for the first time. (Figure 3)

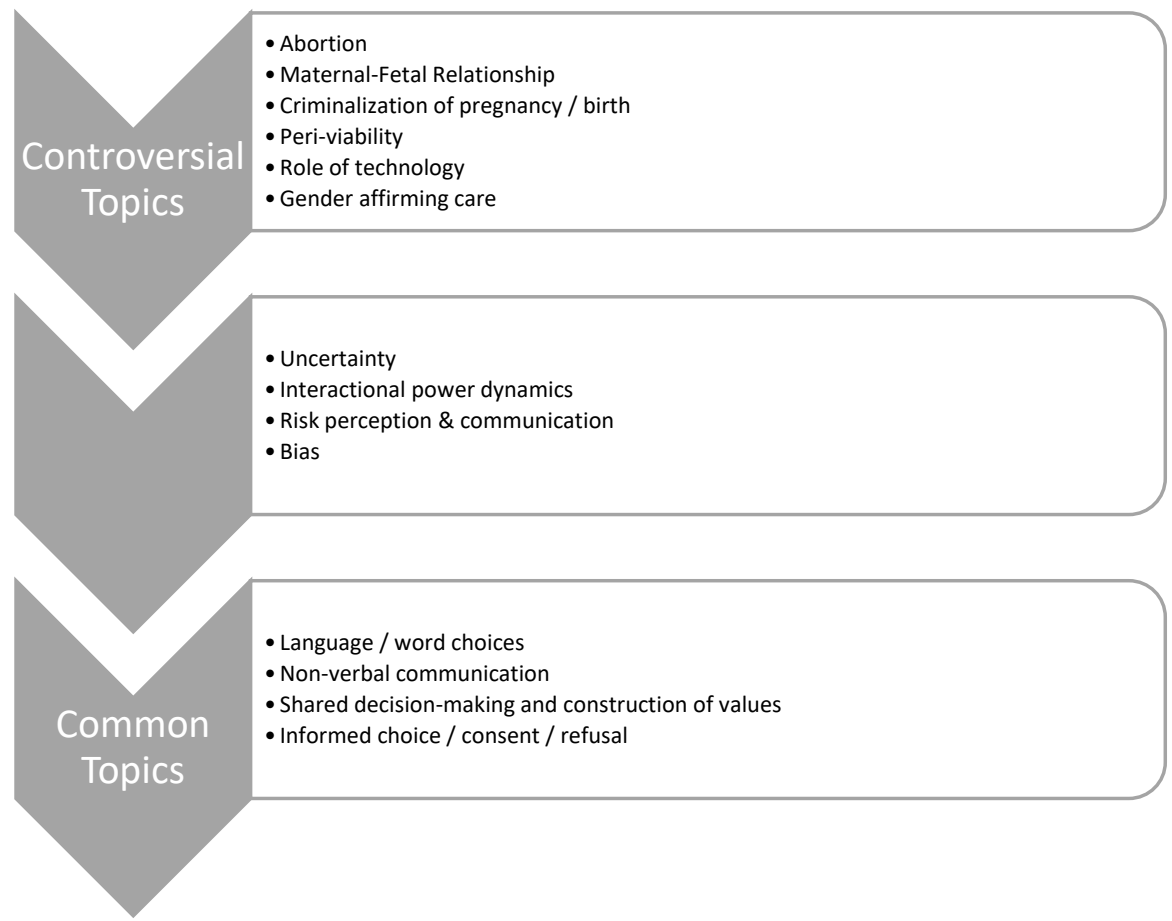

Figure 3: Examples of controversial and common topics 


\section{4|Chapter Eight}

\section{Clinical preceptors as key sources of ethics learning}

The students (Chapter 3 ) and practicing midwives (Chapter 4) clearly identified the experiences with clinical preceptors as key to their ethics learning. Clinical preceptors were expected and relied upon to role-model not only psychomotor skills but also communication skills, professional behaviors, and to provide opportunities for reflection and debriefing. For the students in particular (Chapter 3), the preceptor's successful or unsuccessful demonstration of these skills had a significant impact on the student's absorption of key ethics knowledge and on their willingness to continue learning from that preceptor. In our interviews, practicing midwives (Chapter 4) identified other sources of ethics learning, such as colleagues or mentors, who served as role-models for ethical practice. In the ethics curricular framework presented here, the student is seen as the central figure, surrounded and embraced by academic faculty, clinical preceptors, and the individuals receiving care, who all contribute to student learning. The reliance upon clinical preceptors for ethics learning is consciously recognized and deliberately supported. This would call for closer communication and connection between the academic program and community clinical preceptors, as well as continuing education, resources, and support for clinical preceptors in the area of ethics and ethics learning. (Figure 4)

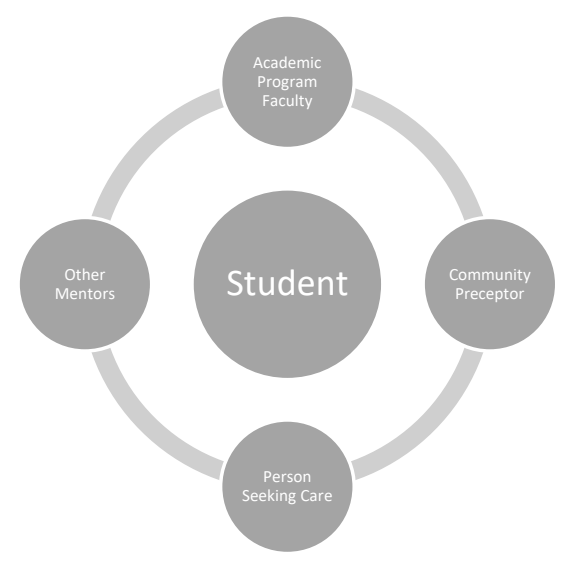

Figure 4: The student is at the center of learning, surrounded and supported by their educators.

\section{Ethics, professionalism, and socialization}

Part of the process of professional development and formation of midwifery identity occurs through the personal integration of the values and attitudes of the midwifery profession. New members to the profession do this by conforming to the expected behaviors that demonstrate the profession's values and foundational philosophy. ${ }^{2}$ These attitudes and behaviors are referred to, often interchangeably, as ethics or professionalism. Didactic courses in midwifery education cover both concepts, often under the same umbrella of "issues in midwifery", in which ethical principles and professional standards are combined or incorporated into the same class time (Chapter 2). Our survey (Chapter 2) of U.S. midwifery education programs showed that 22 of 25 
programs integrated ethics into their professional issues class content and that the majority of programs did not have a separate ethics class. As a result, the similarities and the differences between the broader concepts of ethics and the particular characteristics of professionalism are often blurred for students, faculty, and midwives.

In our framework we propose an ethics curriculum that helps to clarify the understanding of ethics knowledge, ethics decision-making, and the professional behaviors expected of all midwives. The midwifery philosophy of care and the clinical and ethical decisions midwives are expected to enact are based upon particular ethical principles or frameworks adopted by the midwifery profession. In order to fulfill their role as a midwife, students should have a broader understanding of ethical theory and decision-making as well as a commitment to the particular attitudes and behaviors expected of them as midwives. In general, this is a process of socialization and alignment of the professionalization of midwives with the ethical and philosophical frameworks. The topics of ethics and professionalism should be addressed with intention; a deliberate and thoughtful approach to how they are distinct yet related. Included in this approach would be an intentional awareness of the socialization of students in becoming a midwife.

Socialization of students occurs through role modeling, explicit and tacit learning, and the experience of social or relational networks. ${ }^{2,3}$ It is an introduction to the culture of midwifery and contributes to role transition and the formation of a professional midwifery identity. ${ }^{2,4}$ These three distinct principles - ethics, professionalism, and socialization - work together to help students understand what it means to be a "good midwife". (Figure 5)

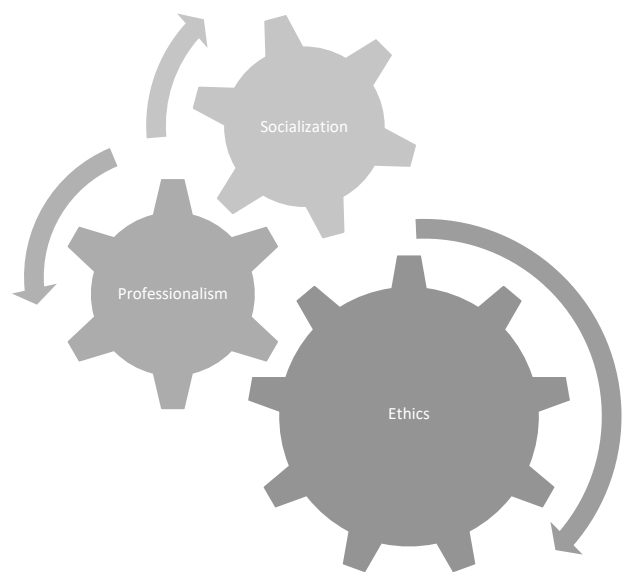

Figure 5: The interconnected relationship between ethics, professionalism, and socialization.

\section{Exemplar Competencies in Midwifery Ethics Education}

Taking advantage of the fact that midwifery education uses a competency-based framework to outline the skills and knowledge required for midwifery certification, our framework offers suggestions for broad competencies that should be included in an 
136|Chapter Eight

ethics curriculum. This framework provides examples of particular concepts and topics that can guide educators in content inclusion and learning activities. (Table 1)

\begin{tabular}{|c|c|c|}
\hline Category & Example Competency & May Include \\
\hline AWARENESS OF BIAS & $\begin{array}{l}\text { Students recognize, acknowledge, } \\
\text { and communicate their personal } \\
\text { biases }\end{array}$ & $\begin{array}{l}\text { Awareness of moral distress } \\
\text { Coping and resilience }\end{array}$ \\
\hline COMPASSION & $\begin{array}{l}\text { Students demonstrate behaviors } \\
\text { consistent with compassionate } \\
\text { care, including courage, empathy, } \\
\text { honesty, kindness, and astute } \\
\text { listening }\end{array}$ & $\begin{array}{l}\text { Willingness to promote well- } \\
\text { being and avoid harm }\end{array}$ \\
\hline CRITICAL THINKING & $\begin{array}{l}\text { Students apply critical thinking } \\
\text { skills, based on a thorough } \\
\text { knowledge base of ethics theories, } \\
\text { principles, and frameworks, to } \\
\text { ethical dilemmas and ethics } \\
\text { decision making }\end{array}$ & $\begin{array}{l}\text { Application of ethics } \\
\text { assessment processes } \\
\text { Reflection of options in } \\
\text { decision making }\end{array}$ \\
\hline EFFECTIVE COMMUNICATION & $\begin{array}{l}\text { Students demonstrate effective } \\
\text { communication skills in their } \\
\text { interactions with peers, } \\
\text { colleagues, and women and their } \\
\text { families }\end{array}$ & $\begin{array}{l}\text { Risk communication } \\
\text { Active listening } \\
\text { Fosters interprofessional } \\
\text { dialog }\end{array}$ \\
\hline MIDWIFERY ROLE & $\begin{array}{l}\text { Students apply knowledge of } \\
\text { ethics principles and frameworks } \\
\text { to the midwifery role in clinical } \\
\text { practice and health policy, as } \\
\text { demonstrated by promoting } \\
\text { autonomy, ensuring } \\
\text { confidentiality, and recognizing } \\
\text { and resolving ethical dilemmas }\end{array}$ & $\begin{array}{l}\text { Understanding of the ACNM } \\
\text { and ICM codes of ethics } \\
\text { Preparation for lifelong } \\
\text { learning of ethics and of } \\
\text { midwifery identity formation }\end{array}$ \\
\hline RESPECT & $\begin{array}{l}\text { In their interactions with women } \\
\text { and their families, students will } \\
\text { promote and provide respectful } \\
\text { care through the demonstration of } \\
\text { ethical conduct and cultural } \\
\text { literacy }\end{array}$ & $\begin{array}{l}\text { Awareness of health } \\
\text { disparities } \\
\text { Understanding of racial and } \\
\text { implicit bias }\end{array}$ \\
\hline SHARED DECISIONS & $\begin{array}{l}\text { Students promote effective } \\
\text { decision making, through an } \\
\text { understanding of the elements of } \\
\text { informed consent and refusal and } \\
\text { skill in the shared decision-making } \\
\text { process }\end{array}$ & $\begin{array}{l}\text { Communicates that a } \\
\text { decision is to be made (choice } \\
\text { awareness) } \\
\text { Recognition and construction } \\
\text { of patient values and goals } \\
\text { Fosters deliberation } \\
\text { Awareness of bias and power } \\
\text { imbalances, and their effect } \\
\text { on shared decision-making }\end{array}$ \\
\hline
\end{tabular}




\section{Reflection on the findings}

Through this thesis, we have endeavored to identify the components of an educational curriculum and provide a conceptual framework that offers guidance and support to train midwifery students in the ethical principles that may inform their approach to and delivery of clinical care. There are three integral concepts that require further exploration and consideration as they apply to a midwifery ethics curriculum. First, the midwifery ethics curriculum needs to integrate clinical preceptors more fully into the student experience of ethics learning. Second, further examination is needed into the challenges of assessing competency in ethics. Last, the concept of shared decision-making must be better understood, in terms of its ethical foundations as a relational process and in terms of the optimal manner of teaching this approach to working with women.

\section{The preceptor gap}

The student experience provided by the clinical midwife preceptor is a cornerstone of midwifery education. The students and midwives in our studies identified their preceptors as the primary source for acquisition of skills and for understanding of expected professional behaviors related to ethics. While preceptor training may include an understanding of how to facilitate clinical skills development, it may not include preparation for ethical skills development, particularly in the awareness of ethics and ethical dilemmas.

Preceptors help to bridge the theory-practice gap. They are the student's guide along the path of progression from an application of theoretical knowledge to clinical decision making, and then from clinical decision to implementation of a specific action. ${ }^{5}$ They role model the actualization of the midwifery management process - data are gathered and analyzed, problems are identified and evaluated, decisions are made and actions are taken, and the process is repeated as outcomes are evaluated. ${ }^{6}$

Preceptors advance students' critical thinking and problem-solving skills by fostering independence and self-confidence. ${ }^{5,7}$ Supportive relationships between students and preceptors have a significant impact upon student learning and selfesteem..$^{5,8,9}$ Interactions that occur in an environment absent of safety, trust or openness impede learning and have a deleterious effect on acquisition of skills and retention of knowledge. ${ }^{10}$ Feelings of vulnerability in their relationships with preceptors add to the stressors of the clinical learning environment, particularly if effective communication and feedback are hampered. ${ }^{7}$ Effective feedback should be nonjudgmental and standardized, with a primary aim to improve performance. ${ }^{11}$ It reinforces appropriate actions and attitudes as students advance toward achieving specific competencies. ${ }^{9,11}$ Effective feedback also includes the opportunity for reflection and debriefing, which were identified by midwifery students as particularly beneficial to the learning environment. ${ }^{9}$ The ability to reflect on their clinical experiences has the potential to consolidate learning, integrate theories and practice, and enhance agency, particularly when the reflective activity is performed directly after a clinical experience and with the guidance of the clinical preceptor. ${ }^{12}$ Critical reflection of the clinical situation and clinical decisions made, as well as one's own reactions and emotional responses to the actions taken, is an 
important and necessary milestone in the professional development of midwifery students. ${ }^{13}$

Critical reflection on ethical situations and ethical decisions is a key component of ethics learning. We found that for ethical dilemmas in particular, critical reflection is embedded in the narrative of one's experience. Similar to nursing and midwifery students in other studies, the students and midwives in our projects described their opinions and perceptions about ethics and ethical dilemmas through narratives and storytelling. ${ }^{14}$ They used storytelling as a means to reflect on their experiences and the experiences of others and to integrate these experiences into their identity as an ethical midwife. ${ }^{12}$ However, for both the students and practicing midwives in our projects, much of their internal work of reflection and integration occurred without the input of the clinical preceptor during their education process. The ethics learning happened outside of the preceptor-student relationship, representing a potential missed opportunity. This missed opportunity highlights the need for conscious, intentional ethics teaching. Just as preceptors are obligated to engage students in teachable moments when key clinical factors are present, such as the diagnosis of preeclampsia, so should they engage in ethics teaching when the situation presents.

Clinical midwife preceptors are the guideposts and gatekeepers who oversee the integration of theoretical and conceptual aspects of student learning into the clinical setting. They cultivate not only the specific physical skills necessary in becoming a competent midwife, but they nurture the student through the accompanying identity change from non-midwife to midwife. The preceptors play a key role in the development of the student's midwifery professional identity and socialization to the profession of midwifery. Students look to the preceptor for guidance in how to act, interact, react, and respond to clinical situations and in interpersonal communications. ${ }^{8,15}$ The manner in which preceptors interact with women in their care, how normal physiologic birth is promoted or diminished, communication styles that encourage open dialogue or are fraught with power struggles and bullying - students are constantly considering and evaluating these facets of a midwife's professional behavior. Role-modeling both positive and negative behaviors, for better or worse, provide the student with the opportunity to define what it is to be a "good midwife". ${ }^{4,16}$ This role modeling may or may not be intentional on the part of the preceptor. Unintentional role-modeling, or the unspoken behaviors that are embedded in preceptor interactions and which are expected to be adopted by students, is often called the hidden curriculum. ${ }^{17}$ This informal socialization can foster student well-being, student learning, and interprofessional collaboration when preceptors act with empathy, respect, and humility. However, more often students recount stories of bullying, public humiliation, and disrespect toward other professionals. ${ }^{9,16,18}$ There is a clear need for a conscious acknowledgement of the preceptor's key role in the socialization of students to the midwifery role, as well as reflective awareness on the part of the preceptors of their capacity to form midwifery identity. ${ }^{13,19}$

Mastery of the preceptor role is akin to any other acquired skill; time, knowledge, confidence, support, access to resources, and practice are needed to achieve 
competency. ${ }^{5,13}$ The students in our project identified a key gap in the relationship between ethics education and the preceptor role. Students did not expect to learn ethics and ethical behavior from their midwifery program but rather from their clinical preceptor. They expected their preceptor to have competency in ethics from the preceptor's midwifery educational program. So we must ask, how do preceptors gain competency in teaching ethics and role modeling ethical behavior? In one study of preceptors working with internal medicine residents, when an ethical issue arose, the ethical issue was explicitly identified and teaching explicitly performed in only $12 \%$ of opportunities presented. ${ }^{20}$ The experiences of midwifery students with midwife preceptors in the clinical setting have been studied, but we are not aware of a study that specifically examines the opportunities and experiences of preceptors and students as they acknowledge and negotiate ethical issues. ${ }^{7,9,13,16}$

Clinical midwife preceptors in the U.S., as in many other countries, hold a unique position in relation to midwifery programs and midwifery students. They are outside of the academic educational framework, yet provide the role-modeling, appropriate clinical opportunities, and summative evaluation of the student's clinical and ethical performances. Currently, the majority of preceptors are not academic faculty; they are practicing midwives who accept the additional responsibility of precepting midwifery students. ${ }^{21}$ Because educational program accreditation requirements include the provision that clinical precepting is provided primarily by midwives, the number of students admitted to midwifery programs is limited by the availability of midwife preceptors. ${ }^{22}$ In a 2014 survey of potential clinical preceptors, Germano et al. (2014) identified significant barriers to midwives accepting students into their clinical practice, including productivity barriers, communication breakdowns, lack of experience, and student preparedness. ${ }^{21}$ While workshops for clinical educators are available yearly during ACNM's Annual Meeting and resources for preceptor education are available on the ACNM website, there is no specific content on the intersection of precepting and ethics to guide preceptors.

\section{The challenge of evaluation}

The question of how to evaluate ethics competency remains. The students and clinical midwives in our study (Chapters 3 and 4) did not offer opinions about methods of assessment or evaluation that they experienced during their midwifery program. The midwives in our Delphi study (Chapter 5 ) did not have a positive response to the inclusion of an evaluation tool or assessment process as part of a teaching strategy for ethics education. Midwifery education in the U.S. and other countries use a competency-based framework to develop midwifery skills and behaviors. ${ }^{6,23}$ Competency-base education focuses on outcomes and the demonstration of learning. ${ }^{24}$

Key to the success of a competency-based framework are clearly stated expected learning outcomes and the associated performance assessments. ${ }^{24,25}$ Expected learning outcomes provide structure and clear expectations for students and midwives as they progress through the program, and identify the progressive building and integration of knowledge, skills, and attitudes. ${ }^{24,25}$ Performance assessment instruments reflect the expected learning outcomes and provide formative feedback to students. The assessment 
of midwifery professional skills includes evaluation of psychomotor skills, such as suturing, clinical management abilities, including both clinical and ethical reasoning, and assessment of professional behaviors, such as demonstration of compassion. Most competency assessment instruments focus primarily upon the psychomotor and clinical decision-making domains of student performance. For example, Woeber et.al. developed the Midwifery Competency Education Tool (MCAT), which is a standardized tool designed to provide clear clinical performance expectations for students, such as "accurately identifies stage of labor". ${ }^{26}$ This assessment instrument is also based on a novice-tomaster framework that allows the student and midwifery faculty or preceptor to track progress over time. ${ }^{26}$

The assessment or evaluation of students' ethics competencies and professional behaviors is complicated by lack of clarity regarding what exactly is being evaluated and how it is evaluated. While validated tools have been developed to assess certain aspects of ethics competency, such as ethical sensitivity, these tools have not been used widely, and it is not clear that using these tools has an impact on learning outcomes, knowledge, student confidence to recognize and negotiate ethical dilemmas - or on students' demonstration of professional behaviours. ${ }^{27-29}$ For example, the Ethical Sensitivity Questionnaire for Nursing Students (ESQ-NS) was developed to provide a self-assessment of nursing students' ability to identify a moral dilemma, using a principle-based framework (autonomy/respect for individual, beneficence, non-maleficence, justice). ${ }^{30}$ Recognition of an ethical dilemma is the first component of Rest's theory of moral decision making, followed by moral reasoning (the process of identifying and evaluating the moral dilemma to determine a course of action), moral motivation (acting on a decision), and moral character (negotiating the challenges to enacting a particular decision). ${ }^{31}$ The Defining Issues Test has been used to evaluate the moral development of medical students. ${ }^{31}$ However, neither of these instruments were created with the intention to evaluate student performance or as part of a competency assessment.

A competency evaluation instrument developed by Favia et.al. is based on the specific curricular components, teaching strategies, and learning outcomes of their ethics class for medical students. ${ }^{32}$ Similar to the Woeber's clinical midwifery evaluation tool (MCAT), this instrument focuses on the acquisition of medical ethics knowledge and skills, such as understanding and application of ethical theories to clinical cases and effective communication skills through oral presentation of ethics cases. In the development of their assessment tool, Favia et.al. decided to deliberately omit evaluation of professional behaviors. ${ }^{32}$ This reluctance on the part of educators to develop competency assessment instruments that reflect student attitudes and behaviors highlights the lack of clarity and guidance in articulating the dual goals of ethics education. ${ }^{32,33}$ As discussed in Chapter 5, the primary aim of ethics education has two overlapping components; the acquisition of deliberative skills in critical thinking and reasoning, and the integration of personal attributes (such as empathy), both of which align the student with the professional values of midwifery. Studies that evaluate the effectiveness of teaching affective attributes such as empathy demonstrate mixed results. Empathy has been identified as both a cognitive skill (an understanding) and an affective skill (a feeling). ${ }^{34}$ Studies of medical students have demonstrated an erosion of empathy upon exposure to in-person clinical care and 
to clinical preceptors. ${ }^{35}$ Studies that used the Jefferson Empathy Scale, and which included midwifery students, also demonstrate mixed results, with either no increase in empathy after a training program or only a small effect. ${ }^{34,36-38}$ Instruments developed to assess the professionalism of medical providers show similar inconsistency in the primary purpose of the evaluation and the practical utility of the instrument. ${ }^{39}$

In addition to a dearth of effective assessment instruments, arguments against the evaluation of professional behaviors of students suggest that an evaluation of observed behavior actually damages the relationship between students and faculty. ${ }^{34}$ Rees et.al. state that assessment of professionalism by observation of behavior is an attempt to control a student's behavior, which erodes trusts and curtails the student's growth. ${ }^{34}$ In addition, professional behaviors can be faked by students while under observation; assessments of professionalism is then assumed, not actually evaluated. ${ }^{34}$ Rees et. al. suggest an ethnographic approach, which includes dialogue and reflection about the student's reasoning behind their particular action or behavior. ${ }^{34}$ These insights indicate the need for a multi-modal approach to evaluating professional behaviors, ethics competencies, and ethical decision-making and highlights the need for research that specifically includes midwifery students. ${ }^{14,19}$

\section{The promise of shared decision-making}

Shared decision-making, the process of a provider and individual engaging in a discussion about medical intervention options, has gained momentum as the favored method of provider-patient communication. It was the fitting response to a medical culture that presumed to make clinical and ethical decisions on the patient's behalf. Nothing about me, without me was the battle cry of patient-centered care. ${ }^{40}$ In its beginning, shared decision-making included decisions that primarily met clinical equipoise. That is, the provider had no preference or recommendation for a specific clinical option and so the decision was left to the patient, based on their values, preferences, and goals. ${ }^{41}$ Since then, shared decision-making has been called upon to meet the challenges of more complex health decisions, particularly in maternity care.

Within ethics, shared decision-making has the potential to mitigate the challenges of medical uncertainty and to alleviate some of the distress that uncertainty engenders. The evidence-based medicine movement has highlighted what is known about certain conditions and decisions, but also what remains unknown, the gaps in medical knowledge. ${ }^{42}$ For example, a 2011 study of practice bulletins published by the American College of Obstetricians and Gynecologists (ACOG) found that only one-third of practice bulletin recommendations were based on good and consistent evidence, indicating that the vast majority were based on unclear or conflicting evidence or on expert opinion. ${ }^{43}$ Clinical uncertainties highlight the limits of medical knowledge and expose the fragility of medical predictions. ${ }^{44}$ While the process of shared decision-making may not have the power to change the uncertainty inherent in some medical decisions, it may mitigate the anxiety that negotiating such uncertainty engenders, as well as serve to balance risk and personal values. 
Shared decision-making also encourages a reflective and caring process, instead of a simple exchange of information. The principle-based ethics framework emphasizes the individual as an isolated entity, and shared decision-making is the primary vehicle for ensuring autonomy. In this framework, a woman's agency is the most important consideration in the shared decision-making process. In contrast, care ethics views the individual as an interconnected being within a social context. ${ }^{45}$ Their identity, and therefore how they make choices and decisions, is interwoven with the other people in their lives, including the midwife. ${ }^{46}$ For example, the refusal of a woman to accede to a midwife's recommended course of action can be a significant source of distress for both the woman and the midwife. ${ }^{47,48}$ However, when the woman's action is characterized as a refusal, the shared decision-making process stays in the domain of a principle-based framework. The woman is exercising her autonomous individual choice to decline a medical intervention. In a relational framework, the agency of the midwife and the woman are on a more equal footing. The midwife's recommendations are neither accepted nor refused. Rather, the relationship between the midwife and woman is characterized by responsiveness and attentiveness. ${ }^{46}$ The shared decision-making process, when undertaken in a relational framework, has the potential to decrease the anxiety of uncertainty by sharing the burden of decision making and by providing opportunities for debriefing. ${ }^{44,49}$ This is a paradigm shift, from a principle-based model of shared decision-making where autonomy is promoted and protected, to a relational model of shared decision-making where identity is defined by context and interdependency. ${ }^{50}$

Accepting both a principle-based framework and a care ethics framework into a multi-faceted complex framework of shared decision-making is congruent with the midwifery philosophy of care. ${ }^{51}$ To midwives, women are viewed as autonomous decision-making agents and as inter-dependent relational beings. The shared decisionmaking process engages women and midwives as these views align and misalign in a constant tension that evolves as health conditions and health decisions evolve. The ethical application of this process to a clinical situation is a learned skill, a competency that must be acquired, practiced, and eventually mastered.

\section{Strengths and Limitations}

Our research has both strengths and limitations. We used a variety of qualitative designs in order to fully explore the richness of the experiences of the stakeholders. We engaged a diverse group of midwifery students from a variety of midwifery programs and who were in different stages of their education paths for the focus group project. The qualitative design allowed us to hear the overall group's voice as they considered their experiences with ethical dilemmas, as well as the individual's private assessment of their own self-efficacy. It also provided an opportunity for the students to express their experiences in a shared setting. An interview format was used to allow for extensive discussions with individual midwives in clinical practice about their experiences with ethical dilemmas. Unfortunately, we were unable to conduct direct observations of student-preceptor interactions, which may have provided additional insight and an opportunity to identify potential strategies for promoting best practices in preceptor education in ethics and role-modeling. While one of the overarching goals of the project 
was to explore students' and midwives' experiences of ethics education in their midwifery programs, it was clear from the first interaction that the students and midwives needed to tell the stories of the women in their care and the complex decisions they face, of the challenges involved in the workplace due to poor interprofessional relationships, even of their exposure to questionable business practices. Their stories added richness and dimension to our projects. We were, however, missing the voices of the women in their care. Future studies should consider including the voices in women when considering content and methodology of midwifery education, particularly with regards to ethics.

Our projects were limited by the number of participants. For the Delphi consensus project (Chapter 5), we invited all of the current program directors of accredited midwifery programs in the U.S. and asked them to forward the invitation to any midwifery faculty member that may be interested. Participation was limited just 5 of 37 program directors and 3 other faculty in Round 1, though the percentage of participating program directors increased in Rounds 2 and 3. We were sensitive to the burden placed on the experts with regard to the workload of participating in the Delphi method, particularly in answering the open-ended questions of Round 1 . However, we may have underestimated this work burden, contributing to the overall low rate of participation and introducing the possibility of bias. ${ }^{52,53}$

Our research confirms the findings of studies of midwives in other countries, but the unique nature of midwifery education in the U.S. requires caution in applying what we learned to an international audience. In Canada and the Netherlands, for example, midwifery education is a university-based, undergraduate three- or four-year program which leads to a Baccalaureate degree. ${ }^{52,53}$ These programs are direct-entry and upon completion of the program students are eligible to take the examination for registration as a midwife. ${ }^{54,55}$ In the U.S., there are multiple pathways to midwifery that represent different end degrees and eligibility for different types of midwifery practice licenses or registration. ${ }^{56}$

\section{Recommendations for future research and education}

Our research provides a framework for an ethics education curriculum for midwifery students. The creation of this framework provided opportunities for future research. As discussed above, the voices of women receiving midwifery care should be included as part of the refinement of midwifery ethics education. In addition, further observation and exploration of the interactions of midwives, women, and students as they engage in shared decision-making is needed. Several studies describe the shared decision-making interactions between physicians and patients, but there is a paucity of research on how midwives engage in shared decision-making. ${ }^{57,58}$ This research is especially needed to inform discussions about common perinatal decision-points that may affect normal physiologic birth, such as induction of labor, fetal monitoring, or the use of active management of the third stage of labor. The wide use, and potential overuse, of these interventions carry risks that necessitate an approach that is informed by ethics as much as evidence. Further research is also needed to examine best practices with regard to teaching students the skills for effective shared decision and to assess methods for 


\section{$144 \mid$ Chapter Eight}

evaluating their progress as they acquire competency in this and other ethics related areas.

Midwives and other reproductive health providers in the U.S. and internationally are currently faced with the challenge of addressing increasing maternal mortality rates and the pervasive presence of disrespect and abuse in maternity care. ${ }^{59,60}$ The midwifery profession in the U.S. is in the midst of a reckoning on the ways that systemic health disparities, structured racism, and deep-rooted discrimination has shaped our education and our profession. This is reflected in the call from the midwifery educators in our project (Chapter 5 ) to create a reproductive and social justice framework for an ethics curriculum. We recommend that an ethics curriculum be thoughtfully nested and integrated into a broader reproductive justice-based midwifery education program. As midwifery programs move toward this goal, research that examines program methodology and effectiveness is needed.

\section{Conclusion}

The primary goal of our research was to explore the current state of midwifery ethics education in the United States and to provide a framework for a competency-based ethics curriculum that would have potential for broad application. Through the voices of midwifery students, midwives in practice, clinical preceptors, and midwifery faculty, we developed a framework for midwifery ethics education that can help guide curricular development and complement current competency-based midwifery programs. As we learned from our study participants, ethics education should be integrated into clinical learning, and midwifery preceptors are key to the success of ethics learning. Shared decision-making is seen as not only an essential component of ethics education as method of effective communication, but it is also the embodiment of respectful, personcentered reproductive care. Intentional midwifery ethics education is critical to the provision of safe, effective, and respectful reproductive care. 


\section{References}

1. Bringedal H, Aune I. Able to choose? Women's thoughts and experiences regarding informed choices during birth. Midwifery. 2019;77:123-129. doi:10.1016/j.midw.2019.07.007

2. Cruess SR, Cruess RL, Steinert Y. Supporting the development of a professional identity: General principles. Medical Teacher. 2019;41(6):641-649. doi:10.1080/0142159X.2018.1536260

3. Byszewski A, Gill JS, Lochnan H. Socialization to professionalism in medical schools: a Canadian experience. BMC Medical Education. 2015;15(1):204. doi:10.1186/s12909-015-0486-z

4. Borrelli SE. What is a good midwife? Insights from the literature. Midwifery. 2014;30(1):3-10. doi:10.1016/j.midw.2013.06.019

5. Lazarus J. Precepting 101: Teaching Strategies and Tips for Success for Preceptors. Journal of Midwifery and Women's Health. Published online 2016. doi:10.1111/jmwh.12520

6. American College of Nurse-Midwives. ACNM Core Competencies for Basic Midwifery Practice.; 2020.

7. Brunstad A, Hjälmhult E. Midwifery students learning experiences in labor wards: A grounded theory. Nurse Education Today. 2014;34(12):1474-1479. doi:10.1016/j.nedt.2014.04.017

8. Krause SA. Precepting Challenge: Helping the Student Attain the Affective Skills of a Good Midwife. Journal of Midwifery and Women's Health. 2016;61:37-46. doi:10.1111/jmwh.12517

9. Licqurish S, Seibold C. Bachelor of Midwifery students' experiences of achieving competencies: The role of the midwife preceptor. Midwifery. 2008;24(4):480-489. doi:10.1016/j.midw.2007.05.001

10. Begley CM. 'Knowing your place': student midwives' views of relationships in midwifery in Ireland. Midwifery. 2001;17(3):222-233. doi:10.1054/midw.2001.0262

11. Myers K, Chou CL. Collaborative and Bidirectional Feedback Between Students and Clinical Preceptors: Promoting Effective Communication Skills on Health Care Teams. Journal of Midwifery \& Women's Health. 2016;61(S1):22-27. doi:10.1111/jmwh.12505

12. Sweet L, Bass J, Sidebotham M, Fenwick J, Graham K. Developing reflective capacities in midwifery students: Enhancing learning through reflective writing. Women and Birth. Published online 2018:411. doi:10.1016/j.wombi.2018.06.004

13. Zwedberg S, Forslund Frykedal K, Rosander M, Berlin A, Barimani M. Midwives' experiences as preceptors and the development of good preceptorships in obstetric units. Midwifery. 2020;87:102718. doi:10.1016/j.midw.2020.102718

14. Paton A, Kotzee B. The fundamental role of storytelling and practical wisdom in facilitating the ethics education of junior doctors. Health: An Interdisciplinary Journal for the Social Study of Health, IIIness and Medicine. Published online November 18, 2019:136345931988910. doi:10.1177/1363459319889102

15. Felstead I. Role modelling and students' professional development. British Journal of Nursing. 2013;22(4):223-227. doi:10.12968/bjon.2013.22.4.223

16. Nieuwenhuijze M, Thompson S, Gudmundsdottir EY, Gottfređsdóttir H. Midwifery students' perspectives on how role models contribute to becoming a midwife: A qualitative study. Women and Birth. Published online 2019. doi:doi.org/10.1016/j.wombi.2019.08.009

17. Hafferty FW, Franks R. The Hidden Curriculum, Ethics Teaching, and the Structure of Medical Education. Academic Medicine. 1994;69(11):861-871.

18. Lehmann LS, Sulmasy LS, Desai S. Hidden curricula, ethics, and professionalism: Optimizing clinical learning environments in becoming and being a physician: A position paper of the American college of physicians. Annals of Internal Medicine. 2018;168(7):506-508. doi:10.7326/M17-2058

19. Benbassat J. Role Modeling in Medical Education. Academic Medicine. 2014;89(4):550-554. doi:10.1097/ACM.0000000000000189

20. Carrese JA, McDonald EL, Moon M, et al. Everyday ethics in internal medicine resident clinic: an opportunity to teach. Medical Education. 2011;45(7):712-721. doi:10.1111/j.1365-2923.2011.03931.x

21. Germano E, Schorn MN, Phillippi JC, Schuiling K. Factors that Influence Midwives to Serve as Preceptors: An American College of Nurse-Midwives Survey. Journal of Midwifery \& Women's Health. 2014;59(2):167-175. doi:10.1111/jmwh.12175

22. Accreditation Commission for Midwifery Education. Criteria for Programmatic Accreditation of Midwifery Education Programs. Published 2020. Accessed June 18, 2020.

https://www.midwife.org/acnm/files/cclibraryfiles/filename/000000007786/ACMECriteriaforProgram maticAccreditationFinalCopyrightMay2019(RevisedMarch2020).pdf

23. International Confederation of Midwives. Essential Competencies for Midwifery Practice.; 2019.

24. Gervais J. The operational definition of competency-based education. The Journal of Competency-Based Education. 2016;1(2):98-106. doi:10.1002/cbe2.1011 
25. Embo M, Helsloot K, Michels N, Valcke M. A Delphi study to validate competency-based criteria to assess undergraduate midwifery students' competencies in the maternity ward. Midwifery. 2017;53:1-8. doi:10.1016/j.midw.2017.07.005

26. Woeber K. Development and implementation of a competency-based clinical evaluation tool for midwifery education. Midwifery. 2018;62:92-95. doi:10.1016/j.midw.2018.03.004

27. Robinson EM, Lee SM, Zollfrank A, Jurchak M, Frost D, Grace P. Enhancing moral agency: Clinical ethics residency for nurses. Hastings Center Report. 2014;44(5):12-20. doi:10.1002/hast.353

28. Oelhafen S, Monteverde S, Cignacco E. Exploring moral problems and moral competences in midwifery: A qualitative study. Nursing Ethics. 2019;26(5):1373-1386. doi:10.1177/0969733018761174

29. Kulju K, Stolt M, Suhonen R, Leino-Kilpi H. Ethical competence: A concept analysis. Nursing Ethics. 2016;23(4):401-412. doi:10.1177/0969733014567025

30. Muramatsu T, Nakamura M, Okada E, Katayama H, Ojima T. The development and validation of the Ethical Sensitivity Questionnaire for Nursing Students. BMC Medical Education. 2019;19(1). doi:10.1186/s12909-019-1625-8

31. Murrell VS. The failure of medical education to develop moral reasoning in medical students. International Journal of Medical Education. 2014;5:219-225. doi:10.5116/ijme.547c.e2d1

32. Favia A, Frank L, Gligorov N, et al. A Model for the Assessment of Medical Students' Competency in Medical Ethics. AJOB Primary Research. 2013;4(4):68-83. doi:10.1080/21507716.2013.768308

33. Buxton M, Phillippi JC, Collins MR. Simulation: A New Approach to Teaching Ethics. Journal of Midwifery and Women's Health. 2015;60(1):70-74. doi:10.1111/jmwh.12185

34. Rees CE, Knight L v. Viewpoint: The Trouble with Assessing Students??? Professionalism: Theoretical Insights from Sociocognitive Psychology. Academic Medicine. 2007;82(1):46-50. doi:10.1097/01.ACM.0000249931.85609.05

35. Hojat M, Vergare M, Maxwell K, et al. The devil is in the third year: A longitudinal study of erosion of empathy in medical school. Academic Medicine. 2009;84(9):1182-1191. doi:10.1097/ACM.0b013e3181b17e55

36. Alhassan M. Effect of a 2-day communication skills training on nursing and midwifery students' empathy: a randomised controlled trial. BMJ Open. 2019;9(3):e023666. doi:10.1136/bmjopen-2018-023666

37. Hogan R, Rossiter C, Catling C. Cultural empathy in midwifery students: Assessment of an education program. Nurse Education Today. 2018;70:103-108. doi:10.1016/j.nedt.2018.08.023

38. Williams B, Brown T, Boyle M, McKenna L, Palermo C, Etherington J. Levels of empathy in undergraduate emergency health, nursing, and midwifery students: a longitudinal study. Advances in Medical Education and Practice. 2014;5:299. doi:10.2147/AMEP.S66681

39. Veloski JJ, Fields SK, Boex JR, Blank LL. Measuring Professionalism: A Review of Studies with Instruments Reported in the Literature between 1982 and 2002. Academic Medicine. 2005;80(4):366-370. doi:10.1097/00001888-200504000-00014

40. Barry MJ, Edgman-Levitan S. Shared decision making - The pinnacle of patient-centered care. New England Journal of Medicine. Published online 2012. doi:10.1056/NEJMp1109283

41. Elwyn G, Edwards A, Kinnersley P, Grol R. Shared Decision Making and the Concept of Equipoise: The Competences of Involving Patients in Healthcare Choices. Br J Gen Pract . 2000;50(460):892-899.

42. Han PKJ, Babrow A, Hillen MA, Gulbrandsen P, Smets EM, Ofstad EH. Uncertainty in health care: Towards a more systematic program of research. Patient Education and Counseling. 2019;102(10):1756-1766. doi:10.1016/j.pec.2019.06.012

43. Wright JD, Pawar N, Gonzalez JSR, et al. Scientific Evidence Underlying the American College of Obstetricians and Gynecologists' Practice Bulletins. Obstetrics \& Gynecology. 2011;118(3):505-512. doi:10.1097/AOG.0b013e3182267f43

44. Berger Z. Navigating the Unknown: Shared Decision-Making in the Face of Uncertainty. Journal of General Internal Medicine. 2015;30(5):675-678. doi:10.1007/s11606-014-3074-8

45. MacLellan J. Claiming an Ethic of Care for midwifery. Nursing Ethics. 2014;21(7):803-811. doi:10.1177/0969733014534878

46. Newnham E, Kirkham M. Beyond autonomy: Care ethics for midwifery and the humanization of birth Nursing Ethics. 2019;26(7-8):2147-2157. doi:10.1177/0969733018819119

47. Jenkinson B, Kruske S, Kildea S. The experiences of women, midwives and obstetricians when women decline recommended maternity care: A feminist thematic analysis. Midwifery. 2017;52:1-10. doi:10.1016/j.midw.2017.05.006 
48. Megregian M, Nieuwenhuijze M. Choosing to Decline: Finding Common Ground through the Perspective of Shared Decision Making. Journal of Midwifery and Women's Health. 2018;63(3):340-346. doi:10.1111/jmwh.12747

49. Nieuwenhuijze MJ, Korstjens I, de Jonge A, de Vries R, Lagro-Janssen A. On speaking terms: A Delphi study on shared decision-making in maternity care. BMC Pregnancy and Childbirth. 2014;14(1):1-11. doi:10.1186/1471-2393-14-223

50. van Nistelrooij I, Visse M, Spekkink A, de Lange J. How shared is shared decision-making? A care-ethical view on the role of partner and family. Journal of Medical Ethics. 2017;43(9):637-644. doi:10.1136/medethics-2016-103791

51. Keeney S, Hasson F, McKenna H. Consulting the oracle: Ten lessons from using the Delphi technique in nursing research. Journal of Advanced Nursing. 2006;53(2):205-212. doi:10.1111/j.13652648.2006.03716.x

52. Butler MM, Hutton EK, McNiven PS. Midwifery education in Canada. Midwifery. 2016;33:28-30. doi:10.1016/j.midw.2015.11.019

53. Gottfređsdóttir H, Nieuwenhuijze MJ. Midwifery education: Challenges for the future in a dynamic environment. Midwifery. 2018;59:78-80. doi:10.1016/j.midw.2018.01.006

54. Maurer H, Kohl A, Cockerham A,. Midwifery Education Trends Report2019.; 2019. Accessed July 10, 2020. https://www.midwife.org/acnm/files/acnmlibrarydata/uploadfilename/000000000321/Midwifery_Ed ucation_Trends_Report_2019_Final.pdf

55. Marzalik PR, Feltham KJ, Jefferson K, Pekin K. Midwifery education in the U.S. - Certified Nurse-Midwife, Certified Midwife and Certified Professional Midwife. Midwifery. 2018;60:9-12. doi:10.1016/j.midw.2018.01.020

56. Légaré $F$, Adekpedjou R, Stacey $D$, et al. Interventions for increasing the use of shared decision making by healthcare professionals. Cochrane Database of Systematic Reviews. Published online July 19, 2018. doi:10.1002/14651858.CD006732.pub4

57. Davis N, Smoots A, Goodman D. Pregnancy-Related Deaths: Data from 14 U.S. Maternal Mortality Review Committees, 2008-2017. Centers for Disease Control and Prevention, U.S. Department of Health and Human Services. Published 2019. Accessed July 10, 2020.

https://www.cdc.gov/reproductivehealth/maternal-mortality/erase-mm/mmr-data-brief.html

58. Morton CH, Simkin P. Can respectful maternity care save and improve lives? Birth. 2019;46(3):391-395. doi:10.1111/birt.12444

59. Martínez-Galiano JM, Martinez-Vazquez S, Rodríguez-Almagro J, Hernández-Martinez A. The magnitude of the problem of obstetric violence and its associated factors: A cross-sectional study. Women and Birth. Published online October 2020. doi:10.1016/j.wombi.2020.10.002

60. Vedam S, Stoll K, Taiwo TK, et al. The Giving Voice to Mothers study: Inequity and mistreatment during pregnancy and childbirth in the United States. Reproductive Health. Published online 2019. doi:10.1186/s12978-019-0729-2 
148|Chapter Eight 


\section{Summary \\ Impact statement \\ Curriculum Vitae \\ Acknowledgments}

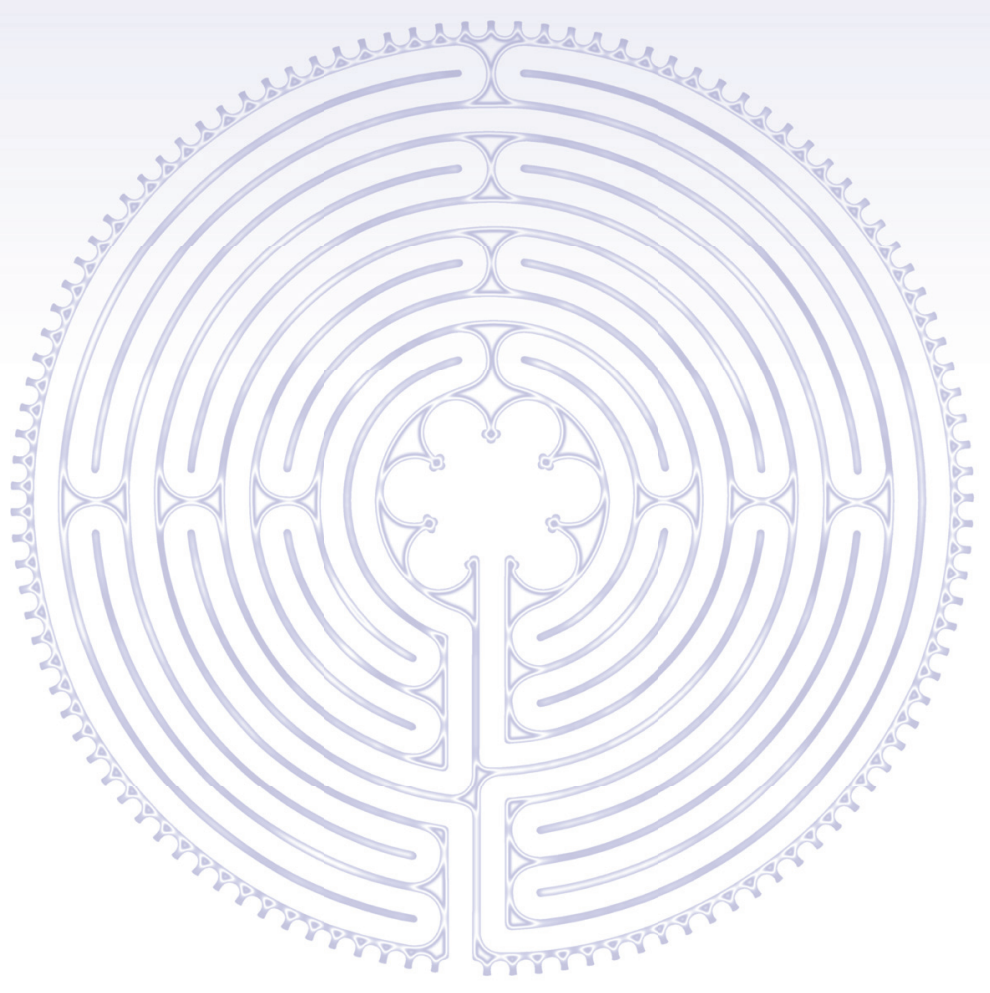


Physiologic events that occur in the course of normal human reproductive development are literally and figuratively transformative events - puberty, menstruation, pregnancy, childbirth, sexuality and gender identity. Yet these transformative events of normal physiology carry with them a vulnerability that allows for mistreatment, abuse, and disrespect of the individual. For example, studies demonstrate that as many as 2 of 3 women report experiencing some type of obstetric violence during childbirth, such as receiving vaginal exams without their consent, verbal abuse, and feeling blamed or shamed by providers. ${ }^{1}$

The promotion of dignity lies at the heart of respectful healthcare, and healthcare providers have an ethical obligation to protect and promote the dignity of persons in their care. Education in ethics and in the application of ethics to clinical care is one critical pathway to fulfilling this obligation. In order to eliminate the systemic mistreatment of women by the maternity care system, providers should possess the awareness, intention, commitment, and accountability that can be gained through ethics education.

The central aim of this thesis is to contribute to the optimization of ethics education in midwifery programs, developing a curricular framework which can complement current educational practice. We endeavored to explore the current state of ethics education and to identify potential gaps through surveys, focus groups, and interviews with midwifery educators, midwives, and students. In addition, given the emphasis placed upon the process of shared decision-making as part of ethics education and its role in the promotion of respectful and person-centered midwifery care, we explored shared decision-making in further detail. It is important that the next generation of midwives are trained not only in the practical application of shared decision-making, but also in the foundational ethical concepts upon which it is constructed. The groundwork for training in ethics, including shared decision-making, would ideally occur in the degree-conferring educational programs. This thesis explores the current state of midwifery ethics education, identifies gaps, and proposes a framework that can complement midwifery curricula, with the aim of preparing new providers to negotiate the ethical challenges that they will encounter in their clinical work.

\section{Chapter 2 Ethics Education in Midwifery Education Programs in the United States, published Journal of Midwifery \& Women's Health 2016}

This study presents the findings of an online survey of program directors of ACME and MEAC-accredited midwifery educational programs in the United States. We explored the logistics of ethics education in their curricula, including the topics covered, learning formats used, amount of time dedicated to ethics learning, and use of evaluation tools. We developed a 13-question, primarily multiple-choice questionnaire, which was modeled after surveys of other disciplines, and which was adapted to include topics specific to midwifery education. A total of 25 of 49 eligible programs participated in the survey, providing a response rate of $51 \%$. Survey results showed that there is considerable variation in ethics education in terms of content, format, and evaluation among accredited midwifery education programs in the United States. Midwifery 
educators have an opportunity to explore the ethical dilemmas unique to maternity care from a midwifery perspective. There is also the opportunity to create a comprehensive and dynamic midwifery ethics curriculum, which incorporates both stand-alone ethics courses and ethics concepts that are woven throughout the core midwifery curriculum. Megregian M. Ethics Education in Midwifery Education Programs in the United States. J Midwifery Womens Health. 2016 Sep;61(5):586-592. doi: 10.1111/jmwh.12462. Epub 2016 Jun 24. PMID: 27341667

\section{Chapter 3 "That was an ethics class?": student experiences of ethics education in midwifery programs in the United States, submitted to Nurse Education Today} This study describes the results of focus groups conducted with student midwives on their thoughts and opinions regarding manner and content of ethics education in midwifery educational programs. We conducted semi-structured focus group interviews with 39 students from three midwifery programs in the United States (U.S.). Transcripts of the interviews were analyzed using an iterative process to identify themes and subthemes. Content analysis revealed three primary themes and associated subthemes: 1) current experience and identified needs, 2) the preceptor dilemma, with subthemes being at the mercy of the preceptor and powerlessness in the face of other providers' demands, and 3) complicated relationships: advocacy, autonomy and choice. Students relied primarily upon clinical preceptors as a significant source of learning ethical behavior. They also reported a lack of direct and purposeful ethics learning in their clinical experiences, and had few opportunities for reflection and integration of their experiences from an ethics perspective. This study demonstrates the need for more deliberate inclusion of midwifery-specific ethics content into overall midwifery education program content, in both classroom and clinical experiences. Midwifery programs should integrate ethics content in their curricula in a way that complements other midwifery content. This study also demonstrates the key role of clinical preceptors in student ethics learning, and underscores the need for further research on the transmission of ethics knowledge and skills to students.

\section{Chapter 4 "I'm sure we talked about it": Midwives' experiences of ethics education and ethical dilemmas, a qualitative study; published Women and Birth 2020}

This study describes the results of individual interviews with midwives regarding their experiences of ethical dilemmas in practice, and their thoughts about their ethics education through their midwifery educational programs. We conducted semi-structured, individual interviews with midwives from throughout the United States (U.S.) ( $n=15)$. Transcripts of the interviews were analyzed using an iterative process to identify themes and subthemes. Midwives described a range of professional ethical dilemmas, including challenges related to negotiating strained interprofessional relationships and protecting or promoting autonomy for women. Ethical dilemmas were identified by the theme of unease, a sense of distress that was expressed in three subthemes: uncertainty of action, compromise in action, and reflecting on action. Learning about ethics and ethical dilemmas occurred, for the most part, outside of the classroom, with the majority of participants reporting that their midwifery program did not confer the skills to identify and resolve ethical challenges. Midwifery educators should consider the purposeful and explicit inclusion of midwifery-specific ethics content in their curricula and in 
interprofessional ethics education. Reflection and self-awareness of bias were identified as key components of understanding ethical frameworks. As clinical preceptors were identified as a key source of ethics learning, midwifery educators should consider ways to support preceptors in building their skills as role models and ethics educators.

Megregian M, Low LK, Emeis $C$, de Vries R, Nieuwenhuijze M. "I'm sure we talked about it": Midwives experiences of ethics education and ethical dilemmas, a qualitative study. Women Birth. 2020 Nov;33(6):e519-e526. doi: 10.1016/j.wombi.2019.12.005. Epub 2020 Jan 27. PMID: 32001185.

\section{Chapter 5 Essential components of midwifery ethics education: results of a Delphi study; submitted to Midwifery}

This study reports the results of a Delphi study on the consensus of midwifery educators regarding the essential components of ethics education for midwifery students. We conducted an online Delphi study in three rounds. Round 1 consisted of open-ended questions to explore and identify key content, competencies, learning outcomes, and teaching strategies. Content analysis was performed on the Round 1 responses, generating the statements for Round 2. In Rounds 2 and 3, experts rated the statements on a 1 to 7 Likert scale, with a positive consensus defined as $70 \%$ or more of the experts scoring $\geq 6$. Of the 12 statements on key content of ethics education, midwives emphasized that content promoting an understanding of shared decision-making is essential for inclusion. Of the statements regarding competencies, learning outcomes, and teaching strategies, 20 of 21 statements met consensus, including those related to shared decision-making and ethical decision-making, as well as attributes such as compassion and courage. Midwives did not agree that an essential teaching strategy includes a validated method for evaluating students on any component of ethics learning (knowledge, skills, behaviour). This Delphi study reveals what midwifery educators consider essential components of ethics education for midwifery students, with a particular focus on the professional attributes of shared decision-making.

\section{Chapter 6 The impact of shared decision making in perinatal care, a scoping review; published Journal of Midwifery \& Women's Health 2020}

This study presents the results of a scoping review on the impact of shared decisionmaking in perinatal care. A literature search of PubMed, CINAHL, Cochrane Library, PsycInfo, and SCOPUS databases was completed for English-language studies conducted from January 2000 through November 2019 that examined the impact of a shared decision-making support strategy on a perinatal decision (such as choice of mode of birth after prior cesarean birth). Studies that only examined the use of a decision aid were excluded. Nine studies met inclusion criteria and were examined for the nature of the shared decision-making intervention as well as outcome measures such as decisional evaluation, including decisional conflict, decisional regret, and certainty. The included studies showed that the impact of shared decision-making interventions on women's perceptions of shared decision-making and on their experiences of the decision-making process were mixed. There may be a decrease in decisional conflict and regret related to feeling informed, but no change in decisional certainty. Despite the call to increase the use of shared decision-making in perinatal care, there are few studies which have examined the effects of a shared decision-making support strategy. Further studies which 
include antepartum and intrapartum settings, and which include common perinatal decisions such as induction of labor are needed. In addition, clear guidance and strategies for successfully integrating shared decision-making and practice recommendations would help women and midwives navigate these complex decisions.

Megregian M, Emeis C, Nieuwenhuijze M. The Impact of Shared Decision-Making in Perinatal Care: A Scoping Review. J Midwifery Womens Health. 2020 Aug 7. doi: 10.1111/jmwh.13128. Epub ahead of print. PMID: 32767740.

\section{Chapter 7 Choosing to Decline: Finding Common Ground through the Perspective of} Shared Decision Making; published Journal of Midwifery and Women's Health 2018 Midwives and women (and her support persons) engage together to make health care decisions, ideally using respectful communication that is based upon the best available evidence and the woman's preferences, values, and goals. Supporting a woman's autonomy, however, can be particularly challenging in maternity care when recommended treatments or interventions are declined. In the past, the real or perceived increased risk to a woman's health or that of her fetus as a result of that choice has occasionally resulted in coercion. Through the process of shared decision-making, the woman's autonomy may be supported, including the choice to decline interventions. This study presents a clinical case report providing an example of the intersection of midwifery ethics and shared decision-making, and demonstrates how a shared decisionmaking framework can support the provider-patient relationship in the context of informed refusal.

Megregian M, Nieuwenhuijze M. Choosing to Decline: Finding Common Ground through the Perspective of Shared Decision Making. J Midwifery Womens Health. 2018

May;63(3):340-346. doi: 10.1111/jmwh.12747. Epub 2018 May 18. PMID: 29775227

\section{Chapter 8: Discussion}

We heard from midwifery students, experienced midwives, and midwifery educators about the ethical dilemmas they face in providing reproductive care, what they consider to be best practices in ethics education, and what they see as the role of midwifery educational programs in preparing students to face these challenges. Through our studies we were able to identify key components of midwifery ethics education and offer a framework for midwifery educators to consider. The framework is based on the following ideas: 1) ethics should be integrated with clinical learning throughout the midwifery program; 2) clinical preceptors are role models that are integral as a source of ethics learning; and 3) ethics, professionalization, and socialization of midwifery students are distinct yet overlapping elements that help to form midwifery identity. In addition, we identified broad competencies that must be considered as part of a competency-based ethics curriculum. (Figure 1) 


\section{Figure 1: Framework for Ethics Education in Midwifery}

- The student is represented at the center of learning.

- The competencies identified by stakeholders surround the student, informed by both clinical and ethics learning.

- The rings of ethics and clinical learning are interconnected, highlighting the idea that they should occur concurrently and should be integrated into everyday learning, but should also be promoted individually

- The outer rings show the influence of socialization and professionalization of midwifery students, which contribute to both clinical and ethics learning and to the formation and ongoing evolution of a midwife's identity.

- The main influencers of student learning are in orbit - the academic faculty, clinical preceptor, other mentors, and the person engaged with them in care

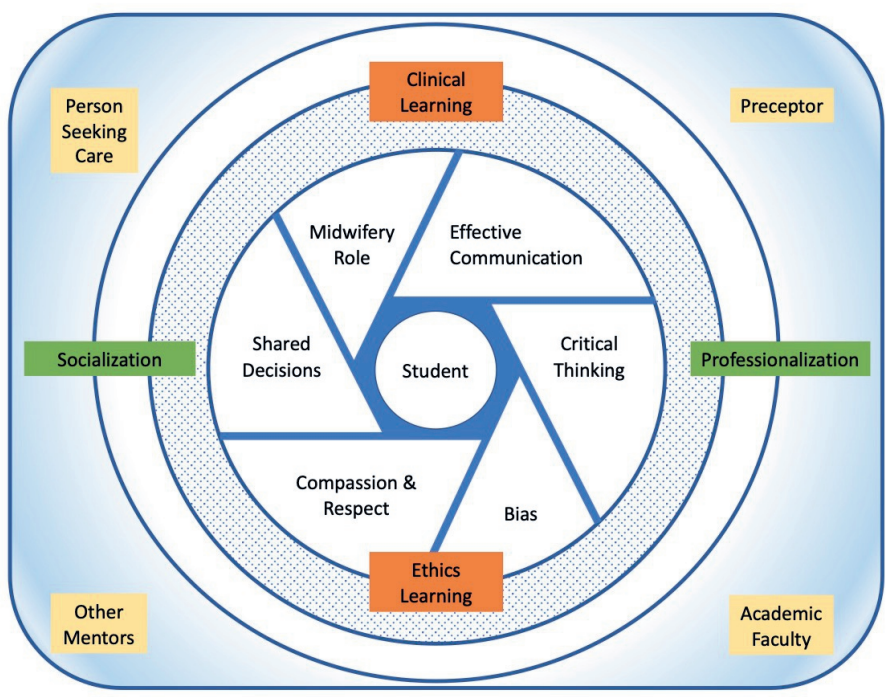

\section{Exemplar Competencies in Midwifery Ethics Education}

Taking advantage of the fact that midwifery education uses a competency-based framework to outline the skills required for midwifery certification, our framework offers suggestions for broad competencies that should be included in an ethics curriculum. This is not meant to be an exhaustive list. Rather, this framework (Table 1) provides examples of particular concepts and topics that can guide educators in content inclusion and learning activities. 


\begin{tabular}{|c|c|c|}
\hline Category & Example Competency & May Include \\
\hline AWARENESS OF BIAS & $\begin{array}{l}\text { Students recognize, acknowledge, } \\
\text { and communicate their personal } \\
\text { biases }\end{array}$ & $\begin{array}{l}\text { Awareness of moral distress } \\
\text { Coping and resilience }\end{array}$ \\
\hline COMPASSION & $\begin{array}{l}\text { Students demonstrate behaviors } \\
\text { consistent with compassionate } \\
\text { care, including courage, empathy, } \\
\text { honesty, kindness, and astute } \\
\text { listening }\end{array}$ & $\begin{array}{l}\text { Willingness to promote well- } \\
\text { being and avoid harm }\end{array}$ \\
\hline CRITICAL THINKING & $\begin{array}{l}\text { Students apply critical thinking } \\
\text { skills, based on a thorough } \\
\text { knowledge base of ethics theories, } \\
\text { principles, and frameworks, to } \\
\text { ethical dilemmas and ethics } \\
\text { decision making }\end{array}$ & $\begin{array}{l}\text { Application of ethics } \\
\text { assessment processes } \\
\text { Reflection of options in } \\
\text { decision making }\end{array}$ \\
\hline EFFECTIVE COMMUNICATION & $\begin{array}{l}\text { Students demonstrate effective } \\
\text { communication skills in their } \\
\text { interactions with peers, } \\
\text { colleagues, and women and their } \\
\text { families }\end{array}$ & $\begin{array}{l}\text { Risk communication } \\
\text { Active listening } \\
\text { Fosters interprofessional } \\
\text { dialog }\end{array}$ \\
\hline MIDWIFERY ROLE & $\begin{array}{l}\text { Students apply knowledge of } \\
\text { ethics principles and frameworks } \\
\text { to the midwifery role in clinical } \\
\text { practice and health policy, as } \\
\text { demonstrated by promoting } \\
\text { autonomy, ensuring } \\
\text { confidentiality, and recognizing } \\
\text { and resolving ethical dilemmas }\end{array}$ & $\begin{array}{l}\text { Understanding of the ACNM } \\
\text { and ICM codes of ethics } \\
\text { Preparation for lifelong } \\
\text { learning of ethics and of } \\
\text { midwifery identity formation }\end{array}$ \\
\hline RESPECT & $\begin{array}{l}\text { In their interactions with women } \\
\text { and their families, students will } \\
\text { promote and provide respectful } \\
\text { care through the demonstration of } \\
\text { ethical conduct and cultural } \\
\text { literacy }\end{array}$ & $\begin{array}{l}\text { Awareness of health } \\
\text { disparities } \\
\text { Understanding of racial and } \\
\text { implicit bias }\end{array}$ \\
\hline SHARED DECISIONS & $\begin{array}{l}\text { Students promote effective } \\
\text { decision making, through an } \\
\text { understanding of the elements of } \\
\text { informed consent and refusal and } \\
\text { skill in the shared decision-making } \\
\text { process }\end{array}$ & $\begin{array}{l}\text { Communicates that a } \\
\text { decision is to be made (choice } \\
\text { awareness) } \\
\text { Recognition and construction } \\
\text { of patient values and goals } \\
\text { Fosters deliberation } \\
\text { Awareness of bias and power } \\
\text { imbalances, and their effect } \\
\text { on shared decision-making }\end{array}$ \\
\hline
\end{tabular}

Through this thesis, we have created a framework for ethics education in midwifery programs, identifying key components that will best prepare new midwives. Such preparation requires an educational and conceptual framework that provides guidance and support for students from a foundation congruent with midwifery 
philosophy. There are three integral concepts that require further exploration and consideration as they apply to a midwifery ethics curriculum.

First, the midwifery ethics curriculum needs to integrate clinical preceptors more fully into the student experience of ethics learning. The students and midwives in our projects identified their preceptors as the primary source for acquisition of skills and for understanding of expected professional behaviors related to ethics. Preceptors are the student's guide along the path of progression from an application of theoretical knowledge to clinical decision making, and then from clinical decision to implementation of a specific action. ${ }^{2}$ They cultivate not only the specific physical skills necessary in becoming a competent midwife, but they nurture the student through the accompanying identity change from non-midwife to midwife. Clinical midwife preceptors in U.S., as in many other countries, hold a unique position in relation to midwifery programs and midwifery students. They are outside of the academic educational framework, yet provide the role-modeling, appropriate clinical opportunities, and summative evaluation of the student's clinical and ethical performances. Currently, the majority of preceptors are not academic faculty; they are practicing midwives who accept the additional responsibility of precepting midwifery students. ${ }^{2}$ In a 2014 survey of potential clinical preceptors, Germano et al. (2014) identified significant barriers to midwives accepting students into their clinical practice, including productivity barriers, communication breakdowns, lack of experience, and student preparedness. ${ }^{3-6}$ In addition, while the experiences of midwifery students with regard to midwife preceptors in the clinical setting have been studied, but we are not aware of a study that specifically examines the opportunities and experiences of preceptors and students as they acknowledge and negotiate ethical issues. ${ }^{7-9}$

Second, the question of how to evaluate ethics competency remains. The students and clinical midwives in our study (Chapters 3 and 4) did not offer opinions about methods of assessment or evaluation that they experienced during their midwifery program. The midwives in our Delphi study (Chapter 5 ) did not have a positive response to the inclusion of an evaluation tool or assessment process as part of a teaching strategy for ethics education. The assessment or evaluation of students' ethics competencies and professional behaviors is complicated by lack of clarity regarding what exactly is being evaluated and how it is evaluated. While validated tools have been developed to assess certain aspects of ethics competency, such as ethical sensitivity, these tools have not been used widely, and it is not clear that using these tools has an impact on learning outcomes, knowledge, student confidence to recognize and negotiate ethical dilemmas or on students' demonstration of professional behaviours ${ }^{10}$. In addition to a dearth of effective assessment instruments, arguments against the evaluation of professional behaviors of students suggest that an evaluation of observed behavior actually damages the relationship between students and faculty. ${ }^{11,12}$ This indicates the need for a multimodal approach to evaluating professional behaviors, ethics competencies, and ethical decision-making and highlights the need for research that specifically includes midwifery students. ${ }^{13}$ 
Last, the concept of shared decision-making must be better understood, in terms of its ethical foundations as a relational process and in terms of the optimal manner of teaching this approach. Within ethics, shared decision-making has the potential to mitigate the challenges of medical uncertainty and to alleviate some of the distress that uncertainty engenders. Shared decision-making also encourages a reflective and caring process, instead of a simple exchange of information. Accepting both a principle-based framework and a care ethics framework into a multi-faceted complex framework of shared decision-making is congruent with the midwifery philosophy of care. ${ }^{13}$ To midwives, women are viewed as autonomous decision-making agents and as interdependent relational beings. The shared decision-making process engages women and midwives as these views align and misalign in a constant tension that evolves as health conditions and health decisions evolve. The ethical application of this process to a clinical situation is a learned skill, a competency that must be acquired, practiced, and eventually mastered.

\section{Conclusion}

The primary goal of our research was to explore the current state of midwifery ethics education in the United States and to provide a framework for a competency-based ethics curriculum. Through the voices of midwifery students, midwives in practice, clinical preceptors, and midwifery faculty, we developed a framework for midwifery ethics education that can help guide curricular development and complement current competency-based midwifery programs. As we learned from our study participants, ethics education should be integrated into clinical learning, and midwifery preceptors are key to the success of ethics learning. Shared decision-making is seen as not only an essential component of ethics education as method of effective communication, but it is also the embodiment of respectful, person-centered reproductive care. Intentional midwifery ethics education is critical to the provision of safe, effective, and respectful reproductive care. 


\section{$158 \mid$ Summary}

\section{References}

1. Morton $\mathrm{CH}$, Henley MM, Seacrist M, Roth LM. Bearing witness: United States and Canadian maternity support workers' observations of disrespectful care in childbirth. Birth. 2018;45(3):263-274. doi:10.1111/birt.12373

2. Germano E, Schorn MN, Phillippi JC, Schuiling K. Factors that Influence Midwives to Serve as Preceptors: An American College of Nurse-Midwives Survey. Journal of Midwifery \& Women's Health. 2014;59(2):167-175. doi:10.1111/jmwh.12175

3. Brunstad A, Hjälmhult E. Midwifery students learning experiences in labor wards: A grounded theory. Nurse Education Today. 2014;34(12):1474-1479. doi:10.1016/j.nedt.2014.04.017

4. Licqurish S, Seibold C. Bachelor of Midwifery students' experiences of achieving competencies: The role of the midwife preceptor. Midwifery. 2008;24(4):480-489. doi:10.1016/j.midw.2007.05.001

5. Zwedberg S, Forslund Frykedal K, Rosander M, Berlin A, Barimani M. Midwives' experiences as preceptors and the development of good preceptorships in obstetric units. Midwifery. 2020;87:102718. doi:10.1016/j.midw.2020.102718

6. Thompson SM, Nieuwenhuijze MJ, Low LK, de Vries R. "A powerful midwifery vision": Dutch student midwives' educational needs as advocates of physiological childbirth. Women and Birth. Published online 2019. doi:10.1016/j.wombi.2018.12.010

7. Kulju K, Stolt M, Suhonen R, Leino-Kilpi H. Ethical competence: A concept analysis. Nursing Ethics. 2016;23(4):401-412. doi:10.1177/0969733014567025

8. Oelhafen S, Monteverde S, Cignacco E. Exploring moral problems and moral competences in midwifery: A qualitative study. Nursing Ethics. 2019;26(5):1373-1386. doi:10.1177/0969733018761174

9. Robinson EM, Lee SM, Zollfrank A, Jurchak M, Frost D, Grace P. Enhancing moral agency: Clinical ethics residency for nurses. Hastings Center Report. 2014;44(5):12-20. doi:10.1002/hast.353

10. Rees CE, Knight L v. Viewpoint: The Trouble with Assessing Students??? Professionalism: Theoretical Insights from Sociocognitive Psychology. Academic Medicine. 2007;82(1):46-50. doi:10.1097/01.ACM.0000249931.85609.05

11. Benbassat J. Role Modeling in Medical Education. Academic Medicine. 2014;89(4):550-554. doi:10.1097/ACM.0000000000000189

12. Paton A, Kotzee B. The fundamental role of storytelling and practical wisdom in facilitating the ethics education of junior doctors. Health: An Interdisciplinary Journal for the Social Study of Health, IIIness and Medicine. Published online November 18, 2019:136345931988910. doi:10.1177/1363459319889102

13. American College of Nurse-Midwives. ACNM Code of Ethics with Explanatory Statements. Published online 2015:1-16.

http://www.midwife.org/ACNM/files/ACNMLibraryData/UPLOADFILENAME/000000000293/Code-ofEthics-w-Explanatory-Statements-June-2015.pdf 


\section{Summary|159}


160|Summary 
"...in a time lacking in truth and certainty and filled with anguish and despair, no woman should be shamefaced in attempting to give back to the world, through her work, a portion of its lost heart". - Louise Bogan (1897-1970), Poet

The central aim of this thesis is to contribute to the optimization of ethics education in midwifery programs and to offer an evidence-based curricular framework that can then guide ethics education in midwifery programs. The framework is based on the systematically collected input of stakeholders. We explored the current state of ethics education and identified potential gaps through surveys, focus groups, and interviews with midwifery educators, midwives, and student midwives. In addition, given the emphasis placed upon the process of shared decision-making and its role in the promotion of respectful and person-centered midwifery care, we explored shared decision-making in further detail.

We found that ethics education should be integrated into clinical learning and that the involvement of midwifery preceptors is essential to successful ethics learning. Improved integration of non-academic midwifery preceptors is needed, as well as providing formal preparation for their role in ethics education and role-modelling. We also found that shared decision-making is seen as the embodiment of respectful, personcentered reproductive care, and as such is an essential component of ethics education. Intentional midwifery ethics education is critical to the provision of safe, effective, and respectful reproductive care.

In 2010, U.S. policy makers issued a vision for high-quality maternity care that included the promotion of normal physiologic birth and the integration of midwives into the maternity care system. ${ }^{1}$ In 2014, The Lancet published a series that further highlighted midwifery care as essential to attaining the goals of improved perinatal outcomes and maternal satisfaction. ${ }^{1}$ However, data from 2017 (the latest national statistics data) shows that midwives in the U.S. still attend fewer than $10 \%$ of births. ${ }^{2}$

An understanding of the potential of midwifery care to effect change in perinatal outcomes includes not only an emphasis on the clinical skills of midwifery care (the clinical decisions that support normal physiologic birth) but also consideration of the ethical precepts that provide the foundation for those clinical decisions. It is, in effect, the midwifery philosophy of care that gives value to midwifery clinical care and to its potential to achieve optimal reproductive health outcomes and improved satisfaction. Just as midwifery educational programs are expected to provide the opportunities for students to develop the clinical skills needed to provide appropriate reproductive care, so too should they expose and guide students to an understanding of ethical concepts in order to develop awareness, knowledge, and critical thinking skills in ethics. Purposeful, evidencebased ethics education can contribute to fulfilling the goals of achieving optimal perinatal care. 
As of the writing of this thesis, over 300,000 people in the United States, and over 1.6 million people worldwide, have died from the global COVID-19 pandemic. ${ }^{3}$ Concurrent with the extraordinary events related to the pandemic (for example, financial crises, economic depression, and politization of healthcare recommendations such as mask-wearing), the U.S. has experienced a reckoning regarding racial justice and its history of racial discrimination, resulting in civil unrest, demonstrations, protests, and threats of violence. In addition, during the course of this project, disparities in maternal mortality rates have gained attention, reports of the mistreatment of women receiving obstetric care continue to be written, and legal assaults on reproductive rights have continued. With these events, ethical questions arise. Who should be tested for COVID-19 first and why? How do we approach individuals who decline to wear a facemask? How do we account for and correct the racial and ethnic disparities in morbidity and mortality? How do we protect women's autonomy in birth during a global pandemic? Should pregnant women be included in clinical trials of vaccines?

The confluence of these events and the responses to these questions has had a tremendous impact on maternity care, the consequences of which are as yet undetermined. For example, in the early days of the pandemic, as a response to the concern about the infectiousness of COVID-19 and lack of personal protection equipment for healthcare personnel, pregnant women were forced to labor alone, their partners, families, and professional support people (e.g. doulas) banned from entry. Maternity care providers were faced with an either/or proposition: possibly risking their own health through increased exposure to individuals who may be infectious or risking the health and wellbeing of laboring women through denial of evidence-based measures shown to decrease maternal morbidity. ${ }^{4}$ While on the surface this may have seemed to be an issue of clinical concern, the regulation of childbirth is an ethical choice, and in this case personcentered care was seemingly set aside. At the same time, maternity care providers were also asked to rely upon the practice of shared decision-making to negotiate the uncertainty resulting from gaps in medical knowledge about COVID-19, for example the potential transmission of COVID-19 through breastfeeding. ${ }^{5}$ And most recently, maternity care providers are being asked to both "highly recommend" and "engage in shared decision-making" regarding the receipt of the COVID-19 vaccine by pregnant and breastfeeding individuals, negotiating the potential increased risks associated with COVID19 infection in pregnancy and the lack of concrete safety data of the vaccine, where pregnant women were excluded from participating in vaccine trials. ${ }^{6}$ The ethical dilemmas borne from these situations demand much of the providers in terms of knowledge of ethics, skill in ethical and shared decision-making, acceptance of the discomfort of uncertainty, and resilience in the face of unprecedented challenges.

Our project and results offer a framework for a curriculum in ethics education, and therefore our primary audience is midwifery educators, including midwifery academic faculty and clinical preceptors. In addition, we deliberately sought the input of midwifery students. All learning is a compact between a teacher and a learner, and as educators we are stewards of student learning. It is important to examine the intersection of the goals of midwifery ethics education and the expectations of students. 
As we stated, one of the limitations of our project was the absence of women's voices in the discussion of ethics education. This represents an opportunity for further research and can contribute to the research that is being done on the identification of women's expectations of, and desire for, midwifery care.

There are multiple opportunities to present the results of our work, and we have presented at national and international midwifery conferences (for example, the ACNM Annual Meeting \& Exhibition and the ICM Triennial Congress), meetings for midwifery educators (for example, the Directors of Midwifery Education biannual meeting), and workshops for all midwives on ethics in midwifery. In addition, we have participated in webinars and presentations that specifically discuss the process of shared decision-making as a contributor to reducing primary cesarean births and improving maternal satisfaction. The next phase of this project is to create and evaluate a detailed ethics curriculum for midwifery programs that is based on our framework. 


\section{4| Impact Statement}

\section{References}

1. Romano A, Kennedy HP, Avery MD. Improving US Maternity Care: A 2020 Call to Action to Scale Up Midwifery. Journal of Midwifery \& Women's Health. 2020;65(5). doi:10.1111/jmwh.13158

2. Essential Facts About Midwives. Accessed December 15, 2020.

https://www.midwife.org/acnm/files/cclibraryfiles/filename/000000007531/EssentialFactsAboutMidw ives-UPDATED.pdf

3. World Corona Virus Tracker and Maps. Accessed December 15, 2020. https://graphics.reuters.com/worldcoronavirus-tracker-and-maps/

4. Yakovi Gan-Or N. Going solo: the law and ethics of childbirth during the COVID-19 pandemic. Journal of Law and the Biosciences. 2020;7(1). doi:10.1093/jlb/Isaa079

5. Parent's Guide To Shared Decision-Making For Breastfeeding And COVID-19 . Accessed January 5, 2021. http://californiabreastfeeding.org/wpcontent/uploads/2020/08/SharedDecisionMaking_Revised_8_10_20.pdf

6. SMFM Vaccine Statement. Accessed January 5, 2021.

https://s3.amazonaws.com/cdn.smfm.org/media/2591/SMFM_Vaccine_Statement_12-120_(final).pdf. 
Impact Statement|165 
166|Impact Statement 
Michele Megregian, CNM was born 10 May 1970 in Madison, Wisconsin, United States, and grew up on the East Coast and the Midwest. She attended St John's College in Annapolis, Maryland, achieving a Baccalaureate degree in Liberal Arts (1992). She trained in midwifery at Columbia University, New York, achieving a Master of Science in Nursing (1998). Upon completion of her midwifery certification and licensing she joined the midwifery practice at Mt. Sinai Hospital, Chicago, Illinois. She worked with different midwifery practices in the Chicago area over the next decade, as well as joining Planned Parenthood as a provider and as the Chicago affiliate's Associate Medical Director (2004).

In 2010 she moved to Portland, Oregon and joined the Oregon Health \& Science University (OHSU) Midwifery Program as an Assistant Professor and midwife. In this role she served as a clinical preceptor for midwifery, nurse practitioner, and physician assistant students, as well as a lecturer in reproductive health. She earned a certificate in Biomedical Ethics from Portland State University (2011) and completed a Fellowship in Ethics with the Center for Ethics at OHSU (2013). Building on these experiences, she continued her study of midwifery ethics and shared decision-making in more detail as a doctoral student at Maastricht University. She has given multiple presentations on shared decision-making, and collaborated with other midwives and experts to draft American College of Nurse-Midwives statement on shared decision-making. 
168| 
The work in this thesis represents a formal step in weaving together two life-long interests and commitments - the warp of reproductive health and the weft of philosophy/ethics. It has been a journey filled, like all journeys, with successes and setbacks, hopes fulfilled and denied, joy and grief, and clarity mixed with uncertainty. I am incredibly grateful to all those who have accompanied me and assisted me on this journey. I would like to express my gratitude to the midwives, midwifery educators, and student midwives who participated in my projects, giving voice to their opinions and thoughts about what is needed in midwifery ethics education. In addition, I would like to thank:

Marianne, I cannot express enough my gratitude for your mentoring and generosity of time and advice. You have helped to mold me into a midwifery scientist, and I will forever appreciate your encouragement (and admonitions) to keep my focus.

Ray, thank you for your expertise, your keen editing eye, and your thoughtful and insightful comments that broadened my perspective. I always looked forward to our discussions about the broader ethical themes that emerge from our work together.

Lisa, I am so grateful for your guidance, advice, and perspective through this journey. You helped me to view this work through the lens of both a midwife and an educator.

Cathy, your formal and informal support throughout this process has been invaluable to me. I am forever grateful for your advice, mentoring, and editing. And I am most grateful for our friendship.

Ellen, Elise, and Laura, my midwife sisters, thank you for always being willing to read draft after draft at a moment's notice, not to mention commiserating over cocktails as needed. Your support has bolstered me in so many ways.

Last, I would like to thank my husband, Ryan, and my family for their love, encouragement and support. I could not have done it without them.

A word about the cover image: While the labyrinth has its origin in Greek mythology as a complicated, multi-branched maze, it became known as a single-path design, the most common design having 7 courses from entrance to center and back. Set on floors in churches or caves, or carved into fields, walking the labyrinth became a form of meditation. For this project, the labyrinth represents the paradox of complexity and simplicity of ethics, as well as the idea that the journey is as valued as the outcome. 



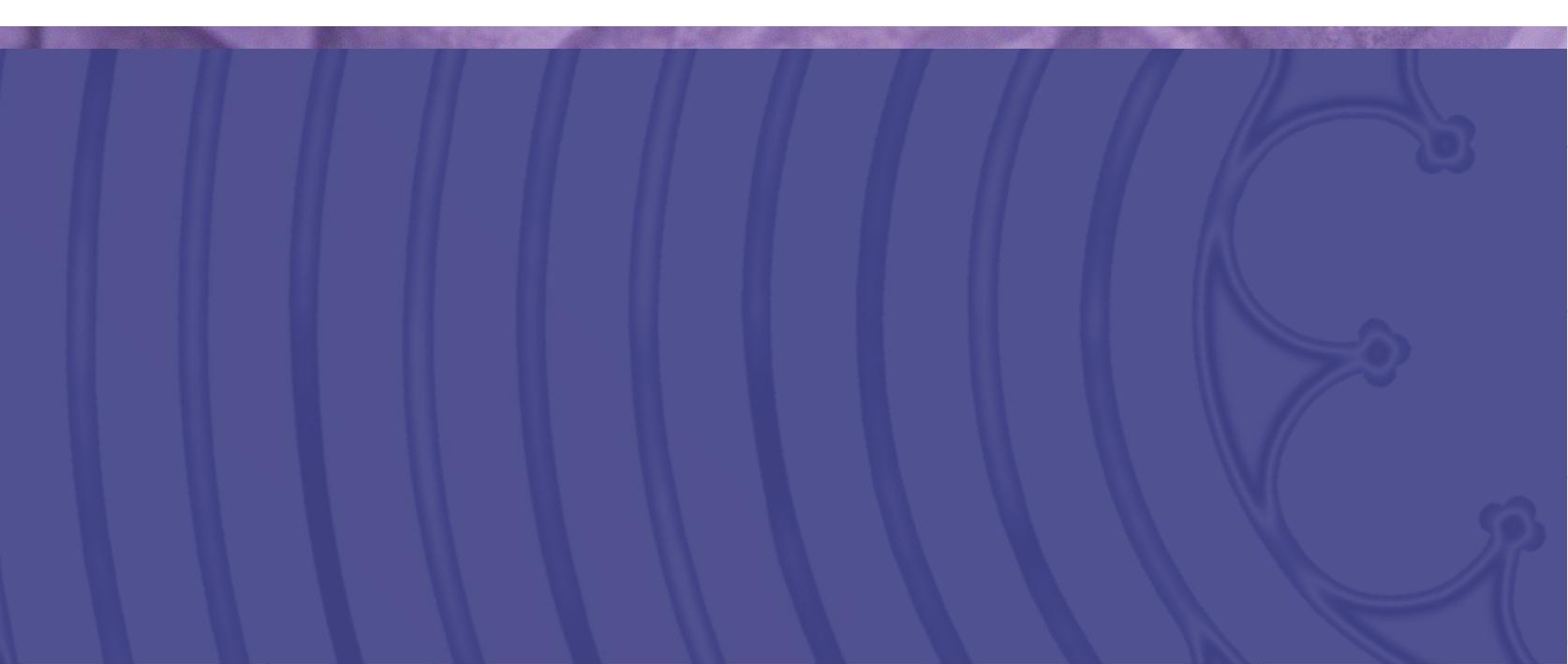

